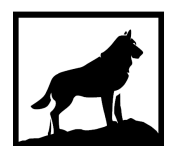

Michigan Technological

1 8 8 5 University
Michigan Technological University

Digital Commons @ Michigan Tech

\title{
LANGUAGE, RHETORIC, AND POLITICS IN A GLOBAL CONTEXT: A DECOLONIAL CRITICAL DISCOURSE PERSPECTIVE ON NIGERIA'S 2015 PRESIDENTIAL CAMPAIGN
}

Yunana Ahmed

Michigan Technological University, yunanaa@mtu.edu

Copyright 2017 Yunana Ahmed

\section{Recommended Citation}

Ahmed, Yunana, "LANGUAGE, RHETORIC, AND POLITICS IN A GLOBAL CONTEXT: A DECOLONIAL CRITICAL DISCOURSE PERSPECTIVE ON NIGERIA'S 2015 PRESIDENTIAL CAMPAIGN", Open Access Dissertation, Michigan Technological University, 2017.

https://doi.org/10.37099/mtu.dc.etdr/400

Follow this and additional works at: https://digitalcommons.mtu.edu/etdr

Part of the African Languages and Societies Commons, Comparative Politics Commons, Discourse and Text Linguistics Commons, International and Intercultural Communication Commons, Rhetoric Commons, and the Speech and Rhetorical Studies Commons 
LANGUAGE, RHETORIC, AND POLITICS IN A GLOBAL CONTEXT: A DECOLONIAL CRITICAL DISCOURSE PERSPECTIVE ON NIGERIA'S 2015 PRESIDENTIAL CAMPAIGN

\author{
By \\ Yunana Ahmed \\ A DISSERTATION \\ Submitted in partial fulfillment of the requirements for the degree of \\ DOCTOR OF PHILOSOPHY \\ In Rhetoric, Theory and Culture
}

MICHIGAN TECHNOLOGICAL UNIVERSITY

2017

(C) 2017 Yunana Ahmed 
This dissertation has been approved in partial fulfillment of the requirements for the Degree of DOCTOR OF PHILOSOPHY in Rhetoric, Theory and Culture.

Department of Humanities

Dissertation Advisor: $\quad$ Victoria Bergvall

Committee Member: $\quad$ Craig Waddell

Committee Member: Ramon Fonkoue

Committee Member: Abraham Romney

Committee Member: $\quad$ Farooq Kperogi

Department Chair: $\quad$ Dr. Ronald Strickland 


\section{Dedication}

For Hassana, Jelani, and Jelena

In Love and Gratitude! 


\section{Table of Contents}

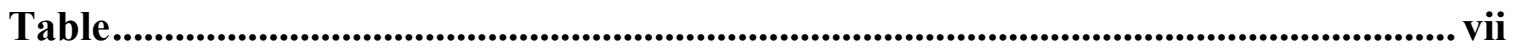

Acknowledgements ................................................................................................................... viii

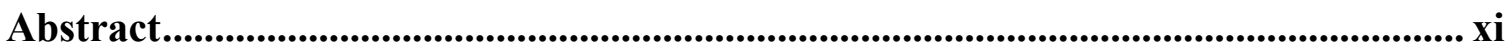

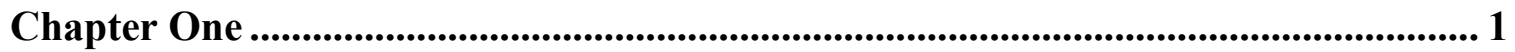

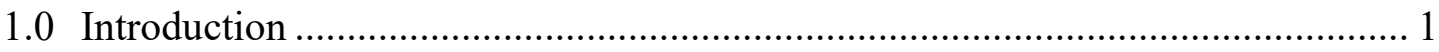

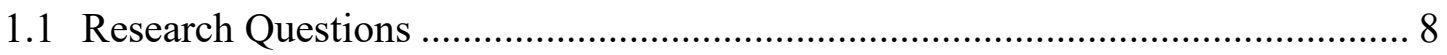

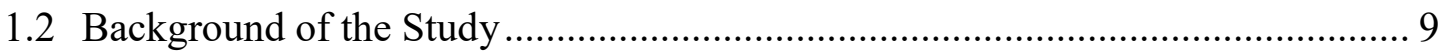

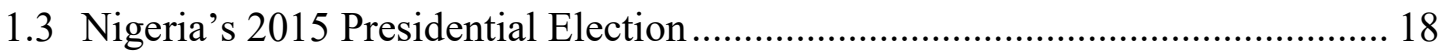

1.3.1 The Major Presidential Candidates in the 2015 Election.......................... 18

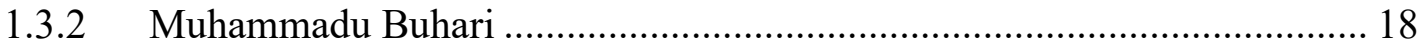

1.3.3 Goodluck Jonathan........................................................................... 19

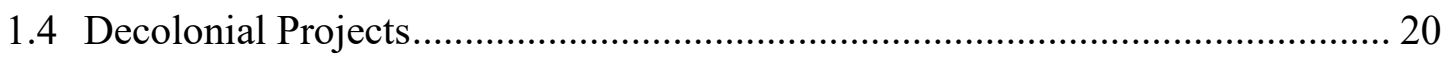

1.5 Decolonial and Postcolonial Debates .............................................................. 24

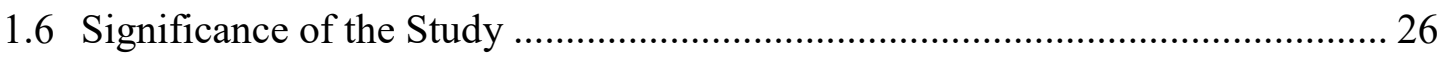

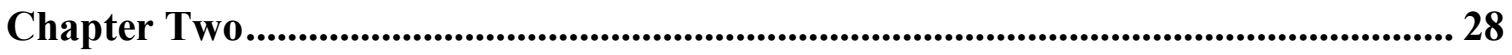

Postcolonial Perspectives: Governance, Globalization, Politics, Nationalism, Nation

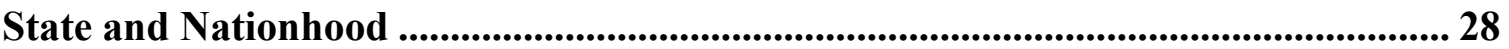

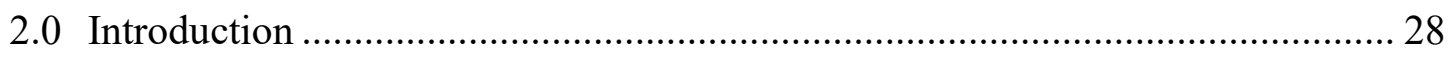

2.1 Governance, Politics, and Political Leadership in Africa (Nigeria).................. 33

2.2 Nationalism, Nation, and State in Africa ................................................... 52

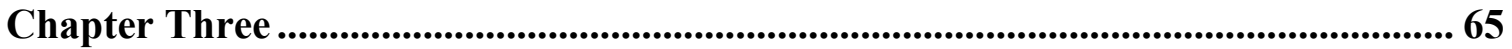

Political Discourse, Presidential Rhetoric, Political Campaign, Rhetoric and Politics

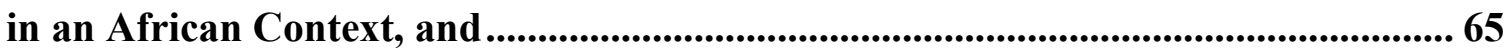

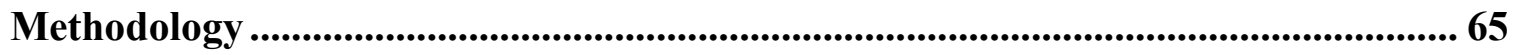




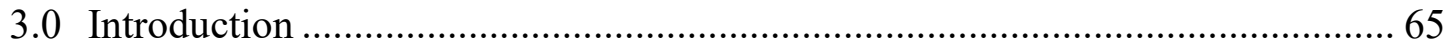

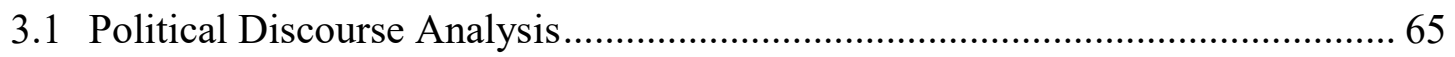

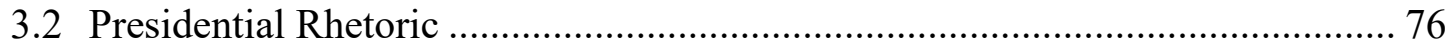

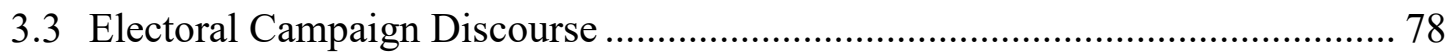

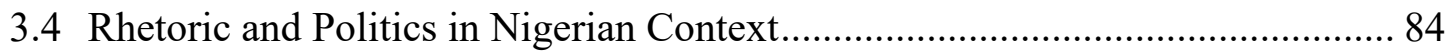

3.5 An Overview of Studies on African Rhetorical Scholarship ........................... 85

3.6 The Problem of Methodology and the Way Forward ..................................... 92

3.7 Theoretical Framework: Integrationist Approach ......................................... 93

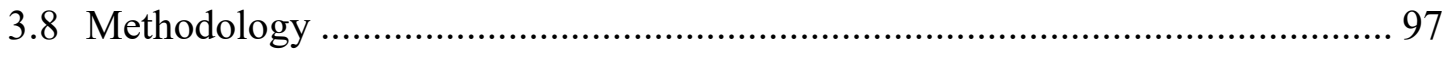

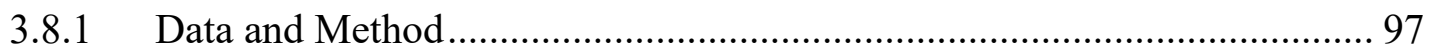

3.8.2 Rationale for the Choice of Text....................................................... 98

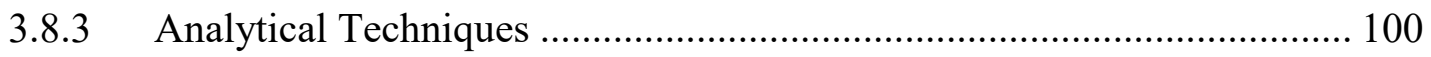

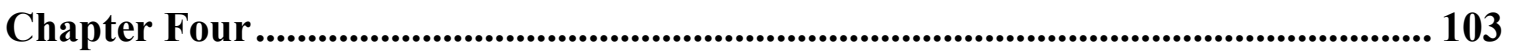

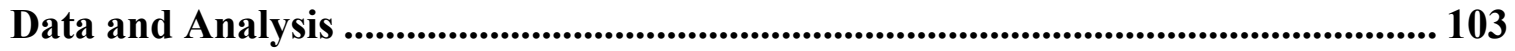

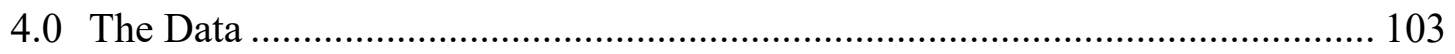

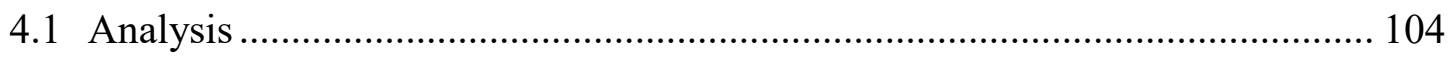

4.2 Jonathan's Campaign Speeches as Deliberative Rhetoric .............................. 104

4.3 Contrastive Tenses as Linguistic Frames in Jonathan's Deliberative Rhetoric 109

4.4 Postcolonial Frames in Jonathan's Deliberative Rhetoric............................. 111

4.5 Rhetorical Appeals and Electoral Campaign................................................. 115

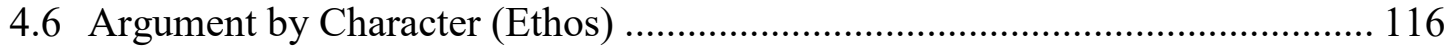

4.6.1 Building Ethos through Apology ......................................................... 117

4.6.2 Building Ethos through Apologia ....................................................... 122 
4.6.3 Building Ethos through the Discursive Construction of Nation and National Identity 130

4.6.4 Building Ethos through the Deictic Use of "We" and its Possessive Form “Our” 131

4.6.5 Building Ethos through Personification.................................................. 138

4.6.6 Building Ethos through Metonymic Use of Personal Names .................. 140

4.6.7 Building Ethos through Religious Discourse...................................... 145

4.6.8 Building Ethos through Call-and-Response ....................................... 150

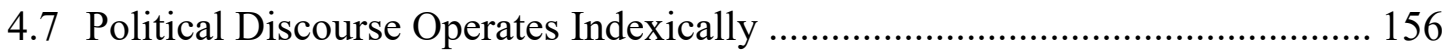

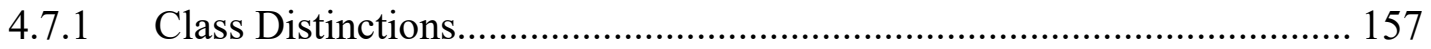

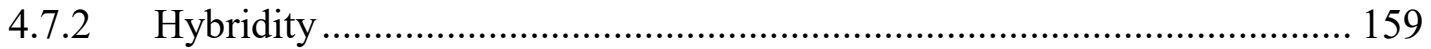

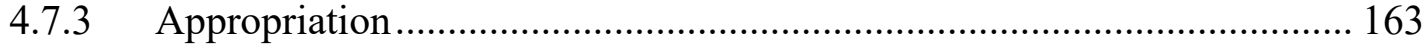

4.7.4 From Postcolonial to Global ................................................................. 169

4.8 Emotional Appeal (Pathos) ................................................................... 172

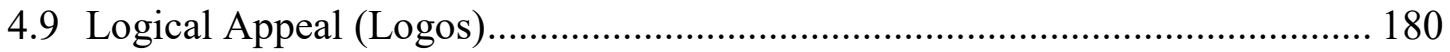

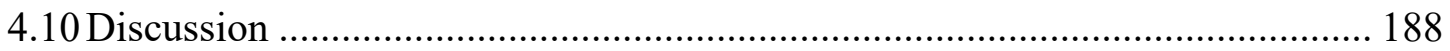

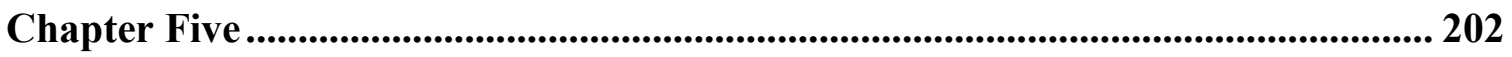

Summary, Conclusion, and Future Research............................................................... 202

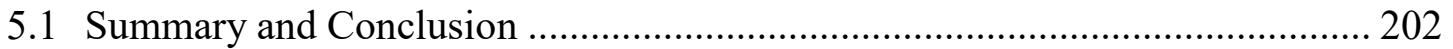

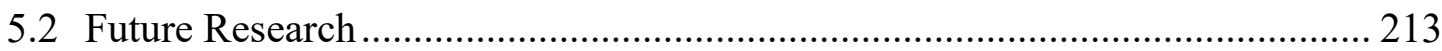

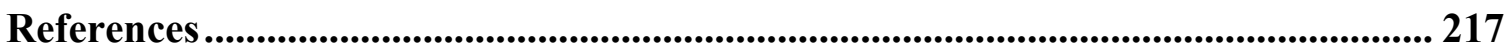

Appendix A

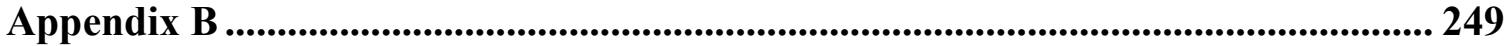




\section{Table}

Table 4-1 Clusivity in Chinese and Tok Pisin ......................................................... 133 


\section{Acknowledgements}

I am highly indebted to my advisor Dr. Victoria Bergvall who has helped to shape and develop my understanding of critical discourse studies and political discourse analysis. Vicky agreed to work as my advisor on my very first day at Michigan Tech. She has been enormously supportive and responsive and always willing to read my work even when she is out of Houghton. She was so dedicated to my research that she made sure she read most of the literature important for my research on decoloniality, postcolonialism, rhetoric, and globalization, even though it is not her primary area of research. Her desire to read these materials culminated in a CDA reading group meeting since the summer of 2015. The reading group helped fine-tune my research and made brought me abreast of the current research in my area (thanks to the members of the reading group: Nancy Henaku, Tolulope Odebunmi, and Stephen Dadugblor). I have learned from Vicky to pay more attention to theory and always ready to answer "And so what," and to be more cautious about which claims I can support and not support. It is a humbling experience to learn how to do research, teach, and develop personal career goals under her.

I also want to acknowledge my committee members who have contributed in various ways to the development of this project. First, I want to thank Dr. Craig Waddell. Craig's knowledge and understanding of the relationship between rhetoric and politics have been instrumental in the development of this research. Particularly, he was the first to suggest that I explore presidential campaign rhetoric for my dissertation. I have benefited from Dr. Ramon Fonkoue's vast knowledge about African politics and 
globalization. He provided most of the readings on postcolonialism and globalization and consistently drew my attention to the new language of imperialism in African political discourse hidden under the name of development, progress, and nation-building. The comparative and cultural rhetorics part of this dissertation were informed by Dr.

Abraham Romney's input. Abraham has always challenged me to approach rhetorical analysis in ways that engage in a critique of the rhetorical canon rather than simply applying terms from the canon without showing their limit in understanding rhetoric in an African context. I cannot overstate the contributions of Dr. Farooq Kperogi. He took time out of his many responsibilities at his own University, Kennesaw State University, to offer detailed critique on my dissertation by drawing from his thorough understanding of Nigeria's political context.

I have been blessed with numerous friends and colleagues who have given graciously of their time to provide suggestions and hard-hitting critiques of my ideas. I cannot imagine this dissertation without their input. In particular, I would like to acknowledge Nancy Henaku (who I spoke with daily about this project), Fatimata Mohammed, Wincharles Coker, Jackie Mullen, Aliyu Abdulkadir, Ayobola Raji, Babangida Danladi, Monday Eje, Ruth Ibbi, Vincent Manzie, Sidouane Patcha, Stephen Dadugblor, Gabriel Agbozo, Olayemi Awotayo, and Kimberly Tweedale. Additionally, I want to acknowledge Abubakar Idris and Nura Abubakar for their help in translating some portions of the speeches into Hausa and back to English. 
I want to offer my thanks to my family members (brothers and sisters) who have been so supportive, always calling to provide their encouragements throughout my stay in the US. Those calls were inspiring. Lastly, I want to thank specially my Sweetness, Hassana for all the sacrifices she made to see that I accomplish this project. Hassana, just know I treasured that surprise cooking of my favorite Nigerian food in Houghton. 


\begin{abstract}
In this dissertation, I conceptualize a rhetorical and linguistic analysis of politics from a decolonial framework (Mignolo, 2011; Smith, 2012). My analysis draws on classical rhetoric (Aristotle, 2007), cultural rhetoric (Mao, 2014; Powell, et al., 2014; Yankah, 1995), and linguistics (Chilton, 2004) to reveal the different ways ideological and hegemonic struggles are discursively constructed in Nigerian political campaign discourse. The data for this study come from two speeches delivered by former President of Nigeria Goodluck Jonathan during the 2015 electoral campaign. This includes his declaration-of-intent speech and his speech marking the commencement of his formal campaign activities. My research demonstrates the richness of conceptualizing political discourse within its immediate and larger contexts and the effectiveness of an interdisciplinary approach — which I call an integrationist approach — in unmasking the different forms of hegemonic struggle in discourse. Analysis of linguistic elements such as tenses, indexicals, and cultural metaphors and the rhetorical elements of apologia, apologies, enthymemes, call-and-response, and fictive kinship terms such as "my brother and sister" reveals that hegemonic discourse in a Nigerian context is neither autonomous, nor flowing from a single dominant power, but constituted by multiple, heteroglossic and complex processes that connect the local and the global. To this end, my analysis focuses on a dual critique of local and colonial forms of hegemonic powers that are now codified in the overall discourse of globalization. This dual orientation is necessary because the social struggles below and above the nation-state are strategic spaces of political intervention that might be ignored when the focus of the analysis privileges just the nation-state. The findings present the merits of combining decolonial epistemologies with the perspectives of linguistics and rhetoric in the analysis of politics. Particularly, such approaches have the potentials to open up ways of knowing that would otherwise be taken for granted or completely marginalized based on our positionality as academics. The awareness of the diversity of cultural ways of knowing and theorizing encourages us to learn not only from dominant Western systems of knowledge, but more inclusively from culturally different, historically marginalized ways of thinking and knowing.
\end{abstract}

Key words: rhetoric, linguistics, decolonial, postcolonial, political discourse, campaign discourse, critical discourse studies, and globalization 


\section{Chapter One}

\subsection{Introduction}

Influenced by the Gramscian idea of hegemony, Edelman (1977), in his book Political Language: Words that Succeed and Policies that Fail, asks: "How is it that people accept poverty amid affluence, hopelessness in a land of opportunity, government by unresponsive institutions that pledge to human service? Why do they not rebel or, at least, speak out more forcefully against the political and the social order" (p. xvii)? Gramsci's

answer to these questions might be the "attainment" by the politically dominant class "of a cultural-social unity through which a multiplicity of dispersed wills, with heterogeneous aims, are welded together with a single aim, on the basis of an equal and common conception of the world" (Gramsci, cited in Mouffe, 1979, p. 191). One of the tools in the hands of the dominant class in the fashioning of the common conception of the world is the critical role of language in everyday politics. In politics, language is essential in evoking patterns of meaning that reflect any given ideology. According to Edelman (1985), “[w]hile coercion and intimidation help to check resistance in all political systems, the key tactic must always be the evocation of meanings that legitimate favored courses of action and threaten or reassure people so as to encourage them to be supportive or to remain quiescent" (p. 390).

Though the argument can be made that not every use of language is ideological and manipulative, the business of politics is carried out mainly through the use of language. My conception of politics in this work is taken from Chilton's (2004) two 
broad conceptions of politics. First, politics is "the struggle for power, between those who seek to assert and maintain their power and those who seek to resist it." Second, it "is cooperation, as the practices and institutions that a society has for resolving clashes of interest over money, influence, liberty, and the like" (p. 3). Whether as a struggle for power or ability to reach consensus, politics is intrinsically and fundamentally constituted and executed largely through language. This means that politics is both formed and operated through language. However even though language is central to politics, language is powerless in itself in the workings of politics. As Weiss and Wodak (2003) posit, "language gains power by the use powerful people make of it" (p. 11). This power behind language, according to Chilton (2004) "can produce the effects of authority, legitimacy, consensus, and so forth that are recognized as being intrinsic to politics" (p. 5). My dissertation is focused on this role of political language in creating political reality. The dissertation is mainly concerned with how power relations and inequalities between dominant groups and marginal groups are reinforced, articulated and resisted in politics over time through language. I seek to understand the role of language in the domination of other people in politics in a changing global order as a step towards social emancipation.

Previous works have looked at the relationship between language and politics from different approaches, such as from social cognitive (van Dijk, 1997, 2005), critical social (Fairclough, 2015), cognitive linguistics (Chilton, 2004), discourse-historical (Wodak \& Meyer, 2009), and argumentation (Fairclough and Fairclough, 2012). Among Nigerian scholars, we have Ademilokun \& Taiwo 2013, Ajilore, 2014, Adegoju \& 
Oyebode, 2015 and Chiluwa \& Odebunmi, 2016. However, these researchers have rarely considered two important things: how the intersection of language and rhetoric can be a productive interdisciplinary enterprise in the analysis of politics, and how to bring the critical language of decolonization into the analysis of politics where the analysis conceives hegemonic discourse in a Nigerian context as neither autonomous, nor flowing from a single dominant power, but constituted by multiple, heteroglossic and complex processes that connect the local and the global. The interdisciplinary approach between rhetoric and critical discourse studies (CDS) would make the analysis of political discourse more nuanced and rigorous. While "rhetoric is concerned with details that facilitate communication and persuasion" (Andrus 2013, p. 4976), CDS aims to develop a critical consciousness of how linguistic and rhetorical strategy contributes to domination and abuse of power. The coming together of the two disciplines will help to bring attention to minute details of linguistic construction of social reality without losing sight of the bigger picture of communication and persuasion. This analysis will be a shift from analyses that have placed more emphasis on the critique of ideological discourse at the expense of the strategy of communication and persuasion in political speeches. Also, our understanding of political reality in postcolonial Africa needs to be seen from a decolonial (a term I will explain below) perspective for three reasons: first, the ubiquitous nature and the changing role of language in an age of globalization; second, the terrain of global domination and its relationships with colonial processes and structures; third, political power dynamics in colonized societies, including the chosen language and the broad colonial legacy. 
Based on these overlapping concerns about how persuasion, domination, and colonialism intersect in the workings of power in political discourse, I borrow van Leeuwen's (2005) idea of an interdisciplinary approach called an integrationist framework to adapt it to my own version of interdisciplinary approach comprising both rhetorical and critical discourse studies (CDS), rooted firmly in decolonial epistemology (Mignolo, 2011). Political discourse analysts have had a fruitful interdisciplinary approach profiting from contemporary developments in linguistic pragmatics, social theory, psychology, discourse analysis, and text linguistics, and they have posited that a discipline-specific approach is no longer able to provide answers to the complex phenomena of political discourse (see Chilton, 2004, 2007; Wodak and Meyers, 2016). Nonetheless, the available analyses have not engaged in a special way with theories from decolonial studies. Decolonial theories provide us with tools to analyze and criticize colonial legacies with the aim of understanding the relationship between existing political structures and other elements of colonial and global structures that are related to the Western idea of modernity and promises of economic growth. According to Mignolo (1995) "reflections on colonial experiences are not only corrective exercises in understanding the past but helpful tools in speaking the present" (p. 314).

While some political analysts have made references to postcolonial conditions (e.g., Kamalu and Agangan, 2011), the decolonial analysis was not their main concern. Thus, in this work, I argue that understanding the mechanism of domination and inequality requires that we engage on two levels of critique simultaneously: (1) the internal critique of hegemonic powers and (2) the critique of colonial powers that are now 
codified in the globalization discourse. This dual approach is necessary because contemporary Nigerian language of politics not only serves the interest of the ruling class, but can also be seen as a discursive residue of colonialism (Mignolo, 2011). Thus, the forms of social struggles that are above and below the nation-state are places of intervention that might be ignored when the emphasis of the analysis privileges just the nation-state. According to Fairclough (2015), there is a dialectical relationship between the global and the national, a two-way process of conditioning and shaping. I am not suggesting that the issues global politics are the dominant issues in internal Nigerian political discourse, but I do want to emphasize that it is of critical importance to know "how what is currently dominant and hegemonic came to be" (Bhambra 2014, p. 117): how the past has shaped the present.

As I situate my analysis within the decolonial epistemology, my task is to unveil the silences of the dominant Western epistemologies. It is also worth pointing out that previous dominant frameworks in rhetorical theory and in CDS in themselves are not the problem; instead, the problem is the Eurocentric foundation these disciplines have, which often ignores (African) context-specific issues. According to Mignolo (2009), some of these theories fail to address colonial logics because the ideas are designed with little or no African needs and visions in mind but mainly to serve the needs and visions of their Western initiators. But it could also be that the dominant theorists didn't have the kind of colonial experiences that would inspire them to create pragmatic space for colonial analysis. 
My dissertation focuses on selected presidential campaign speeches associated with the 2015 Nigerian election with the objective to finding the various ways power and power abuse work in discourse, and to understand how the dialectical relationship between discourse and social world marginalizes certain groups whose interests are not best served by the societal structures. My dissertation focuses on selected presidential campaign speeches associated with the 2015 Nigerian presidential election with the objective of finding ways power and power abuse work in discourse, and how the dialectical relationship between discourse and the social world operate to marginalize certain groups whose interests are not best served by the existing societal structures.

The first focus of my dissertation is rhetorical, especially those patterns that reveal a speaker's strategies of persuasion. Specifically, I investigate how the former President of Nigeria Goodluck Jonathan, who as an incumbent seeking reelection, used different rhetorical and linguistic strategies to pursue his political goals. I do this by drawing concepts largely from Aristotelian (classical) models, such as the genres of rhetoric (ceremonial, forensic, and deliberative), rhetorical appeals (ethos, pathos, and logos), stasis, enthymeme, and apologia to indicate the different ways through which rhetoric can help us understand politics. Rhetoric, in this case, is the adaptation of Aristotle's sense as the "ability, in each [particular] case, to see the available means of persuasion" [1356a]. The means of persuasion available to speakers according to Aristotle are speakers' credibility and trustworthiness (ethos, while Aristotle says that ethos consists of good will towards the audience, good sense, and good moral character), their persuasive arguments (logos), and the speaker's appeal to the emotions of the 
audience (pathos). The classical rhetorical traditions have a significant influence on how rhetoric is conceived in Africa, however, the rhetorical canon has been challenged and elaborated upon and Plato, Aristotle, Cicero, and Quintilian are no longer the last word on rhetoric. Among the new conversations, my work is situated within the cultural and comparative rhetorical understanding of rhetoric as an attempt to "understand meaningmaking as it is situated in specific cultural communities" (Powell et al, 2014, p. 4). The cultural and comparative rhetorical perspectives bring to bear Nigeria's colonial experience and the various traditions that informed and emanated from this experience.

However, I am aware of the potential tension between the classical and cultural/comparative rhetoric as some approaches to cultural rhetoric try to articulate a kind of cultural studies that would cast off the classical tradition as unnecessary or even inappropriate for understanding non-Western rhetorics. I still believe that using both is significant in my own analysis. The classical tradition "provides a method for looking at rhetoric as a human phenomenon, for learning how to use it, and also for a system of criticism, in that the features of speech that Aristotle describes can be used not only to construct a speech, but also to analyze and evaluate other forms of discourse" (Kennedy 2007 , p. 20). And the cultural/comparative is significant in bringing attention to the "practices of meaning-making" in a particular culture and "how particular practicesways of thinking, ways of problem solving, ways of being in the world — are valued (or not) within specific cultural systems and/or communities" (Powell et al, 2014, p. 6).

The second focus of my dissertation is linguistic, specifically from the perspective of critical discourse studies. Here, I examine lexical and grammatical patterns in 
Jonathan's speech, particularly those patterns that express social power abuse, dominance, and inequality. The linguistic analysis uses analytical tools drawn from cognitive linguistic insights from Chilton's (2004) theory of political discourse such as indexicals, the binary conceptualizations of political discourse, and metaphor.

Running through both the rhetorical and the linguistic analyses is an attempt to approach political discourse analysis from a decolonial standpoint, drawing largely on Smith's Decolonizing Methodologies (2012) and Mignolo's The Darker Side of Western Modernity: Global Futures, Decolonial Options (2011).

\subsection{Research Questions}

This study addresses the following research questions:

1. What does it mean to study political rhetoric in a postcolonial country such as Nigeria, amidst a call to a globally focused analysis?

2. In what ways were Goodluck Jonathan's rhetorical and linguistic choices during the 2015 election influenced by Nigeria's postcolonial lived experience?

3. Is it possible to subsume the project of decolonization into the conceptual framework of critical discourse analysis?

4. If yes, what transformations are needed in critical discourse studies for decolonial projects to be fully incorporated in its conceptual framework? 


\subsection{Background of the Study}

The interest in the critical analysis of language began as a consequence of what has been called a linguistic turn in philosophy in the twentieth century, where significant interests were drawn to the study of language and its role in the representation of reality. The most significant thing that took place took place during that time, however, "was not the linguistic turn itself, rather the beginning of a thoroughgoing rethinking of certain epistemological difficulties which have troubled philosophers since Plato and Aristotle" (Dallmayr, 1984, p. 16). These epistemological problems centered on the challenge of understanding reality unmediated by language. The consensus among scholars across disciplines in the social sciences and humanities is that the relationship between language and the world is not merely referential but is shaped by the discursive representation of the world (van Dijk, 2005).

In linguistics, the current consideration is no longer whether reality can exist outside the discursive representation of language, but whether the use of language to represent reality is a transparent or neutral medium. The main contention on the neutrality of language in the description of the world is between the formalist and the functionalist approaches in linguistics. The formal approach focuses on the structure of language, emphasizing the formal properties of the language system (generative rules, algorithms) and affirming that these linguistic elements are neutral and can be studied from a scientific point of view (see Chomsky's 1957 distinction between competence and performance). The functionalists, on the other hand, focus on the communicative properties of language and the way that ideas are organized within it. They emphasize 
that the communicative function of language is influenced by its social context and that it must be studied from such a view. Drawing from Halliday's analysis, Fowler, Hodge, Kress, and Trew (1979) stressed that language is not a transparent medium of thought, especially when one considers the fact that language "encodes" and "expresses" social structure, and is moreover an "instrument" of legitimizing that structure (Fowler, Hodge, Kress, \& Trew 1979, p. 146). Language, then, can be influenced by the ideological structures within which it operates, and it is possible to uncover it through linguistic analysis.

The current interest in using linguistic analysis to reveal the structures of power in discourse started with critical linguists (see Fowler, Hodge, Kress, \& Trew 1979). Although systemic functional linguistics paid much attention to the use of language in context, the ideological study of language started with the publication of Language as Ideology by Hodge and Kress, 1980. The role of ideology and power in language has been influenced by earlier philosophical movements, such as the Frankfurt School, The Center for Contemporary Cultural Studies at Birmingham, and scholars such as M.A.K. Halliday and Michel Foucault, among others. These various influences provided a fertile ground for the offshoot of a network of scholars called Critical Discourse Studies (CDS) (Wodak and Meyers, 2016), which is "primarily interested in the way social power abuse, dominance, and inequality are enacted, reproduced, and resisted by text and talk in the social and political context" (van Dijk, 1993, p. 249). CDS as a network, therefore, aims at understanding how language enacts inequality and advocates for change based on its findings. 
Before the advent of CDS, Marxist scholars had spoken in a similar fashion (e.g., Horkheimer \& Adorno, 2002; Fuchs, 2014; Kperogi, 2015) that the forms of social life are not given, but rather an outcome of historical and social choices, therefore subject to change. Although CDS is also a critique of the existing social reality, it begins with the analysis of discourse. According to Fairclough (2015), "CDA combines a critique of discourse and explanation of how it figures within and contributes to the existing social reality, as a basis for action to change that existing reality in particular respect" (p. 6 , emphasis in the original). This combination of critique and explanation is central to CDS. It not only identifies various features and types of language use that are manipulative and hegemonic, but it further seeks to find answers to why discourse is the way it is, and ascertain its role in shaping the way people think of their society and themselves. The underlying assumption is that without a close and critical analysis of language, language would not readily yield its hegemonic and ideological undertones.

CDS practitioners have mostly focused on the elite because it is they who have institutional, political and economic power and who in their exercise of power have created other forms of inequality including class, political, racial, gender and ethnic differentials. While it is true that in order to dominate, the economically and politically dominant class must forge alliances with other classes through the integration of the masses in "a system of absorption and neutralization of their interests in such a way as to prevent them from opposing those of the hegemonic class" (Mouffe 1979, p. 182), most CDS practitioners believe that the reason for the inequality rests primarily on the elite who use different strategies at their disposal, such as the monopoly on the "legitimate" 
use of violence. Moreover, the alliances usually do not genuinely embrace the interests of the dominated class, but, rather, allow for the dominant class to sustain its tendencies to dominate. The ideological unity is imposed on the allied groups by the influential roles the dominant group has in articulating the interest of the group's reality through ideological struggle that gets accepted by other classes as "common sense" (Gramsci, 1999).

CDS analysts focus on the large body of politicians' talk and speeches because of the influential roles these have in shaping the consent of the masses. But one might argue that Gramsci's idea of hegemony does not refer to a single dominant class but it is an unstable and shifting alliances of different classes, a bloc of social forces. In this sense, focusing only on the elites' discourse excludes “critical challenges that arise from nonelites who [tend to] resist the restrictive reproduction of power" (Bergvall and Remlinger 1996, p. 454). As rightly pointed out by Bergvall and Remlinger (1996), what constitutes the elites is a complex question because there are several levels of elitism. My notion of elites focuses on those members of the ruling class who have been elected to occupy positions in Nigerian politics, such as the president, governors, and the members of the legislative arm. These individuals possess institutional and political power and control and influence the nature of politics and political discourses in Nigeria. However, my analysis does not only focus on dominance from top-down approach (elite's discourse) but also on bottom-up resistance. The bottom-up resistance focuses on two factors: theory and the systems of translation. Theoretically, I argue that while critical discourse studies have achieved much in the critique of power, they remain limited by not foregrounding 
the fact that politics in postcolonial context is imbricated in the logic of coloniality and the global neoliberal movement. CDS thus appears to be complicit in the reinforcement of the colonial logics. My work is a challenge from below to articulate a new explanatory understanding within the overall parameters of critical discourse studies and produces conclusions that contribute a particular standpoint in critical discourse studies.

Regarding resistance through translation, it is vital to be reminded that English is a language of wider political communication at the national level in Nigeria as Kperogi (2015) indicates that there are more English speakers in Nigeria than there are in the UK, the birthplace of the language. Yet, looking at the population of Nigeria, which stands at approximately 170 million, half of this population cannot speak English (Ethnologue, 2017), as such they get the versions of political communications translated mainly by indigenous language media and through social mediums as the family. The business of translation, however, is not neutral. It involves "controlling the quantity of the original text, reorganizing its structure, transforming" the message and supplementing messages (Schäffner 2010, p. 273). Though it should be noted that controlling and transforming are not unique to translation. Even English-language journalists choose what they report from a speech. Generally, media houses have the potentiality of leaning towards the ideological position of the political actors to which the media houses/translators openly or tacitly lend their voice. According to Schäffner (2010):

The textual transformations performed by journalists as translators as well as by editors can thus also be explained concerning gatekeeping functions. That is, controlling the quantity of the original text, reorganizing its structure, 
transforming messages (such as changes between active and passive sentence structures), and also supplementing messages (for example by adding contextualizing information) are functions which reflect the importance of ideology in the translational. (p. 273)

Through these various roles, the translators can mount a resistance from below. This form of resistance was the case during Nigeria's 2015 election, as the indigenous language media, primarily from the Northern part of Nigeria (which excludes, Kwara, Kogi, and Benue) were involved in various acts of resistance to the dominant discourses of "freedom" and "justice" that features in former President of Nigeria Goodluck Jonathan's campaign speech.

Nevertheless, it is not enough to focus only on analyzing the various ways language is used in the interest of those in power. We also need to find answers to what it means to analyze political rhetoric in a postcolonial country such as Nigeria. This is pertinent because rhetoric in the first place evokes negative connotations in the public domain, and its association with politics is considered as lacking impact, as a ploy to "spin" or as a waste of time. According to Martin (2014), "a common prejudice is that politicians are utterly self-interested, amoral actors who neither merit close scrutiny nor require theoretical analysis" (p. 8). Hence, people are quick to dismiss political rhetoric as mendacious, manipulative, and deliberately misleading.

In the United States and Britain, there is a strong tradition in the analysis of political rhetoric (e.g., Edelman, 1977, Tulis, 1987, Martin, 2014). The rhetorical approach is also central to Murray's frame of political analysis and is a key theoretical 
analysis by political scientists in the UK such as Martin (2014), Hay (2013), and Finlayson (2007). What is not yet made clear in their analyses is the relationship between political theories and postcolonialism. Nonetheless, even the role of rhetoric and linguistic analysis (whether devoid of decolonial perspective or not) in understanding political processes and theories has not yet taken a firm root in political discourse analysis in Africa especially during election campaigns. Although there are calls to focus attention on the role of rhetoric in understanding governance (Ige, 2012 and Okediran, 2013) in Africa, the analyses seem to be significantly tilted towards analyzing persuasive and argumentative strategies without necessarily relating general phenomena of political rhetoric to political activities and actions. The role of rhetoric in election campaigns seems pushed to the periphery, while, as noted by Lumumba-Kasongo (2007), the focus is largely on the credibility of electoral processes, the possible negative and positive impact of elections on the economy, and the political stability of the countries after elections. Thus, political analyses of presidential election campaign speeches in Africa are not considered to contribute much to the body of knowledge on election matters. It is a time that we begin to see rhetoric as an analytical framework that does not simply see speech as an object of analysis but as a basis for studying political strategy (Turnbull, 2015). Thus, in this dissertation, I adopt Weberian ideal-type of politics conceived as rhetoric (Burke, 1982) to argue that politics can best be understood through the eyes of rhetoric. Especially in an election campaign, we can say that politics is primarily a rhetorical affair. According to Burke (1982) election campaign "is a rhetorical contest, in which each side (it takes at least two sides to make a contest) tries to out-persuade the 
other" (p. 51). The main aim of persuasion in an election campaign is to accrue electoral votes. To achieve that ultimate goal, candidates must attempt to persuade as many voters as possible to reach a coalition with their audience that they are the right candidates for the job. Achieving a coalition with the audience might require the candidates to rely on the society's beliefs and values just as a means to an end - electoral votes. Persuasion is central to politics not only that it is "ceasing to be merely the means of selling a policy and becoming rather the process through which policy in itself is created" - the epistemic view of rhetoric (O'Shaughnessy, 2014, p. 20). But it also remains an important means of understanding the process of decision-making in society, where decisions are made not purely on objective values or absolute values but on the power of persuasion. Turning to rhetoric as a means of understanding politics becomes more and more imperative.

There is also an ongoing debate about which lenses and tools Africans should use in studying their rhetorical contexts and realities. The problem of methodology and theories are significant in these debates. Some scholars have advocated that in studying the African context, we need to seek explanations within "African cultural codes and 'webs' of meaning" (Chabal, 2009, p. 5). For instance, Mao (2014) notes that our "central question to ask is not 'what is rhetoric in/for these other cultures' but '[w] hat does the other do in/with rhetoric, and how does the other do it?" (p. 450)

Critical discourse analysts have raised concerns over the Eurocentric drift of their practitioners (Chilton, 2007, Dunmire, 2012, Wodak \& Meyer, 2016), and are advocating that CDS must begin to move beyond the dominant Eurocentric models to a transglobal status. A close look at the lists of prominent discourse analysts composed by van Dijk on 
his websites clearly shows this Eurocentric focus. There is no mention of a single African discourse analyst or a person reflecting the realities of a decolonial African perspective, even when there are many Africans regularly publishing in his journals Discourse and Society and Discourse and Communication (see for example, Chiluwa, 2012, Ademilokun and Taiwo 2013, Ajilore, 2014, Adegoju and Oyebode, 2015 and Chiluwa and Odebunmi, 2016). In fact, one of the earliest editions of Discourse and Society has an African's article in it (see Yankah, 1991). The problem is not that they are not represented, and/or their names are missing from the lists, it is the extent to which those authors themselves relied on European theories, such that African perspectives are not firmly projected even when the studies are on discourses in Africa. However, it is important to mention that just because they have relied on Western theories does not mean that there is no merit to consider extending those theories to other contexts. Importantly, "in view of the increasing exchanges between cultures, [Africa] cannot exist without Western contacts and without the contexts of Western texts. It is not possible to speak of a 'purely' [African] tradition, nor of Western tradition that is "uncontaminated"' (Chen 1995, p.3). The primary concern is:

[t]he manner in which we engage, orient about, or produce scholarship matters. We must be mindful that research methodologies are not value-free tools. Our practices, including our research methodologies, are imbued with ideological and epistemological beliefs and values that have material effects in the world. (Powell et al., 2014, p. 11) 
As we adopt different theoretical perspectives (Western and non-Western) our analysis must not end in the critique of power alone. It should also be seen as a way of decolonizing the dominant theories we use so that we don't end up being complicit in the reinforcement of the logics that have enslaved us.

\subsection{Nigeria's 2015 Presidential Election}

Since 1999 when Nigeria moved from military rule to civilian government, presidential elections have taken place after every four years. The 2015 election is the fourth-time Nigerians went to the polls to choose their president. However, since 1999 the People's Democratic Party (PDP) has been the winner in those elections, though in most cases the results were all challenged in court because of allegations of irregularities in the conduct

of the elections. There are more than twenty political parties that participated in the 2015 presidential election, but the main political parties that had the chances of winning the election based on their geographical spread and the popularity of their candidates were the All Progressive Congress (APC) and the People's Democratic Party (PDP).

\subsubsection{The Major Presidential Candidates in the 2015 Election}

\subsubsection{Muhammadu Buhari}

General Muhammadu Buhari was the candidate of the All Progressive Congress during the election. President Muhammadu Buhari was born December 17, 1942. He is a retired Major General in the Nigerian army and previously served as the nation's head of state from December 31, 1983, to August 27, 1985, after taking power in a military coup. He 
unsuccessfully ran for the office of the president in 2003 and 2007 under the All Nigeria People's Party (ANPP), and in 2011 under the Congress for Progressive Change (CPC). After the merger of Action Congress of Nigeria (ACN), All Nigeria People's Party (ANPP), and Congress for Progressive Change (CPC) on February 6, 2013, to form a new party called All Progressive Congress (APC), in December 2014, Buhari emerged as the presidential candidate of the newly constituted party. Buhari won the 2015 elections defeating the then incumbent President Goodluck Jonathan, which marked the first time in Nigerian history since independence, that an incumbent president lost to an opposition candidate in general elections. He was sworn in on May 29, 2015.

\subsubsection{Goodluck Jonathan}

Goodluck Jonathan was born November 20, 1957. Before becoming president in 2010, he served as Vice-President to the late President Umaru Yar'adua from 2007 to 2010 (Yaradua died on May 5, 2010). He was also the deputy governor from 1999 to 2005 to former governor of Bayelsa State Chief Diepreye Alamieyeseigha who was later removed from the office for corruption allegations which paved a way for Jonathan to take over as the governor of Bayelsa from December 9, 2005 to May 29, 2007. Before joining politics in 1998, he worked as an education inspector, a lecturer, and an environmental-protection officer in Rivers State. He holds a Ph.D. in Zoology from the University of Port Harcourt, Rivers State. He was first elected as the president of Nigeria on April 18, 2011. His major opponent in the election was Muhammadu Buhari who he defeated with 22 , 
495, 187 (58\%) against Buhari’s 12, 214, 853 (31\%). In his bid to get re-elected, he contested the 2015 election and lost to Muhammadu Buhari with a popular vote of 12, 853, $162(44.96 \%)$ as against Buhari's 15, 424, 921 (53.96\%). He served as the President of Nigeria from May 5, 2010 to May 29, 2015.

My analysis focuses on the 2015 campaign speeches to understand the different ways that a rhetorical and linguistic analysis situated within decolonial methodologies can add to our understanding of the various forces and flows that operate within Nigerian political discourse. Since my dissertation focuses on the place of rhetoric and linguistic analysis in understanding politics in a decolonizing world, not about whether it is necessarily successful or not, I only use Jonathan's selected campaign speeches as a representative of this type of discourse from a decolonizing world. Also, Jonathan's position in power at the time situated his speeches at a locus of understanding the ways different ways Nigerian political discourse is impacted by the influences of multiple contexts, histories, and knowledge systems from both the local and the global. Future analysis can utilize the findings from this dissertation to explore the forces of colonial, postcolonial, and global structures in multiple presidential discourses.

\subsection{Decolonial Projects}

According to Fanon (1961), decolonial research began in postcolonial nations as a realization that colonialism was short of improving the material conditions of colonial nations (It wasn't its purpose in the first place). Colonialism rather had devastating consequences on the indigenous peoples' cultures and ways of knowing. The postcolonial 
intellectuals began to think seriously about research, beginning to see their research projects not merely as a single contribution to the body of academic knowledge, but rather in dialogue with their people's interests and needs. They firmly resolved that research should reflect the local people's interests, knowledge, and experiences. Some of the issues the postcolonial perspective must engage with, according to Smith (2012), include "imperial legacies of Western knowledge and the ways in which those legacies continue to influence knowledge institutions to the exclusion of indigenous peoples and their aspirations" (p. xii). But for Fanon (1961), the aim of anti-imperialism was not to entirely reject Western ideas but to reclaim and reframe them for all of humanity. This means that decolonial approaches to research are not expected to compete with or replace the Western research paradigm; rather, they should challenge and expand it. Decolonial research aims to interrogate the structures of imperialism with the view of "understanding the complex ways in which the pursuit of knowledge is deeply embedded in the multiple layers of imperial and colonial practices" (Smith, 2012, p. 2). The use of the term "decolonial" here refers to ways of telling "stories from the perspective of colonized cultures and communities that are working to delink from the mechanisms of colonialism. This delinking encourages a shift to a set of knowledge-making practices that don't reinforce colonial logics - logics that also form the roots of systems like capitalism" (Powell et al. 2014, p. 7).

The issue of language is important in any discussion on a decolonial project in Africa. According to Yankah (1999), Africa lacks the "power of metalanguage possessed by dominant cultures" (p. 144), as the dominant languages of scholarship (English, 
French, and German) are foreign and colonial languages to Africans. Ngũgĩ (1994) has been at the forefront in advocating for writers in Africa to write in their indigenous languages. Ngũgĩ questioned the use of foreign languages to write literature for Africans. He argues that because language is an important carrier of our culture, the continuous use of written English (and French) reinforces a colonial mentality, and this might defeat the project of decolonization. Ironically, even Ngũgĩ himself wrote most of his scholarship in English (not in his native Kikuyu). Even those he wrote in Kikuyu are translated into English.

The question of language is one of the difficult topics with which African intellectuals still grapple. Smith (2012) notes that the issue of indigenous language is a great irony because the matter can only be seriously "debated in the language of the colonizers" (p. 37). This use of foreign language, according to Smith, alienates indigenous people from their own "history, geography, music and other aspects of culture" (p. 38). Although a few writers of fiction in Africa, such as Ngũgĩ, have taken the challenge in writing literature in indigenous languages, most African scholars who work in the social and other sciences still struggle to write, theorize and research in foreign languages, as does Ngũgĩ.

The establishment of the dominance of English language in Nigeria whereby it has taken over major social institutions such as government, law, religion, and education can be associated with two relations of power: while on the one hand it incorporates differences of power, on the other hand, it gives rise to particular relations of power that stemmed from colonialism. Whereas as Fairclough (2015) asserts it is associated with 
political "power and as the language of the politically powerful" (p. 67), it does that at the expense of the local languages and replicates the "dominance of the capitalist class and the [subordination] of the working class" (p. 67).

Apart from language, there are other colonial legacies that continually frame African experience. For example, some of the structures of colonialism are being reenacted through neoliberal discourse and development paradigms that have remained the organizing principles of our social and political lives. For instance, orature (oral literature) (see Zirimu, 1978) as existed in traditional African societies prior to colonialism has now been largely replaced or subsumed by literature, such that a struggle is visible to subsume all forms of African literature under the western genres of prose, poetry, and drama. While it is true that culture in Africa has not remained static since Africa's ongoing encounter with Europe, a decolonial approach does not mean going back to find vestiges of ancient Africa and reassert them to replace the status quo. Decolonial projects mean giving back voices to the colonized people to tell their own stories from their vantage point and to reflect on their lived experience and the problems that affect their well-being and social development. In other words, it can be seen as a project that aims at cultural pragmatics. An account of Africans' lived experience has to analyze the role of colonialism in shaping the knowledge of Africa and the world. This work, therefore, takes an emancipatory political stance with the belief that Nigerian political discourse is constitutive of colonial and imperial legacies on a multiplicity of trajectories, within which there are practices that align closely to Nigeria's cultural heritage. Thus, my analysis is geared towards a critique of discourse that emanates from 
Nigeria's political multiple histories ranging from precolonial context to our encounter with colonialism.

\subsection{Decolonial and Postcolonial Debates}

There are ongoing debates on the use of the terms "decolonial" and "postcolonial." The terms both first evolved after the end of the formal colonization of African and Asian countries by their European colonial administrators. Decolonization, which was "once viewed as the formal process of handing over the instruments of government, is now recognized as long-term process involving the bureaucratic, cultural, linguistic and psychological divesting of colonial power" (Smith 2012, p. 100). According to Mignolo (2011), decolonial analysis works to show the limits of Eurocentrism. It is a model of analysis that is "necessary to extricate oneself from the linkages between rationality/modernity and coloniality, first of all, and definitely from all power which is not constituted by free decisions made by free people" (p. 45).

Post-colonialism on the other hand (with a hyphen) was first understood as a period after the formal colonialism, but in its modern use postcolonialism (without the hyphen) is "integral to the exercise of opening out and questioning the implied assumptions of the dominant discourses by way of which we attempt to make sense of the worlds we inhabit. It has further provided the basis from which to reclaim" (Bhambra 2014, 117). Spivak (1990) also argues that postcolonialism is "a series of regulative political concepts, the supposedly authoritative narrative of whose production was written elsewhere" (p. 225). Both postcolonialism and decolonial thinking have the radical 
potential to unsettle and reconstitute standard processes of knowledge production and understanding the world from colonized perspectives. However, there is a disciplinary difference between postcolonialism and decoloniality. Postcolonialism emerged as an intellectual movement consolidating and developing the ideas of Edward Said, Homi K Bhabha, and Gayatri C Spivak. While much work around postcolonial studies have directly addressed issues of the material, of the socio-economic, there has also been a tendency for it to remain firmly in the realm of the cultural. In contrast, the decoloniality school emerged from the work of, among others, sociologist Anibal Quijano, philosopher and semiotician, Walter D. Mignolo and an educationist Linda Smith. It is strongly linked to the theory of development and underdevelopment and the Frankfurt School's critical social theory tradition.

My use of "decolonial” is prevailed by my readings of Mignolo $(1995,2011)$ and Smith (2012). These are scholars from whom I draw my methodological inspirations, and as such, I adopt their choice of the term "decolonial." Even though, I choose to use the word "decolonial" over "postcolonial" in my analysis; I draw widely from both theories. The primary goal for me is not to privilege one theory (decolonial) over the other (postcolonial) but to focus on scholars from both disciplines whose ideas can enable me to interrogate the colonial world order established by European empires and the new imperial order embodied in Nigerian political discourse. 


\subsection{Significance of the Study}

The present study confirms previous findings on the importance of critical discourse theories in revealing the role of language in sustaining and maintaining elites' centered agenda in social and political processes. My study's goal is for CDS to begin to incorporate other approaches from the disciplines of rhetoric and decoloniality that would pay attention to unveiling discursive strategies associated with the colonial order. Even though the domain of political discourse analysis has had an unprecedented crosscultural, multidisciplinary, and interdisciplinary approach to the analysis of political discourse (Chilton, 2007), political discourse analysis failed to engage deeply with decolonial epistemologies. It is through the incorporation of other disciplines such as decoloniality that CDS will be broad enough to resonate across cultural, social and political landscapes and become flexible enough to allow for the extent of diversity demanded by the global flows. CDS scholars' apprehension should not be limited to the critique of power in discourse only, but also a way of decolonizing the dominant theories in practice. To this end, this work suggests a novel fusion of rhetorical, linguistic, and decolonial approaches, called an "integrationist framework" (see van Leeuwen, 2005) in the analysis of politics in a postcolonial context such as Nigeria. Herein lies my hope to contribute to the field of political discourse analysis in particular and critical discourse studies in general. While this integrationist framework fully endorses the use of discursive methods to critique social and political process, the framework is enriched with rhetorical theory. 
Another significance of this work is its attempt to close the gap between internal (within Nigerian) and external critique (impacted by neocolonialism etc). I argue that the forms of hegemonic struggles and the logics of politics cannot be fully understood if we fail to recognize that contemporary Nigerian political discourse is a constellation of the society’s precolonial, colonial, and neocolonial experiences. Focusing exclusively on either internal (ethnicity, religion, and power struggles) or external (neocolonialism, discourses of globalization and development), might ignore some of the bases of the elites' discursive strategies. 


\section{Chapter Two}

\section{Postcolonial Perspectives: Governance, Globalization, Politics, Nationalism, Nation State and Nationhood}

\subsection{Introduction}

Central to any serious discussions and meaningful understanding of Nigerian politics is an awareness of the forces (economic, historical, political, and social) that have shaped and still shape the country's politics, as well as an in-depth account of different discourses that emerge from different political occurrences and episodes. If we must have a deeper understanding of the contemporary political discourse, then we need to provide a useful historical evaluation of the major happenings that took place within our political space. As Rodney (1972) observes, "just as given medical remedies are indicated or contra-indicated by a correct diagnosis of a patient's condition and an accurate casehistory" (p. vii), the same concept applies to political discourse analysis. We need to understand how the present came into being and what the likely trends are for the future. Thus. In this chapter, I set out to establish the context and background of Nigerian political discourse by identifying the essential features of Nigerian politics, and the recurring political patterns that have dominated Nigeria's politics over time. But I do this by consistently drawing attention to the discursive side of politics and how it can be understood from a decolonial framework.

It is important to start with this question: what does it mean to analyze political discourse from a decolonial perspective at a time we are witnessing the most dramatic 
connections around and across the world called globalization? This question becomes significant because of transnational cultural flows that tend to create a homogenization of culture, yet it is expected that the global culture will at the same time achieve unity amidst diversity. Instead of plurality and diversity the world is becoming culturally smaller or more uniform. According to Moghadam (2009) "world polity places primacy on cultural and political institutions and norms, emphasizing norm diffusion and convergences in political and cultural developments which is interpreted as a kind of global Westernization" (p. 3). The tendency of globalization to move towards global Westernization or isomorphism in values, cultures, practices, and norms across the world probably prompted Dallmayr (1996) to argue that the theory of globalization should be in favor of a nonassimilative stance "where dialogical exchange respects otherness beyond assimilation." The fear of assimilation into one global culture is not only shared among non-Western societies but also Western countries. According to Betts (2016) people voted mainly for Brexit as a demonstration of the rising tide of disillusionment with the expectation of a better life in a global neoliberal economy and the desire to take back control over their own lives. In his TED talk titled, "Why Brexit Happened and What to do Next," Betts (2016) says that contemporary politics is no longer about the right or the left, it is about those who embrace globalization and those who fear globalization. Those who fear globalization are embracing an orientation where the emphasis is on local values, economy and beliefs rather than the neoliberal global economy.

Moreover, those who fear globalization are concerned with its contradictions. According to Harvey (2006), this contradiction is noticeable in "the gap between rhetoric 
(for the benefit of all) and realization (the benefit of a small ruling class) increases over space and time" (p. 66). The gap between the rhetoric of globalization and the reality on the ground has led to the thinking. That globalization has been hijacked to support elites' agenda, who are considered to benefit more than all (Betts, 2016), perhaps at the expense of groups without power. This elite type of globalization, championed by the proponents of neoliberal philosophy is embedded in power relations that reproduce inclusions and exclusions, or what some people call globalization-from-above and globalization-frombelow (Brysk, 2002). Those who identified with globalization-from-below assert that neoliberal globalization has contributed to wider income and wealth disparities without addressing the persistence of poverty and unemployment, which are its consequences, in a serious fashion (Brysk, 2002). Although we cannot dismiss the benefits of globalization in that it has "promoted growing contacts between different cultures, leading partly to greater understanding and cooperation and partly to the emergence of transnational communities and hybrid identities" (Moghadam 2009, p. 26), the focus has been largely on economic terms, ignoring the multifaceted phenomenon of the emergence of multiple and overlapping identities (Moghadam, 2009).

Nevertheless, although the conversation has been skewed largely to economic terms, scholars such as Abrahamsen (2012) still hold the view that it is impossible to understand African politics without also paying attention to the rising hybrid sites of global culture that has affected Africa immensely. Of particular interest to me is the changing role of language in the globalized new economy and how globalization creates new world order in which language is implicated. In this sense, we cannot analyze 
globalization purely in its economic forms; there have to be efforts to point up to the linguistic aspect because the multiple flows and nexuses have indeed reshaped global arrangements, including linguistic ones. It is imperative therefore to offer a discursive approach to globalization through drawing attention to how the discourses that drive globalization are constructed, consumed and structured on global configuration.

Political discourse analysts, such as Chilton, 2007, Wodak, 2012, Wodak and Meyer, 2016 have advocated for a shift to a global perspective where the field of political discourse analysis would be more inclusive and encourage communication and shared understanding across cultures, race, and class. We have not seen the global approach to political discourse analysis taking everyone with it yet. Notably, the decolonial perspective has not yet been adequately represented in the field of political discourse analysis. Political discourse analysis should strive to provide every culture and society an avenue to be active participants in shaping the global discourse. Mainly, for a postcolonial nation like Nigeria, to put in the words of former UN Secretary General Kofi Annan, the glasshouse of globalization must remain open (Annan, 2002). Corroborating with Annan's appeal Ngũgĩ (1993), in his book Moving the Center: the Struggle for Cultural Freedoms offers valuable insights into the need to embrace and appreciate pluralities, multiplicities, and cultural differences against global uniformity. To him, "the wealth of a common global culture will then be expressed in the particularities of our different languages and cultures very much like a universal garden of many-coloured flowers" (1993, p. 42). The plea for inclusive globalization arises because of how globalization is enacted in a neoliberal way where it focuses on capital accumulation, 
with less attention paid to rising social inequality, destruction of natural resources and the erosion of cultural diversity. Thus Annan's "closed glasshouse" of globalization "highlights the unevenness, asymmetry, and inequality that are embedded in the new global mélange" (Moghadam 2009, p. 26). The discourse of globalization is not neutral. It works ideologically. "It is a discourse of power - a discourse which is used in conjunction with other potent resources by those in power to enhance their power" (Fairclough 2015, p. 243). Language is involved in this struggle to naturalize the neoliberal version of globalization. The critique of language of politics becomes an essential element in creating an understanding about the kinds of political discourse that depends more on the global economy and less responsive to local needs.

While the focus area in my work is Nigerian political space, this analysis sometimes makes general reference across the continent, especially in identifying common elements within these societies such as the idea of communalism, PanAfricanism, and the problems of poverty and inequality. The focus on Africa and Nigeria doesn't mean that the practice of politics on the continent of Africa is different from political processes found elsewhere in the world. My analysis uses the familiar concepts in political theory, such as nationalism, nation-state, governance, democracy, ethnicity, and sovereignty. However, the chapter examines how these linguistic concepts relate to other social elements such as ideologies, social institutions, and power relations within the new neoliberal global order. 


\subsection{Governance, Politics, and Political Leadership in Africa (Nigeria)}

The merits and the problems of governance have been an integral part of our everyday public discourse in Nigeria. Recent research has suggested that good governance and political leadership have ensured critical development and have provided significant benefits to people around the globe. Despite the benefits, however, governance and political leadership in Africa suffer from several significant drawbacks. A classic problem of good governance and political leadership in Africa is the foundation (Fanon 1961, Ngũgĩ 1993, Mbembé 2001). A thoughtful diagnostic analysis of good governance and political leadership in Africa cannot be achieved without looking critically at the challenges involved in founding a new government and polity out of the rubble of colonialism. It might not be totally out of place to agree with Mudimbe (1988) "But it can be admitted that the colonists (those settling a region), as well as the colonialists (those exploiting a territory by dominating a local majority) have all tended to organize and transform non-European areas into fundamentally European constructs" (p. 14). This transformation of non-European areas becomes visible the moment one begins to pay attention to the system and structures of governance and political leadership in Africa. Although Mudimbe's view is supported by Mbembé (2001), who writes that governance in Africa is a product of "colonial rationality... that postcolonial African regimes have not invented what they know of government from scratch" (p. 9), Mbembé took a broader perspective and argues further that governance in Africa is also the "product of several cultures, heritages, and traditions of which the features have become entangled over time, 
to the point where something has emerged that has the look of 'custom' without being reducible to it, and partakes of 'modernity' without being wholly included in it" (p. 25). Mbembé's work is complemented by Mazrui's (2005) concept of “Africa's triple heritage." According to Mazrui (2005), Africa is a product of three civilizations Africanity, Islam, and the impact of the West. I agree with the view of multiple African heritages and would like to extend it to governance and leadership in Africa, specifically Nigeria, and say that our various heritages should be incorporated into the theories of political discourse analysis and be made into "a major new paradigm for interpreting Africa" (Mazrui, 2005, p. 76) and a possible explanation for the style and type of discourses prevalent on the continent. The word "paradigm" here is an extension of one of Thomas Kuhn's multiple definitions provided in his book The Structure of Scientific Revolutions. Kuhn (1996) defines paradigm as "the entire constellations of beliefs, values, techniques, and so on shared by members of a given community" (p. 175). These constellations of these beliefs, values, and techniques are in part linguistic phenomena. Hence the compelling reasons to analyze the relationship between these dialectic relationships between language and the social conditions.

I also believe that the rhetorical and linguistic choices politicians make to convey their agendas and the visions of their governments are informed by the multiple heritage raised by Mazrui and Mbembé above. For instance, it is common to hear politicians in Nigeria make declarations of allocation of public funds to praying for the nation. Likewise, although increasingly fewer Nigerians avow of being practitioners of traditional religion in public, we still hear politicians recognize Christianity, Islam, and 
Traditional Religion as the dominant faiths of the nation. This is a clear mapping of the triple heritage of Mazrui (2005). Thus, in this work, my main point of emphasis is that political ideas and practices are interwoven with Nigeria's multiple heritage, and the analysis of politics in Africa has to be situated within these complexities. More so, the analysis should not be predisposed to the "tendency to construct a dichotomy between the internal and the external and to examine the two in isolation, with little or no attention [paid to] the way in which the two levels of politics overlap and intertwine" (Abrahamsen 2000, p. 7). Corroborating Abrahamsen's argument is Mudimbe (1988), who says that it is puzzling to see Africanist scholars attempting "to separate the 'real' African from the Westernized African and rely strictly upon the first" (p. 10). Whereas Abrahamsen's and Mudimbe's arguments speak to the analysis of African condition in general, I contend that there is nowhere this multiplicity of histories and knowledge system coexist and intersect more prominently more than political discourse.

Turning now to the historical trajectories of governance and political leadership in Nigeria, one would recognize that the nature of Nigerian political institutions and systems have differed from time to time. Before the colonial era, indigenous African political systems and structures were the predominant system in the kingdoms and empires that were located within this territory. During colonialism, the British indirect rule became effective through using and manipulating traditional structures. Some parts of Northern Nigeria before the coming of the British had well-developed political structures in the ancient kingdoms of Kanem-Bornu which Shehu Usman dan Fodio and jihadists absorbed into the Muslims Fulani empire (Achebe, 2012). These ancient kingdoms 
previously ruled by chiefs later took Islamic names commonly called the emirs. In the west, it was Oyo Empire and Ife kingdom governed by the Alaafins and Oonis respectively. In the East, which is predominantly Igbo, the indirect rule was challenging to implement because Igbos lacked a centralized system of kings. Notwithstanding, there was the establishment of "warrant of chiefs" in the East so as to implement the indirect rule too in that region. To make it easy for British administrators to adapt those indigenous pre-existing structures for its smooth implementation of the indirect rule, the British established what they called "House of Chiefs" a semblance of "House of Lords" of the British Parliament, comprising emirs and obas (Achebe, 2012). Achebe reports that with British indirect rule, the traditional African structures continued as they existed centuries ago with just "one exception-there was a new sovereign, Great Britain, to whom all vassals pledged fealty" (p. 2). The establishment of "House of Chiefs" and the unique positions occupied by the British "set in motion new social forces which eventually played a decisive role in shaping the social and the political structures of Nigeria” (Tar, 2009, p. 91).

During colonialism, the British ruled through such traditional structures wherever possible. However, the British style and structures of governance that were superimposed on the existing indigenous structures affected those local structures and set in a new configuration that complicated Nigeria's style governance to date. The main complication with the British political structure was not only that it was alien to African political system, but also "the bureaucratic principles were not compatible with the beliefs and practices of African society... and because the underlying cultural premises of 
Western state institutions were foreign to the continent, these institutions started to crumble the moment the colonial administrations left" (Smith 2006, p. 130).

Another reason factored in the crumbling of Nigeria's political system was that the colonial economic system imposed on Nigerians and other African states were for the benefit of the colonizers. The economic system encouraged the "development of a commodity-based trading system, a cash crop agriculture system, and building a trade network linking the total economic output of Africa to the demands of the colonizing state" (Nnaocha 2015, p. 278). African states became core dependent systems and their economy subordinated to the interest of colonialists, which continued after independence. According to Okafor (2006) the "dominance of the system in the post-colonial era effectively works to the advantage of powers which have physically left the stage" (p. 28). The national bourgeoisie noticed these contradictions and the problems associated with the colonial system but did little to change it because they were committed to maintaining the colonial-bureaucratic state that benefited them too (Hansen, 1974). Ngũgĩ (1993) supports this argument when he says that because of corruption the "class that took over power after independence was an underdeveloped middle class which was not interested in putting the national economy on a new footing, but in becoming an intermediary between Western interests and the people, a handsomely paid business agent of the Western bourgeoisie" (p. 83).

Continuing with this theme of the national bourgeoisie and their failure to effect change after colonialism, Fanon's classic analysis of the origins of political leadership in postcolonial Africa is certainly a significant contribution to this theme. Fanon's (1961) 
chapter "The Pitfalls of National Consciousness" in his book The Wretched of the Earth explores the continuity between the colonial middle-class structure of the mother country and the native middle class. As a major theorist for postcolonial movement, Fanon uses a Marxist humanist analysis to examine classes and class interest in a postcolonial context. With the end of the colonial regime, Fanon observes, the national middle class who took over the leadership of their native countries from the colonial powers remained underdeveloped. They were not able to bring the needed transformation people yearned for when they were under the colonial rule. Some of the reasons Fanon provided for the failure of what he called the national bourgeoisie included that they have "practically no economic power, and in any case, it is in no way commensurate with the bourgeoisie of the mother country which it hopes to replace" (p. 149). Moreover, seen from their perspective, the national 'bourgeoisie's mission has nothing to do with transforming the nation; it consists, prosaically, of being the transmission line between the nation and capitalism, rampant though camouflaged, which today puts on the masque of neocolonialism" (p. 152).

One of the underlying causes of misgovernment throughout the continent of Africa can be traced to the colonial times and the national bourgeoisie's lack of preparedness for governance before the termination of the colonial rule. As the native middle class becomes the conduit in which neocolonialism was realized, the existence of a worldview which tends to serve the interests of the neocolonialist was institutionalized. Although one can say that the middle class replicates the systems of domination that created power imbalances which look like the Manichean colonial world - the colonizer 
and the colonized, "the inability of the indigenous bourgeoisie to impose its own hegemony on Nigeria's social formation" (Okafor 2006, p. 12) created two categories of subalterns - the ruling middle class and the masses. Both the ruling middle class and the masses are subaltern in the sense that by definition, they are epistemologically below the dominant culture" (Maggio 2007, p. 427). The Nigerian ruling middle class are subalterns whose loyalties are to the imperial powers that have been historically and geopolitically inscribed (Spivak 1988). Although the local ruling class is in a privileged position, ironically this status is co-opted for the service of the new empire. In other words, the ruling class is complicit in the continuous muting and domination of its people. A significant point is that the ruling class are not necessarily muted completely. It is just that they "can speak as long as they speak in a 'language' that is already recognized by the dominant culture of the West" (Maggio 2007, p. 431). Speaking in this sense means the imperial powers were speaking through the native ruling elites without an attempt by the native ruling class to find their authentic voice or self. According to Mignolo and Escobar (2010):

It is important here to distinguish the "epistemic location" from the "social location." The fact that one is socially located on the oppressed side of power relations does not automatically mean that he/she is epistemically thinking from a subaltern epistemic location. The success of the modern/colonial world-system consists precisely in making subjects that are socially located on the oppressed side of the colonial difference think epistemically like the ones in dominant positions. (p. 67) 
In the second category of subalterns are the masses who are victims of the foreign interests, oblivious to the domestic problems. The two classes of subaltern status merely repeat the colonial regime and bring up Spivak's (1988) question again and again, "Can the subaltern speak?" And if they speak, can they be heard? As to whether the subalterns can speak, there is yet no significant change in the intermediary role the national middle class has been occupying since independence. However, the case of Nigeria's 2015 presidential election brings a glimpse of hope that at least in the local context the subaltern's voice can be heard and respected through the ballot box. Although an important political philosophy's concept, consent of the governed, was achieved, where through different rhetorical platforms, the two main contending candidates, former President Goodluck Jonathan and the incumbent President Muhammadu Buhari, sought the consent of the governed to be their president, the winner of the election might not have necessarily heard the "speaking" of the people. As long as the programs and the agenda of the government do not relate to the aspirations and desires of local communities, one cannot be sure if the subaltern can yet speak. With the problems of unemployment, poverty, environmental degradation, especially caused by the activities of oil companies in the Niger Delta oil-producing states, among others, transforming the fate of Nigerians to a better life is something that is much desired. The future lies in promoting stronger and more diverse economies designed with the local needs in mind that will be an alternative to the current Neoliberal project.

Another dimension Fanon (1961) raises is the question of representation and legitimacy. The fact that most of the ruling class owe their wealth to their access to state 
resources rather than economic productivity (Okafor, 2006) has made Nigerian elections sometimes violent, instigated by politicians whose primary goal is to enrich themselves rather than to render national service. The desire to amass wealth rather than serve contributes largely to institutional corruption and bad management practices over the years and have "made the Nigerian economy susceptible to external manipulation, dictation, and control" (Akindele, 1999, p. 283). Thus, in the eyes of the masses, the leaders have lost their moral credibility (ethos). They cannot mostly win the respect of the masses purely based on ideas. Hence, they entice the masses with the politics of money amidst an ideological void. Amidst the monetary inducement, rhetoric remains significant in the ways campaign elections are organized and executed. The rhetorical activities that go on during elections become not a mere election ritual but a political process that has a social effect.

This discussion on the effect of colonial structures on contemporary African politics cannot be complete without mentioning Achilles Mbembé, an influential postcolonial scholar that has paid significant attention to the analysis of African postcolonial politics and its connections to its foreign origins. Mbembé (2001) in his book On the Postcolony reveals how colonial rationality continues to be the practice in postcolonial Africa. For the purpose of this work, I will draw two significant points from Mbembé's (2001) book to drive home my point. First, Mbembé argues that when we engage in political analysis in Africa, we must be mindful that the dominant political ideas, such as democracy, governance, nationalism, state, sovereignty, and civil society 
materialize out of European historical experience and may veil and conceal more than they reveal.

Second, according to Mbembé, the colonial state was not a liberal state where the individual's rights and civil liberties of freedom and power to speak, think, or act without undue government imposed restraints were guaranteed. Instead of government's strict adherence to the supremacy of law and established proper procedures, the government became to a significant degree a destroyer of liberty. Mbembé believes that the postcolonial state replicates these colonial ideologies. Under this form of government, the citizen's engagement with the state is relatively narrowed by the dominant actors. Under such form of government, political campaign would appear to be performing the usual election ritual. In Nigeria, according to Tar (2009), that by 1999, Nigeria witnessed a resurgence of civil society where avenues were provided for people to demand that the government act in their interests and sometimes even challenge unpopular decisions by the government. One of the factors that contributed to this liberal political space was the restoration of democracy in 1999, a remarkable transmutation in the global economy that led to neoliberal economy and "political conditionality" imposed on Nigeria by developed Western countries. Sixteen years later, Nigeria for the first time in its history of democracy has achieved a peaceful transference of power from one party to another by ousting a sitting president at the polls, as former President Goodluck Jonathan lost the election to Muhammadu Buhari in the 2015 presidential election.

The question of a foundation is not a novel topic in postcolonial discourse (see Said, 1978, Mudimbe, 1988), as it has been a point of discussion among African scholars. 
What is worth noting here is that in decolonial thinking, a foundation is a critical stage in any analysis of politics in Africa and "one of the most intractable issues in political theory" that political theories of decolonization cannot escape from addressing (Kohn and McBride, 2011, p. 153). From the perspective of African history, Mudimbe (1988) observes that the "most active period of colonization lasted less than a century, [yet the colonial period] signified a new historical form and the possibility of radically new types of discourses on African traditions and cultures" (p. 14). In a similar fashion, Said (1978) considers understanding the philosophy behind Napoleon's invasion of Egypt (even though it was not the genesis of colonialism) as significant in providing a clue as to why the pre-colonial political system was disrupted in less than a century. According to Said (1978) “with Napoleon's occupation of Egypt processes were set in motion between East and West that dominate our contemporary cultural and political perspectives - the very model of a genuinely scientific appropriation of one culture by another, apparently stronger one" (p. 50). This led Ngũgĩ (1993) to say that any study "which ignores structures of domination and control and resistance within nations and between nations and races over the last four hundred years is in danger of giving a distorted picture" ( $p$. 46).

It is important at this juncture to recognize that while the modern form of governance currently being operated in Nigeria lacks indigenous roots, focusing on the external factors alone provides a fraction of the big picture and plays down with the complex nature of Nigeria's political history and leadership. It is not possible to "recover some pristine, 'pure' pre-colonial culture, because colonialism has an irreversible 
rupturing effect" (Ahluwalia 2001, p. 7). Yet, it is also not possible to completely wipe out some of the precolonial African political heritage from the contemporary political system, even though these legacies overlap and intersect in significant ways with the foreign systems, and this has the aftermath of producing a different culture, a hybrid culture which is a product of the intermixture and the amalgamation. Mazrui and Tidy (1984) insist that there are elements of continuity between the precolonial and postcolonial eras. Mazrui and Tidy (1984) note that it will be of value "to study those elements of continuity which link Africa's pre-colonial history with its present, and in particular to take note of continuing styles of political leadership" (p. 185). These precolonial origins of much of the political culture of Africa's new nations are grouped under two broad categories: nations and leaders.

Focusing on a nation, during pre-colonial times, the territory that constitutes present-day Nigeria was composed of centuries-old empires and kingdoms such as the Yoruba Empire of Oyo, Benin Kingdom, the Onitsha Kingdom and the Kanem-Bornu Empire. There was also a confederation of Hausa states which rose to prominence in the thirteenth century (but later came under Muslim/Fulani domination from the 18th century). These are Biram, Daura, Gobir, Kano, Katsina, Rano and Zaria (Okafor, 2006). On its part, British colonial rule brought about the amalgamation of the northern and southern protectorate of Nigeria, inter-ethnic tensions and sub-nationalities became a strong factor in Nigerian politics. Some scholars, for example, Okafor, argue that the genesis of disunity based on ethnicity was as a result of the Richard's Constitution of 1946 (Richard's Constitution came into operation on January 1, 1947 which has the goal 
of encouraging greater participation of Nigerians in the discussion of their own affairs), which brought about the concept of regionalism as the House of Assembly was established for each of the three top provinces: Northern, Western, and Eastern. The Yoruba are the dominant group in the West, Igbo in the East and Hausa-Fulani in the North. Richards' regionalization failed to recognize other minority groups of Niger Delta, Mid-West and the Middle Belt regions of Nigeria. According to Achebe (2012) "many of them - Ijaw, Kanuri, Ibibio, Tiv, Itsekeri, Isang, Urhobo, Anang, and Efik - were from the ancient nation-states in their own right" (p.47). The minority groups were "uncomfortable with the notion that they had to fit into the tripod of the largest ethnic groups that was Nigeria - Hausa/Fulani, Yoruba, and Igbo" (Achebe 2012, p. 47), and this became a significant factor in Nigerian politics and caused the first attempt to break up Nigeria led by General Isaac Boro. In fact, if the minorities were to team up with the other groups, Mazrui and Tidy note they would outnumber the three major ethnic groups. This alliance of minorities, in particular between the Middle Belt movement and NigerDelta movement, had always been a significant political bloc and the great contribution to former President Goodluck Jonathan 2011 election as he is the first minority to be elected president. However, because of the dominant position the major ethnic groups have taken since independence, the minority ethnic groups seem to be silent in the power struggle at the center. They have become accustomed to their lack of significance. Another significant problem with the Richard's Constitution was the mistake of not obtaining and considering the opinion of Nigerians in its drawing. Richard found himself faced with a 
spate of bitter criticism from not only of the minority groups but also from the major ethnic groups too (The National Conference, 2014).

Scholars are of the opinion that Nigeria's pre-colonial empires and states traded among themselves and internationally with other parts of West Africa and North Africa, without the contemporary tensions Nigeria continues to witness (Mazrui and Tidy, 1984; Okafor, 2006). They posit that the pressure today can be attributed to the system of divide and rule where ethnicity has been politicized, starting with the 1946 political regionalization for the sole purpose of gaining political power. It is important to point out that the Richards Constitution had the goal of promoting unity and recognizing Nigeria's diversity, even though the resulting effect was ethnic politics and disunity. Mazrui and Tidy (1984) suggest that by creating ethnopluralism in Nigeria, the Richard's Constitution created not only the potential for a competitive democracy but also the framework for latent violence. Mazrui and Tidy further contend that the plurality of cultures wasn't a threat to national and national consciousness. However, the survival of precolonial cultural nations in a new form of ethnic-subnationalities does pose a problem for national unity and nation-building. Although Nigeria has one flag, national anthem and pledge, national logos, and symbols on money as semiotic resources to metonymically produce meanings about Nigeria as a nation which people can identify with, the political ethnic competition continues to reify ethnicity as an essential tool of identity.

Unarguably, ethnicity is one of the key features of, and a recurrent theme in Nigeria's politics. It is essentially one of the postcolonial legacies inherited from 
precolonial patterns of consciousness heartened by colonial rulers. Politically, ethnicity was reinforced and enshrined in the creation of Nigeria's earliest political parties, and the practice continues. These political parties based on ethnic nationalities, according to Okafor (2006), sowed the seeds of Nigeria's political instability and are still one of the biggest problems threatening coexistence of different ethnic groups, along with religion. The three political parties that came to dominate the politics of the first republic were, by and large, regionally and ethnically conceptualized. For instance, Action Group (AG) was dominated by the Yoruba ethnic group from the West, Northern People's Congress (NPC) was mainly for the Hausa-Fulani ethnic group from the North, and the National Council of Nigeria and the Cameroons was dominated by the Igbo from the East. I need to emphasize here that even parties founded based on ethnic solidarity don't necessarily develop programs that address the pertinent problems of the ethnic groups but can be seen as a political tool to get to power. In fact, Achebe (2012) asserts that postindependence Nigeria's problem was political corruption. According to Achebe:

The structure of the country was such that there was an inbuilt power struggle among the ethnic groups, and of course, those who were in power wanted to stay in power. The easiest and simplest way to retain it, even in a limited area, was to appeal to tribal sentiments, so they were egregiously exploited. (p. 51)

The post-independence Nigerian politics abruptly came to an end because the military considered the 1964 elections as highly manipulated and rigged in favor of ethnic affiliations. Even though Nigeria's two main political parties today: the All Progressives Congress (APC) and the People's Democratic Party (PDP), were not overtly founded 
based on ethnic configurations, it is hard to take away the ethnic factor in Nigerian politics. The politicians seem to exploit people based on ethnicity rather than good governance. This exploitation of ethnicity has helped heighten inter-ethnic tensions and sub-nationalism in Nigerian politics, especially when one looks at the crises that engulfed the People's Democratic Party on power rotation between the South and the North after the death of former president Umaru Yar'adua. Ethnic problems have a way of structuring people's lives that made democratic government difficult and led to the coups of 1966, 1976, 1983, and 1993, countless riots, and the civil war of 1967-1970.

The democratic dispensation that began in 1999 was not removed from these conditions. Not a surprise, a robust articulation of ethnicity was one of the key attributes of the 2015 presidential campaign rhetoric. Although some scholars are of the view that the exploitation of ethnicity in the elite's rhetoric began the day Europe arbitrary partitioned Africa and "concentrated diverse and often hostile (ethnic) groups into territories which ultimately became sovereign states, making internal strife inevitable” (Okafor, 2006, p. 15), the politicians have substantially helped in sustaining the feelings of disunity among Nigerians. The dilemma now is whether to weaken these ethnic and cultural sub-nationalities that affect nation-building, as suggested by Dr. Nnamdi Azikiwe, the first ceremonial president of Nigeria, who said that Nigeria should "forget the differences (perhaps efface) rooted in the past" (Adebanwi and Obadare, 2010, p. 381), or to find positive ways ethnicity can still be a factor in political discourse but remove the hate and bigotry associated with it that have led to violence. I subscribe to the second option. We cannot change who we are; we have to embrace our pluralistic society 
where different ethnic groups coexist. The most important thing as the former premier of Northern Nigerian Sir Ahmadu Bello said in his response to Nnamdi Azikwe, is "to understand (and perhaps permanently honor) these differences" (Adebanwi and Obadare, 2010, p. 381). The politics of ethnicity is not so much about the existence of different ethnic groups or the competition among them, but as Venkatasawmy (2015) points out, is a product of combinations of factors, such as power struggles between political leaders, localized economic discrimination, and opportunistic exploitation of popular ethnicreligious fears.

The question that persists is whether it is possible to construct a rhetoric that will galvanize support on a shared national culture and symbolism that will cut across ethnic divides. This question occupies a portion of our leaders' rhetoric. All the leaders Nigeria had in the fourth republic since 1999 to date have articulated their different versions of the ways of achieving a common national culture and identity. What seems to be missing from their rhetoric is that there is as yet no tangible mechanism on the ground to ensure an evolution of national identity that can pull Nigerians together. Nigeria has witnessed various articulations of unity and different conferences have been held to buttress this. Of recent is the 2014 National Conference successfully organized by the former President Goodluck Jonathan. The national conference had the objective of providing a "formal platform for dialogue by constituent units of the nation... to discuss issues or problems that inhibit national progress or challenge national cohesion... [and] proffer appropriate solutions that will assist in moving the nation forward" (The National Conference, 2014, p. 1-2). 
Apart from ethnicity, religion is one of the domestic issues and a dividing factor in Nigerian politics. It must be acknowledged here that the two main religions in Nigeria - Christianity and Islam - are not indigenous religions; however, the fact that Africa was a deeply religious society before the coming of these two religions made it easier for the adaptation of these foreign religions. Interestingly, Nigeria considers itself a secular state, but the significant role religion is playing in the nation's politics and both in private and public life "points to the contradiction between the avowed claims of state secularity and the strong influence of religion on state-society relations and elites politics in particular" (Obi, 2010, p. 4). According to Tar and Shettima (2010), the construction of Nigeria as a secular state is a colonial legacy carried forward to this era, and it is an anomaly that is daily contested. Because of this anomaly inherent in the Nigerian constitution and Nigerians' daily lives, Tar and Shettima (2010) reported that the then-President Olusegun Obasanjo (when asked on a BBC Talking Point program why he allowed the implementation of Sharia law in a secular state like Nigeria) stated that "We are not a secular state - we are a multi-religious state" (p.10). Obasanjo is right to a certain extent, especially when one considers how the Constitution contradicts itself in some ways. For example, section 10 of the 1999 Nigerian Constitution, which states that "the government of the Federation or a state shall not adopt any religion as state religion" has in the same section of the constitution affirming the resolve of the Nigerian people "to live in unity and harmony as one indissoluble sovereign entity under God." The problem there, is as Tar and Shettima (2010) observe "writing God into a secular constitution not only 
constructs the state and citizens as religious" but also raises questions such as: Whose God?

Arguably, one cannot deny the linkages between religion and politics in Nigeria. However, what is often not discussed is the specific role religion should perform in politics and how these roles should be carried out in a democratic process. Nigeria is not the only country where religion is intricately connected to its politics (see O'Connell, 2015), but Nigeria has allowed religion to be used as a tool in the hands of the political class to "seek relevance, legitimacy, and access to power" (Obi, 2010, p. 4). The rhetoric of religion is primarily used to advance a struggle over power and resources, taking advantage of the deeply religious masses mostly living in poverty. This divide-and-rule syndrome sustains tribal rivalries.

As a rhetorical strategy, politicians use various religious narratives to appeal to particular adherents of religion. They can tell their audience that they are "divine will of God," "God sent" or begin to connect themselves to some spiritual symbols and pillars. During the election campaign, it is common to hear different prophesies about who God has ordained to take the mantle of Nigeria's leadership. Election times are when politicians will make their appearance in religious gatherings and rituals more pronounced through the instruments of media. They employ all these strategies not simply for spiritual or moral reasons, but more importantly (some will say exclusively), for their political ambition. These practices become more prominent during elections as a way of achieving and/or sustaining hegemony over the society. 


\subsection{Nationalism, Nation, and State in Africa}

Nationalism, nation, and nation-state are closely related terms, such that each is difficult to examine without directly or indirectly referring to the others. Nonetheless, I attempt to focus on each of the concepts and analyze the way they have been operationalized in Nigerian political discourse. A notable fact about these political ideas is that they originated outside the physical space of Africa. According to Heywood (2012), the process of colonialism "involved not only the establishment of political control and economic dominance, but also the importation of western ideas, including nationalism," (p. 97) nation, and nation-state. While it is true that the foundation that supported modern colonialism also encouraged the spread of these Western political concepts (nationalism, nation, and nation-state), how they are conceived and operationalized within the context of colonialism varies slightly from the mother countries. This is evident in the case of nationalism where in Europe the doctrine is "reflected in the belief that, as far as possible, the boundaries of the nation and those of the state should coincide" (Heywood, 2004, p. 97). In the case of Africa, this was not so. Mazrui and Tidy (1984) aver that Europe's transfer of its own state system to Africa was not accompanied by any pre-assessment of African conditions to make statehood coincide with nationhood. Mazrui and Tidy further reveal that there was little desire "for cultural congruence between the unit of the state and the national unit or even cultural similarities among the different units being ruled by the same colonial government" (p. 374). As such, Mazrui and Tidy argue that very few of the newly independent African states could be described as nations in the classical European sense. Needless to say, even Europe itself has not always had a neat 
coincidence between nationhood and statehood especially with the different struggles for statehood in Britain, Belgium, and Yugoslavia. However, Mazrui and Tidy reiterate that the African political challenges differ in two significant ways: how to move from nationalism to modern nationhood and how to close the gap between statehood and nationhood.

Interestingly, nationalism is a commonly used term in Nigerian political context, and yet, there is still no consensus on how to define it. Pamir (1997) observes that the meaning of nationalism is fluid and varies from one context to another. For example, nationalism is seen as liberatory in developing countries but as reactionary in developed countries. Pamir suggests four possible definitions that might be subsumed under the term:

It is the defining ideology of political movements seeking some form of autonomy or independent statehood; of groups striving to achieve or to improve their cultural, political, social and economic rights within a given state; of protest movements on the part of communities threatened by either state policies or by other social groups; to the core ideology employed by the state to galvanize public support for its policies or to reaffirm its legitimacy (p. 1).

Nationalism during the colonial era fits into Pamir's first definition as “ideology of political movements seeking some form of autonomy or independent statehood" (p. 1). The struggle championed by the elites had two goals: first, to agitate and achieve independence for their various countries. Second, that the independence status should eventually lead to nationhood. But, for Nigeria, the dream of becoming a nation - a body 
of people bound together by a shared cultural heritage, such as a common language, religion, traditions, or historical and national consciousness (Heywood 2004) - is yet to be achieved. For example, regarding language, Nigeria, more than five decades after gaining its independence, is yet to adopt an indigenous language that would function as a national language (even if side-by-side English) and thereby serve as a cultural symbol around which the country may be united while enhancing the national identity. Nigeria still communicates, officially, through the English language. Although the 1999 Constitution provides that deliberations in the legislatures can take place in indigenous languages, the provision has remained in abeyance because, without doubt, any legislator that chooses to use an indigenous language invites ridicule to themselves since English alone is elitist.

The new African states created out of territories under colonial administration successfully instilled the spirit of the nationalist movement to fight colonialism but failed to do the same in nation-building. Although nation-building is a continuous process that can never be finished within a particular period, the sense of purpose which enveloped the pre-independence nationalists' struggle in Nigeria began to shift to how to solve the problems of deep ethnic rivalries and hostilities in Nigerian politics. This issue featured prominently in the speeches of the people involved in Nigeria's first military coup. Nzeogwu, one of the protagonists of the first military coup said in his coup speech that the enemies of Nigerian state are "those who seek to keep the country divided permanently so that they can remain in office as Ministers and VIPs of waste; the tribalists; the nepotists" (Mazrui and Tidy, p. 239). 
After a series of coups and secession attempts (see Adebanwi and Obadare, 2010 for full lists of all the military coups and secession attempts since the amalgamation of Nigeria in 1914), Nigeria appeared to have headed towards disintegration. Apart from maintaining the inherited federal system and military service, there were different structures put in place in an attempt to keep Nigeria as one united country. For example, a new national anthem and nation pledge were composed after independence to emphasize Nigeria's unity. Phrases such as "one nation bound in freedom, peace, and unity" and "to defend her unity" were emphasized. Moreover, the National Youth Service Corps (NYSC) was established in 1973 after the civil war, a creation aimed at strengthening Nigeria's unity. It requires Nigerian university and polytechnic graduates to be posted to cities in states other than their state of origin (so as to appreciate other ethnic groups) for one-year mandatory national service. Another institution aimed at ensuring a united Nigeria is the Federal Character Commission (FCC), established in 1996 with the responsibility of enforcing "fairness and equity in the distribution of public posts and socio-economic infrastructures among the various federating units of the Federal Republic of Nigeria" federalcharacter.gov.ng.

Anderson's (2006) concept of “imagined community," which presupposes imagined connections or shared experience, might be at odd with Nigeria's experience because most Nigerians are yet to perceive themselves as part of the nation. The agitation for the state of Biafra by some Igbo ethnic groups is a clear example. Therefore, some people called Nigeria the "mistake of 1914" or "a mere geographical expression" (Adebanwi and Obadare, 2010, p. 381). This is because there is not yet a collective 
consciousness where the citizen's first allegiance is to the entity Nigeria rather than to ethnic groups, religious affiliates or regional forces. In other words, national cohesion remains elusive. The nationalists' collective consciousness that helped defeat colonialism is yet to end the multiple strata of internal divisions. Although collective identity is a constant and never ending process of negotiation, there is as yet no clear path to a national culture that transcends ethnic, religious, and regional differences. In other words, Nigeria must work towards building a nation where what unites people matters more than what divides, a reflection of unity in diversity.

Nigerian leaders have made some attempts at various stages in the country's existence to keep the country united and forge a national spirit among disparate ethnic nations, where loyalty will be first to the nation-state before and above loyalty to any other group. As recently as January 2017, past Christian heads of state and deputy heads of state were featured together in a music video produced at the behest of the country's current government on the theme of national unity. But because of Nigeria's historical antecedence, the celebrated poet Niyi Osundare insisted that "Nigeria has no unity to negotiate or not to negotiate" (Guardian, August 1, 2016) since most ethnic groups are not part of Nigeria by any prior negotiation in the first instance but by colonial accident. Some groups of people remain part of the union not voluntarily but through the price of their people's blood as in the case of Igbo from the South-Eastern region of Nigeria. In 1967, the Igbo ethnic group, led by Odumegwu Ojukwu, declared the secession of Igbo land from Nigeria to form an independent country called Biafra. The declaration led Nigeria into three years of civil war from 1967 to 1970 . Biafra was incorporated back 
into Nigeria after it was clear that the Nigerian military power had defeated the Biafran army. Chinua Achebe, in his memoir recounting his personal view about the Nigerian civil war, insisted that Biafra was actually a country, not just an agitation, and that since 1966, "[t]here was much discussion of the difficulties of coexisting in a nation with such disparate peoples and religious and cultural backgrounds" (Achebe, 2012, p. 83). The movement for the secession of Igbo land is still ongoing, led today by Nnamdi Kanu. Even though the Nigerian government has incarcerated the leader of the agitation, the fact that there is such a movement casts doubt on Nigeria's unity and reminds us of Achebe's (2012) comment: "If the Berlin Conference sealed [Nigerians'] fate, then the amalgamation of the southern and northern protectorates inextricably complicated Nigeria's destiny" (p. 2).

The post-1999 Nigerian leaders seem to be convinced of the effectiveness of nation-building, but more often than not, the term nation-building has become synonymous with the neoliberal notion of development. The idea of nation-building as a means of establishing "a supra-ethnic identity, which cuts across ethnic and religious divides, by mobilizing all ethnic identities to participate in a common national culture" (Gounden, 2010, p. 1) cannot be from an exclusively economic or neoliberal definition of development. The justification for developmentalism as a form of nation-building is that economic growth has a direct link to other indices of development in society. African politicians have been one of the advocates this theory as it is evidence in Nigeria's 2015 campaign speeches. 
The idea that more development will lead to nation-building is an emulation of the developed world. The view holds that economically successful countries in the world have depoliticized ethnicity and religion to a significant extent. It is believed that they did this because of real economic growth that has created more wealth for their people. The saying goes that if people are prosperous, there is a high chance their prosperity would foster acceptance of diversity. As such proponents of developmentalism posit that "what is good for developed countries is good for undeveloped as well because the former know 'how to get there' and can lead the way for underdeveloped countries to reach the same level" (Mignolo 2009, p. 173). However, Achebe (2012) views nation-building differently and suggests:

A new patriotic consciousness has to be developed, not one based simply on the well-worn notion of the unity of Nigeria or faith in Nigeria often touted by our corrupt leaders, but one based on the awareness of the responsibility of leaders to the led - on the sacredness of their anointment to lead - and disseminated by civil society, schools, and intellectuals. (p. 253)

The development of patriotic consciousness is in part a discursive construction based on a shared political past. Of course political decisions concerning the present and future have a lot to do with continuous re-negotiation, re-production, and co-construction discursively. Since national cultures are constructed in and by discourse, a discursive examination of the process is inevitable.

Turning now to states, one can say that state-building was easier than nationbuilding in newly independent African states because newly independent African states 
inherited a whole statecraft from their European colonialists after independence. Also, since state-building has a lot to do with administrative structures and relies on technocrats, there were some indigenous people trained to some degree in the Western bureaucratic system. However, the "contradiction between the principles of state sovereignty, particularly non-interventionism, and the realities of multilateral developmental intervention” (Tar 2009, p. 57) poses a big problem for contemporary African states.

While maintaining their European colonial ties, post-colonial African states are still caught up in the paradox of power struggle between the assertion of sovereignty and their inability to map out their future due to their reliance on foreign institutions and agencies. Included in this new configuration are the multinational corporations and nongovernmental organizations such as the World Bank, the International Monetary Fund (IMF), World Trade Organization (WTO) and a host of regional and non-governmental organizations (NGOs) which determine and dictate fundamental developmental policies in these states. The developing countries started relying on the global institutions during the so-called developmental agenda period starting from the 1970 s. According to Moghadam (2009), developing countries got themselves into debt trap due to borrowing for infrastructure building anchored upon structural improvement necessities. Unfortunately, by 1980-1982, due to a sudden rise in the interest rates and the collapse of the market for developing countries commodities such as copper, coffee, and oil, the developing countries could not repay their loans. 
In their bid for new loans to service their debts and carry out their development plans, the developing countries turned to the World Bank and the International Monetary Fund (IMF) for assistance. The additional loans came with lots of conditions, which entailed moving from state-directed economic models to neoliberal or a free-market economy. The neoliberal economy means reducing the control of the government in welfare services, opening up fields for capital accumulation and privatizing sectors formerly run or regulated by government such as transportation, telecommunication, natural resources, education (Harvey, 2006). But more than efficiency and balancing of budgets, Structural Adjustments Policies (SAP) were created for austerity measures, such as cuts in social spending, public sector restructuring, and the promotion of private capital. According to Heywood (2012), while the rollback economic policies promise free trade, deregulation, and economic growth, the policies contributed to the economic collapse of many African countries. Failure of SAP in African nations is likened to the failure of the rhetoric of modernity that preaches economic growth but enriched few (Mignolo, 2011). Recognizing these colonial structures, Mignolo comes up with the idea of for a "decolonial epistemic shift" from the rhetoric of modernity that promises development and progress to rethinking ways of emancipating through "de-linking" and the rhetoric of decoloniality.

The question to ask is, to what extent are nation-states still relevant in the new order of neoliberal economics? Moreover, are the sovereignty and the autonomy of nation-states in the developing world over national economies weakened by the new international economic order, perhaps ushered in by the creation of the United Nations in 
1948? Even in the new global order, the concept of state is still relevant. According to Moghadam (2009) state matters for several reasons. First, neoliberal capitalism cannot function properly without state regulations. Thus, states are not the "victims of globalization so much as they are agents of it" (p. 24, italics in the original). Moreover, according to Moghadam, the state is conferred with the responsibility of implementing treaties, conventions, resolutions, and norms.

In developing countries such as Nigeria, the role of the state was weakened. The political conditions that came from these institutions affect the ability of Nigeria to deliver developmental projects initiated by it and for the benefit of the Nigerian people. Most economic policies rolled out by Nigerian leaders are not born out of the problems and desires of their people but "it is the World Bank, the IMF and a host of nongovernmental organizations (NGOs) which determine and dictate major policy. They are, in many respects, the new colonial administrators" (Ahluwalia 2001, p. 54). This external control has seen a disconnect between "the people" and state powers - a disconnect that is emblematic of our neoliberal times (Shome, 2016). Even though the contemporary neocolonialism is different from earlier periods of the twentieth-century colonialism, the adopted measures are still authoritarian and promote the interests of neo-colonialists rather the interest of local peoples. The attendant effect is seen on the alienation that is caused by the state policy and the needs of the people.

A discussion on the nation-state will be incomplete without bringing Foucault's et al. (1991) focus on the genealogy of modern states called governmentality. Through a way of historical reconstruction covering the period from ancient Greek to modern 
neoliberal times, Foucault tries to explain the nature and the idea of a state. He defines government as "the conduct of conduct" which means governing the self and governing others what it considered as the birth of biopolitics. According to Foucault biopolitics is a power that targets populations by generating a pattern of knowledge that makes people monitor themselves. This knowledge can come from social sciences, knowledge about ourselves and our world that aims at making people see themselves in a quantifiable way. The biopolitics is another form of power that Foucault feels it is becoming more efficient because it works in subtle ways. There are two significant points we can draw from Foucault's biopolitics to make our argument. First Foucault set out to correct the erroneous belief that there is a separation between the state and the economy. Foucault insists that the art of government is not limited to the field of politics as separated from the economy; it must not be seen instead as a conceptually and practically separate space, governed by autonomous laws. The political structure is itself an element of economic government (Lemke, 2002) or what is usually referred to as the political economy. If politics and economy are inseparable, then one can elaborate on Foucault's ideas to say that the role of the colonial state was not only one which had to fulfill the role of policing but one which had to meet the development objectives of both its metropolitan master and its subjects. This configuration is still what is in existence in most postcolonial states. The postcolonial state is not just about governing the newly independent states, but it also has to fulfill the economic objectives of the neocolonialist dictated by international institutions such as the World Bank and IMF. 
Thus, to understand the political concepts of nationalism, nation, and nation-state, the concepts have to be disrupted from their imperial perspectives. If we continue to focus on what these concepts connote in their mother countries, our understanding of how they are operationalized in postcolonial nations like Nigeria might be limited. The decolonial framework attempts to expose the paradox inherent in these political concepts in a postcolonial context by offering a rigorous analysis of our leaders' political rhetoric. Moreover, the study employs critical research tools to examine the political rhetoric of the ruling elite who"live in a world of make-believe and unrealistic expectation....[a] belief that someday, without any exertion whatsoever on their own part, a fairy ship will dock in their harbour laden with every goody they have always dreamed of possessing [cargo cult]" (Achebe, 1983, p. 9).

Overall, the themes identified in this chapter (colonial legacies, neocolonialism, ethnicities, religion, national bourgeoisie, and nation-state and nationhood) suggest strongly that contemporary Nigerian political structures are constellations of precolonial, colonial and neocolonial processes. These constellations have influenced the forms and contents of Nigeria's political rhetoric. What is interesting in the foregoing discussions is the recognition of the significance of contextualizing and relaying political ideas in Nigerian context and how such an endeavor in the analysis of political speech would significantly foreground our awareness that the meaning of the speeches politicians make are embroiled and rooted within and among multiple contexts, histories and knowledge systems. More importantly, speeches made by politicians are not merely simple speeches to be analyzed; rather, they are an integral part of our political system, which extends 
beyond us and cannot be confined to an individual. "[A political speech] is always a part of a larger community, a larger conversation, a network of relations" (Powell et al., 2014, p. 23). One cannot ignore the role of rhetoric in influencing how these political concepts are interpreted and operationalized as well as well how the social structures of the society impact on rhetoric. As our politicians construct a system of language and meaning that shape people's interpretation of these political ideas (ethnicities, religion, the national bourgeois, and nation-state and nationalism) and move people to action, the politicians have the opportunity to position themselves as nationalist, transformationist and divinely ordained, unifiers, developers. It can be concluded that politics is a social activity that finds its true expression through the medium of language. As politicians articulate, rearticulate and dearticulate different political ideas, language becomes more than simply a means of communication, but a political arsenal deploy to convey political intents for power, authority, and legitimacy. However, and importantly, because of the place of Nigeria in the history of the world, the meaning of political terms such as politics, nation, state and nationalism, among others cannot be taking for granted. The words might exist in Nigeria's political rhetoric, but their manifestation and actual existence in the lived experience of Nigerians is highly contentious and raises some questions. 


\section{Chapter Three \\ Political Discourse, Presidential Rhetoric, Political \\ Campaign, Rhetoric and Politics in an African Context, and \\ Methodology}

\subsection{Introduction}

In this chapter, I begin by tracing the emergence of a political discourse analysis research, showing how it differs from other dominant approaches to the study of politics in the humanities and the social sciences. The specific topics covered here are political discourse analysis, presidential rhetoric, electoral campaign discourse, rhetoric and politics in the Nigerian context. This chapter also presents the basic concepts and theoretical approaches used in this dissertation, also showing how they have been employed in the analysis of my texts. I finally conclude by presenting my methodology, which is comprised of the sources of my data, analytical data techniques and the rationale for the choice of the data.

\subsection{Political Discourse Analysis}

Political discourse analysis has a long tradition, from the classical Greek period to contemporary times. According to Chilton and Schäffner (2002) the interest in the relationship between language and politics in the ancient Greek tradition centered on the connection between persuasion, truth, and morality, with a deep suspicion of the power of language in politics. For example, Aristophanes, in his comic play The Clouds, argues 
that making persuasive arguments for economic and political gain causes political rhetoric to be an inferior form of knowledge, and this to him, is politically dangerous. Plato too expressed his discontent about rhetoric. Rhetoric, Plato insists, "is merely a knack and not an art because it has no rational understanding of the nature of the various things it applies to or the person to whom it applies, so that it can't explain anything" (465a). Although the later classical rhetoricians such as Aristotle recognized rhetoric as an art of communication that "was morally neutral, that it could be used for either good or ill" (Kennedy 2007, p. x), the perception about the relationship between language and politics persisted to date. George Orwell, in the twentieth century, popularized the problematic nature of the relationship between language and politics. In Nineteen EightyFour and "Politics and the English Language," Orwell focused on the role of language in politics and examined the ways political language is "designed to make lies sound truthful and murder respectable, and to give an appearance of solidity to pure wind" (Orwell, 1946, p.10). Although he recognized that the problem of bad English stemmed from the decay of the society because "when the general atmosphere is bad, language must suffer" (p. 1), he still demanded a deep change of attitude from the use of language because to Orwell "one ought to recognise that the present political chaos is connected with the decay of language, and that one can probably bring about some improvement by starting at the verbal end" (p. 10). Orwell insists that understanding how political language is used is central and the first step towards political regeneration. To him, one can only struggle against the bad use of language when he has the knowledge of how it can be used manipulatively. 
The contemporary interest in the analysis of political language shares and recycles some of these concerns with language raised by Aristophanes, Plato, and Orwell. However, while Plato believes that "oratory is a semblance of a branch of the art of politics" that is "dishonourable undoubtedly" (463b), and Orwell was concerned with the decline of good language in politics, the contemporary interest in political discourse analysis (PDA) is centrally concerned with how we employ linguistic analysis to reveal the way hegemonic struggles are discursively represented in politics. Political discourse analysis sees political language not simply as a powerful tool to be used in the struggle for power but also as sites of social and ideological struggle. Language in this sense is considered as less transparent and more constitutive, less as a means of communication and more as social and political action. As Van Dijk (1997) contends, "political discourse analysis is about political discourse and it is also a critical enterprise." [In its essential critical business, PDA focuses on analyzing the] reproduction of political power, power abuse or domination in discourse." [Its contribution is not only] to discourse studies but also to political science and the social sciences" (p. 11, italic in the original).

Although political scientists might also be interested in political realities that are constructed in and through language (Schäffner, 1997), their political analysis tends to invoke discourse analytical perspectives episodically (see Blakeley \& Bryson 2002, Heywood, 2012). Political scientists focus on developing theories and conclusions based on empirical observations of what Chilton and Schäffner (2002) call "hard evidence from voting figures, constitutional arrangements, party configurations, economic statistics, 
military stockpiles, [and] the patterns of military conflict" (p. 4) without necessarily showing the opaque connections between language and other political systems and processes. However, it is not possible to imagine political actions and political processes of parliament, for example, without ascribing the constitutive role of discourse. This constitutive role of language becomes apparent when we focus our attention on the fact that governance and policy making involve "a constant discursive struggle over the definitions of problems, the boundaries of categories used to describe them, the criteria for their classification and assessment, and the meanings of ideals that guide particular actions" (Fischer, p. 60). The basic argument here is that language is not the only means through which the material world of politics is understood, but that it can also construct the material world itself. In other words, there are many political actions and practices which are equally discursive practices. For example, the act of promising, defending, and attacking are largely or solely enacted through discourse. According to Chilton and Schäffner (2002), the minimal focus on language in political science and related disciplines of social science is problematic on two counts: first, how to observe and analyze the complex linguistic phenomena and, second, the popularization of the "mere rhetoric' mantra of political rhetoric, and that plain truth can only be discovered through scientific proof, as the only form of reasoning. Thus, the search for genuine knowledge is considered to be an exclusive prerogative of the domain of science, forgetting even as Booth (2004) contends, that "nobody denied that even brilliant scientists had to have training in how to write well, to promote their discoveries" (p. 43). According to Chilton and Schäffner (2002), this "belief in the objectivity of scientific language obscured the 
utility of the study of rhetoric" (p. 4). Regarding how to observe and analyze the linguistic processes and actions of politics, there are currently rigorous tools that can help in a detailed description of political language, mostly provided by critical discourse studies (CDS) and allied field in theoretical and applied linguistics. However, the notion that all truth can be found through scientific inquiry persists and affects the utility of employing rhetoric to study politics. There are though few exceptions (see Martin 2014 for those exceptions).

My dissertation, therefore, follows in the footsteps of Chilton (2004) to show the connection between the study of politics and the study of language, and to argue that the integration of the two fields can add depth to the understanding of politics. My work further reflects rhetorical and decolonial perspectives not prominently featured in Chilton's work, and argues that in responding to discourses on genuine political questions and political realities constructed in postcolonial contexts such as Nigeria, political discourse analysis has to also be subjected to analysis and criticism through rhetoric and decolonial lenses.

In addition to the rhetorical and decolonial perspectives, I intend to achieve a close alliance with political science by arguing in the same vein with van Dijk (1997) that the "problems in political science can in principle, be studied more completely and sometimes more adequately when it is realized that the issues have a critical discursive dimension" (p. 12). While critical discourse analysts can borrow from the meta-language of political scientist's terms such as "sovereignty," "ideology," "hegemony" and "power" 
among others, political science can also borrow tools from CDS to analyze the discursive form of politics.

It is important to point out that even though political discourse analysis is mainly studied in the discipline of linguistics; political discourse analysis is not the same as some of the linguistic analysis of discourse. For example, political discourse analysis is not the same as the study of linguistic-stylistics, which looks at how to identify distinctive stylistic features of a text even if the focus of linguistic-stylistics is a political text. It is also not the same as conversational analysis or discourse analysis, which focuses on providing the descriptive, structural properties of a text without "a systematic account of the context and its relations to discursive structures" (van Dijk 1997, p. 15). According to Gee (2014):

While non-critical approaches can and do, indeed, study social practices, critical approaches, and non-critical ones take a different approach to social practices and to how to study them. Non-critical approaches tend to treat social practices solely concerning patterns of social interaction (e.g., how people use language to 'pull off a job interview'). Critical approaches, however, go further and treat social practices, not just regarding social relationships, but, also, concerning their implications for things like status, solidarity, the distribution of social goods, and power. (p. 86)

Fairclough and Fairclough (2012) in their elaboration of van Dijk’s (1997) description argue that political discourse analysis is "understood as the analysis of political discourse 
from a critical perspective, a perspective which focuses on the reproduction and contestation of political power through political discourse" (p. 17). Focusing purely on the descriptive approach to language, Gee (2014) contends is an evasion of social and political responsibility.

Although the analysis of political discourse from a linguistic perspective is becoming one of the cornerstones in the academic disciplines concerned with politics, it is not as old as other allied disciplines of political science. According to Wilson (2001), the linguistic approach began only in the early 1980s and 1990s. Some well-known political discourse analysis could be found in scholarly works such as van Dijk (1993, 1997), Chilton (2004), Wodak (2011), Wilson (2001), and Fairclough and Fairclough (2012), among others. In Africa (e.g., Nigeria), Chiluwa (2012, 2015), and Taiwo (2008, 2010) have significantly contributed to the study of political discourse. Moreover, Edelman $(1977,1988)$ represents some of the linguistic turns in political science. A common theme that cuts across the different models of political discourse analysis is the role of language in creating political realities. PDA analysts believe that politics cannot exist without the strategic use of language. In fact, Bourdieu (1991) argues that language is not only a means of communication in political discourse but also an instrument of symbolic power by which individuals pursue their interests.

So far, I have been discussing political discourse analysis without actually defining the term "political discourse." This is because political discourse does not have a straightforward meaning, perhaps as a result of how the term "political" is defined. The 
term “political” falls under Gallie's (1956) coined term “essentially contested concepts.” These "concepts are subject to persistent contests and debates at strategic points" (Connolly 1993, p. xi). Some of the terms considered as essentially contested concepts include "power," "legitimacy," "political," and "politics." The 'essentially contested concepts' definitions are neither neutral nor settled, but rather shift according to each theorist's ideological and normative views.

Another reason provided for the difficulty of defining "political discourse" is the broad way in which the word 'political' is construed. In Orwell's (1946) words "all issues are political issues" (p. 2), or better put, "there is hardly any topic which cannot somehow be brought within the purview of political analysis" (Dallmayr, 1984, p. 1). However, some political discourse analysts (e.g. Chilton 2004; van Dijk 1997; Wilson, 2012) see the ambiguity of meaning in the definition of political discourse from the close connection of the term with other senses of the words such as "power," "control," "domination," "manipulation," and "struggle". Wilson (2012) observes that when one looks at the connection between 'political' and other associated words, then 'almost all discourses may be considered political, because all of these concepts associated with 'political' may be employed in any form of discourse" (p. 27). We cannot avoid defining what "political discourse" is as Connolly (1993) surmises that an attempt to avoid taking a position on these contestable terms affects our comprehension of politics and our wish to escape politics. More importantly, for this study, we need an operational definition that would guide our analysis as well as delineate our object of study. In this way, there is a 
need to choose one interpretation over others in order to differentiate the kind of discourse we analyze from other discourses, which have possible political effects but in the context of this research might not be considered as political discourse. For example, we need to differentiate what we mean by political discourse distinct from medical, legal, and educational discourses among others.

To define what is political discourse; the first step is to provide a distinction between what Chilton and Schäffner (2002) refer to as "institutional politics" and “everyday politics.” Institutional politics are political actions and practices that take place in formal political institutions such as parliamentary debates, cabinet meetings, rallies, interviews and election campaign among the many genres of institutional politics, while everyday politics deals with the conflict between different genders, workers and managers, police officers and black youths which are characterized as political (Chilton and Schäffner, 2002). Seidel (1985) contends that discourse of any kind is political because it serves as a site of struggle, a "semantic space in which meanings are produced and/or challenged', (45). In spite of the fact that there is a difficulty in disentangling the fuzziness between everyday discourse and institutional discourses, as Wodak (2002) strongly suggests, everyday discourse is infiltrated by the elites' discourse on the one hand, and on the other, institutional discourse is influenced by everyday discourse. For the sake of clarity on the object of my study, I will still maintain the distinction between the institutional politics and everyday politics, with a focus on institutional politics. From the angle of institutional politics, Gastil (1992) defines "political discourse as when 
political actors in and out of government, communicate about political matters, for political purposes" (p. 469). Dunmire (2012) extends Gastil's definition to comprise not only "the actions and practices of professional politicians, in formal political institutions, [but also] citizens who participate in the political process" ( $p$ 737). My dissertation adopts the definition of political discourse put forward by van Dijk (1997). According to van Dijk context is central to the definition and delimitation of political discourse. These contextual factors in political discourse are: political actors (politicians and citizens), political institutions involved in political processes (State, government, parliament, political parties, electoral body), political events (political campaign, parliamentary sitting, press conference, political interview), and formal and informal political gatherings (conventions, fundraising, dinner and banquets).

Although political discourse can be virtually about any topic, most of the topics usually analyzed are reflexive of political systems, ideologies, institutions, the political process, political actors, and political events (van Dijk 1997, p. 25). My work focuses on analyzing an aspect of political discourse that deals with the political process of an election campaign. Political processes of election campaigns can be considered as universal processes practiced during elections across countries of the world that practice democracy. This is because such processes represent most fundamental tenets of representative democracy where citizens are given a chance to assess and evaluate the actions of their elected public officials (Maisel \& West, 2004). However, the actual context in which this universal political process takes place is significant in any political 
analysis. According to Chilton and Schäffner (2002) more often than not because of the theories we use, there is a tendency to "assume an Anglo centric attitude to political discourse, and ignore the potential - though always controversial - implications of Whorf's hypothesis" (p. 8).

My approach attempts to reflect the relative version of Whorf's hypothesis which states that there is some kind of connection between one's language and culture, and that the structure of one's language to some extent affects one's worldview and vice versa. In an attempt to find out the relationship between political language and the culture of the people, I situate my analysis in a postcolonial context bringing attention to what possibly might be ignored when "Eurocentric" perspectives drive our analysis. However, at the same time, I equally draw attention to the intricate connections between globalization and neoliberal philosophy on Nigerian political discourse. By situating this study within postcolonial contexts and globalization, my ultimate intention is to advance a theoretical re-articulation of critical discourse studies' framework that can account for the complex realities of the Nigerian context. My critique does not engage in the bifurcation between the North and the South, or between the Western and the non-Western; it looks mainly at the analysis of a mode of knowledge-production situated methodologically within globalization and decolonial frameworks with the aim of explicating the discursive operation of politics. 


\subsection{Presidential Rhetoric}

There are many forms of institutional political discourses. These include parliamentary debates, press conferences, political interviews, and presidential speeches. Presidential speeches constitute one genre of political discourse that has received attention over the years. This has resulted in the various delineations and classifications of political speeches such as inaugural addresses, addresses to the party congress, campaign speeches, and acceptance speeches. Inaugural and victory speeches have received more attention than other forms of presidential speeches, because of the importance of these speeches to the representation of institutional voices. Because of this vital function of presidential speeches, they have been subjected to numerous linguistic investigations and inquiries, for example, Schäffner (1997), van Dijk (1997), and Chilton (2004), while in Nigerian scholarship, there are analysis by Adetunji (2006), Kamalu \& Agangan (2011), and Ahmed (2012).

The focus on presidential speeches in the 1980s gives rise to the concept of "rhetorical presidency." The original thesis of rhetorical presidency according to Saldin (2011) is rooted in the idea of a difference in presidential speeches in the pre- $20^{\text {th }}$ century called the "old way," and the "new way" in the 20th century where presidents make themselves more visible and attractive through public speaking due to the role of mass media. Tulis (1987) is one of the people who contributed to the evolution of this discipline of presidential rhetoric. In his book, Rhetorical Presidency, Tulis argues that presidential communication has changed since the presidencies of Theodore Roosevelt and Woodrow Wilson, from presidential communication directed towards Congress 
seeking support about policies, to one that addresses the public directly to defend their policies and inspire support. This developmental shift in presidential rhetoric has brought in a new discipline called presidential rhetoric. Presidential rhetoric as a discipline "is concerned with the study of presidential public persuasion as it affects the ability of a president to exercise the powers of office. It is the study of how presidents gain, maintain, or lose public support” (Windt 1986, p. 103). Presidential rhetoric in this sense, deals with how the president as a chief executive of a country executes the powers of their office through the means of rhetoric. According to Windt (1986) in the United States, there are three areas of power available to the presidents: the power granted by the Constitution or conferred by law, the power as head of their political party, and the power of public opinion. This power with public opinion lies largely on the ability to persuade and place the "locus of presidential power in the President-as-persuader instead of residing solely in the formal legal powers or the political powers of the office" (Windt 1986, p. 102). By this, it means that modern presidents do not only set out to inform their audience or make a speech to fulfill some formal requirements, but they also set out to persuade their constituents, mainly to establish their credibility and goodwill with the citizens.

One central issue that my work draws attention to is the recognition that the power to influence in campaigning is different from the power to persuade when governing. According to Windt (1986), campaign rhetoric presents a set of either/or choices, seeking the defeat of the enemy in a war-like strategy. However, a governing 
rhetoric is one that stresses accommodation, theoretically. Although the two forms of rhetoric might overlap, the recognition that there is a conflation between the power of modern presidents to persuade as to govern and influence for election should be given a special place in the analysis of politics in an African context. Although rhetoric provides a variety of tools through which to analyze and criticize electoral campaign, contrary to what has been the case in the United States (and elsewhere), in Africa, the focus has been on hard facts such as electoral system management, voter registration, political parties and candidates, voting operations (ballots, polluting stations, voting procedures, vote counting), elections and technology, media and elections and so forth, with less attention to the discursive aspects of electoral system. The discursive feature of presidential elections in Africa has too often been relegated to the background. This dissertation focuses on the discursive components of elections by specifically analyzing the different rhetorical and discursive strategies Nigerian President Goodluck Jonathan used in his 2015 election campaign speeches to galvanize support.

\subsection{Electoral Campaign Discourse}

Elections are a crucial part of democratic processes, which affirm the core values of representative democracies. In modern democracies, the government's legitimacy to govern and rule over the people is solely derived from the consent of the governed in a free and fair election process, at least in theory. The principal means by which the consent of the people is solicited is through electoral campaigns. According to Maisel and West (2004), election campaigns deal with the different ways through which political 
actors communicate with the voting public during elections. The communication can be from the candidates or their campaign organizations. In all these communicative acts, campaign discourse "draws on the constitutive and consequential power of rhetoric [what Scott (1967) calls "rhetoric as episteme"], as well as other factors like institutional authority and financial resources" (Asen 2010, p. 121). When politicians "speak about themselves as candidates, about the elections, about policies they promise to support when elected," (van Dijk 1997, 25) and about how to make people vote for them, "not only do they use language to do many different things, but any utterance is often meant simultaneously to carry out more than one action" (Gee 2014, p. 50). In this sense, during a campaign the use of language is much more than giving and getting information, but it also allows them to do things, such as engaging in actions of promising and of proposing a policy. It also allows them to take different social identities, such as acting as candidates in an election or party officials. Politicians employ the three resources of language "to say things, do things and be things" (Gee 2014, p. 3). In other words, their use of language is meant to do three things: "saying, doing, and being" (p. 2).

In his study that spans the last fifty years of US election campaign, Benoit (2007) categorizes three verbal acts typical in the election campaign: "acclaiming," "attacking," and "defending," what is usually known in as epideictic in Aristotelian model. According to Benoit, acclaims are "statements that stress a candidate's advantages or benefits. Such self-praise can address the candidate's character or policy” (p. 36). Attacks, on the other hand, criticize the opponents by stressing an opponent's undesirable attributes or policy missteps. The final is defending against attack from an adversary. If 
an opponent attacks a candidate, the recipient of the offensive can choose to refute that attack (Benoit, 2007). Benoit's three typologies can be subsumed under Chilton's (2004) two strategies that politicians linguistically manage their interests in what he calls the "strategies of delegitimization (of the other) and legitimization (of the self)" (p. 47). These discursive ways of delegitimization and legitimization shows, various types of polarization a strategy van Dijk (1997) called the "ideological square":

Emphasize our good things

Emphasize their bad things

De-emphasize our bad things

De-emphasize their good things

According to van Dijk (1997), the polarization is semantically constructed, for example:

Whereas WE are "democratic," THEY are not, and whereas our soldiers, or those who share our cause, are "freedom fighters," those of the others are obviously “terrorists." Thus, lexical items may not only be selected because of official criteria of decorum, but also because they effectively emphasize or de-emphasize political attitudes and opinions, garner support, manipulate public opinion, manufacture political consent, or legitimate political power. (p. 28)

For example, words might be chosen as "acts of negative other-presentation, acts of blaming, scapegoating, marginalizing, excluding, attacking the moral character of some individual or group, attacking the communicative cooperation of the other, 
attacking the rationality of the other" (Chilton, 2004, p. 47). According to Chilton legitimization forms the core of political campaign and it largely focuses on self which “includes positive self-presentation, manifesting itself in acts of praise, self-apology, selfexplanation, self-justification, self-identification as a source of authority, reason, vision and sanity, where the self is either an individual or the group with which an individual identifies or wishes to identify" (p. 47). If campaign discourse works in this simple way of semantic polarization of topics by emphasis and de-emphasis, how do people usually come to believe some politicians and no other? That is one of the questions Chilton (2004) sought to answer in his book Analyzing Political Discourse. Chilton borrows from Austin's (1962) and Searle's (1969) felicity conditions to infer the conditions in which politicians' verbal act can be accepted.

First, several of these "felicity conditions" depend on how utterers align their intentions with the wants of their audience. Second, situating all speeches within a political framework, as distinct from the decontextualized framework of ordinary language philosophy, it is impossible to say that people are more likely to believe a politician based on the politician's level of credibility in the eyes of the audience. Credibility (ethos) takes a central place in persuasion during election campaigns because the rhetorical polarization does not always mean that the referents are different, but it depends on the ways the various political actors place different significance to phrasing and wording (Chilton 2004). 
Stuckey \& Antczak (1995) similarly categorize the verbal act of election campaigns in three ways: First, is the establishment of interpretative dominance "by presenting the image of the candidate "as representative of the electorate" (p. 118). Second, the "ideological unity with the audience" (p. 118). Third, "all language use is tropic, that is, any use of language involves a choice about how to figure language - how to shape, and thus in one way or another, selectively define reality" (p. 118). Since it is not possible at all times politicians to have the physical resources to back up their claim of credibility, verbal communication becomes crucial in political interaction and in establishing credibility (Chilton, 2004). This means that during a campaign, candidates must make strategic and tactical communication choices to get the attention of their voters. In a postcolonial context what is the status of election promises by politicians considering that the national ruling class lacks economic power and that the issue of:

Economy has always developed outside the limits of their knowledge. They have nothing more than an approximate, bookish acquaintance with the actual and potential resources of their country's soil and mineral deposits; and therefore they can only speak of these resources on a general and abstract plane...it is completely canalized into activities of the intermediary type. (p. 157)

Of what value then does it have to analyze campaign speeches knowing fully that these talks might be substantially influenced by outside forces? According to Joslyn (1986), an examination of political discourse, in general, ought to reveal "the rhetor's political worldview, the rhetor's intentions, the locus and intensity of political conflict, the locus, 
and legitimacy of political power, and the role of the public" (p. 287). Those who are on the other side of the debate might still say that the analysis of political leaders' policies, economic plans, and the type of advisers they have can tell us the direction of where their leadership can lead people to (see Acemoglu \& Robinson, 2012; Moyo, 2009). Many would say it's all about getting it right, not about empty talk, and so, analyzing campaign rhetoric would mean nothing if the focus is on empty talks, which are usually polarized. Interestingly, sound economic and social policies become salient through mediated role of rhetoric.

Thus, most political processes and election campaigns in particular, are mainly exercised through language. Of course, this is not to argue that other factors such as "economic and situational needs, power relationships, and a whole host of additional elements and demands do not affect the campaign process or outcome, but rather is to say that all of these other factors become important in the electoral system principally through the offices of communication" (Trent, Frieddenberg, \& Denton 2011, p.16). "The exercise of power, in modern society, is increasingly achieved through ideology and more particularly through the ideological workings of language" (Fairclough 2015, p. 51). However, for a postcolonial context such as Nigeria, the analysis of campaign discourse offers us an opportunity to be critically aware of the double-bind of hegemonic struggles in political discourse where the battle rages not only with the power of dominant institutions within our society but also with the multiple and contested histories that have produced the kind of political discourses prevalent in our communities. These are the 
discourses that remind us that the independence of postcolonial countries does not mean freedom in real terms but can be described as a change in the political actors or what Royster (1996) describes as "when the subject matter is me and the voice is not mine" (p. 31). Besides postcolonial issues my analysis also emphasizes the notion widely expressed by political discourse analysts and aptly captured in Connolly's (1993) words here that "the language of politics is not a neutral medium that conveys ideas independently formed; it is an institutionalized structure of meanings that channels political thought and action in certain directions" (p. 1).

\subsection{Rhetoric and Politics in Nigerian Context}

It is not possible to understand fully rhetorical strategies without looking to the different ways that local environments influence the structure of communication, and how local initiatives adapt to global communication systems to suit needs of both the local and the global (Yankah, 2012). What this means is that our understanding of rhetoric in a political context should focus on how a particular community makes meaning and negotiates systems of communication to disseminate knowledge (Mukavetz, 2014). Nevertheless, due to the colonial legacy and how our rhetorical practices are deeply informed by Western models of communication, Ige's (2009) question in the first issue of African Journal of Rhetoric becomes necessary. Ige asked, does an African rhetoric exist and if it does, what traditional practices can we draw on in an attempt to discover what an African rhetoric is? Looking through the contents of African Journal of Rhetoric seven years after, the rhetorical analyst is still grappling with how to investigate meaning 
making as situated within a particular cultural community in Africa. The journal has made a significant contribution on the relationship between rhetoric and governance as it is indicated in the themes they covered, for example, in 2013 the theme was on "rhetoric and political leadership," and 2016: "rhetoric for good governance." However, even though the analyses focus on African discourses, the theoretical underpinnings are highly influenced by Western rhetorical tradition. Thus, this dissertation section critically examines studies on African rhetorical traditions to argue that, Africa's colonial and postcolonial experiences should be taken highly into consideration, rather than paying undue attention only to the continent's pre-Western indigenous rhetorical traditions, or only to its postcolonial context. Rather, there must be a dialectical relationship between the pre-Western and the postcolonial conditions, mainly focusing on the different ways through which rhetoric is employed in the new nation-states. This type of research concern ought not to be in finding answers to what rhetoric is, but to understanding the different ways of using rhetoric, and the forms in which it manifests within our cultural and social milieu (Mao, 2014). Understanding the different ways rhetoric is used emphasizes practice, which Mukavetz (2014) regards as "things that communities do to make something - central to understanding how rhetoric and culture are interconnecting concepts" (p. 110).

\subsection{An Overview of Studies on African Rhetorical Scholarship}

Three key trajectories can be isolated as far as studies on African rhetoric are concerned: studies by Euro Americans, studies by African Americans, and studies by Africans. The 
first category includes people who are mainly anthropologists, ethnographers and a handful of rhetoricians. Their primary concern is to examine the different modes and components of African culture and its various forms of communication--they also theorize about African rhetoric. In this group, I include Ruth Finnegan's book Oral Literature in Africa (first published in (1976) [2012]. From a rhetorical perspective, I include the work of George A. Kennedy and his book "Comparative Rhetoric: A Historical and Cross-cultural Introduction” (1998). Both Kennedy and Finnegan did detailed work on African modes of communication, and their works are still relevant reference texts for African rhetoricians.

Finnegan's book on oral literature is mainly considered a classic and a compendium of African oral forms and performance. The book has a detailed discussion on the different oral art forms that include poetry, prose, drama, riddles, and proverbs from various parts of Africa such as Ghana, Nigeria, Sierra Leone and Senegal. Although the book is not mainly about rhetoric, she still devoted a chapter on oratory and rhetoric in Burundi. In that chapter, she extensively analyzes the value of rhetoric in Burundi and the various contexts in which it can be used. Finnegan must be commended for her broad study that provides a thorough and insightful study across sub-Saharan Africa covering more than 150 ethnic nationalities. The study is not only very important in bringing together an array of African oral art forms in one book, but also serves as a source from where some African rhetorical theorists like Yankah $(1995,2012)$ and Bokor (2014) drew their inspiration. Nevertheless, in her presentations, she claims that Africa does not have 
a significant (p. 133) and that proverbs are simply quotable and used for instrumental purposes in African societies (p. 121). These claims are profoundly challenged by African scholars (see e.g., Okpewho, 1979; Yankah, 1991). The book's shortcomings are not just an issue of making contentious claims but also that "identifying corresponding structures bypasses any project of engaging [African] culture as an equal other" (Hum and Lyon, 2008, p. 155). As such, the reliability of her analyses as representing African art forms is questionable, since it has not entirely disconnected itself from Western forms of seeing and knowing.

Kennedy's work is another interesting study on African rhetorical traditions. Though Kennedy's book was not just on African rhetorical traditions, he touched on some important aspects of African culture, especially with his chapter on formal speech in some non-literate cultures. The chapter brought into the spotlight some rhetorical acts in African societies that are not popular in the literature, such as a form of an epideictic rhetoric of Hausa culture in Northern Nigeria called roko - eulogy or praise song (Kennedy, 1998, p. 75). However, the problem with Kennedy's approach, just as with Finnegan's, is his attempt to fit non-Western concepts into a Western template. For example, Kennedy claims that "[j] udicial rhetoric is the least developed in traditional societies" (p. 76). However, Yankah (2012) has elaborately analyzed the uses of proverbs in judicial rhetoric by the Akan people of Ghana, which point to the highly developed nature of judicial rhetoric in Akan's society. It is possible Kennedy attempted to understand judicial rhetoric from the lens of his cultures. Although "comparisons are not 
neutral: they are inevitably tendentious, didactic, competitive, and prescriptive" (p. 454), there is a need to prioritize the study of African rhetorical practices in their own terms and for their own sake. The insistence and attempts to impose different models onto aspects of African rhetorical practices will not only trivialize the different cosmogony and cosmology of the differing cultures but also perpetuate the hegemonic tendencies of Western rhetoric. Thus, as valuable as Finnegan's and Kennedy's works are, they failed to offer an analysis from the perspective of Africans

The second trajectory of work is by African American scholars. In this section, I review the work of two scholars, Molefi Asante and Kermit E. Campbell. Asante (1999) is a widely known scholar in the field of intercultural communication and African American studies. His main contribution to rhetorical theory is called "Afrocentric discourse." However, he (under the name of Arthur Smith) also has a paper specifically talking about the nature of African rhetoric titled "Markings of an African Concept of Rhetoric" (1971). In this article, he bases his discussions of African concepts of rhetoric on his understanding of African philosophy. He says that African traditional philosophy is built on society's coherence, participation, and stability, and since in Africa, "speech is a functioning and integral part of the society and cannot be separated from the entire world view because the word-power is indeed the generative power of the community" (1971, p. 15), any understanding of African rhetoric must be understood from its role in achieving coherence, participation and stability. Although some of the factors identified by Asante reflect some of the ways rhetoric is used, those factors identified do not 
represent the complete story of rhetorical practices in Africa. This is because Asante's approach tends to give a broad-spectrum analysis of an "African" rhetorical tradition, which often ignores the diversity that is on the continent (Hum and Lyon, 2009) and portrays Africa as if it were one big homogenous country. Africa is, in fact, a highly different quilt of people and places.

The next important discussion on African rhetoric is a paper by Kermit E. Campbell titled "Rhetoric from the Ruins of African Antiquity" (2006). Campbell explores the nature of rhetoric in ancient Egypt and Nubia. He says that even though extensive data on ancient Africa is lacking, ignoring the ancient rhetorical tradition completely and focusing on the contemporary rhetorical practices will make us miss an important trend in the history and development of African rhetoric. Campbell debunks the view that Africa was mostly oral. Drawing evidence from ancient Egypt and Nubia, he claims that Africa had a means of recording its use of language. Although an insightful analysis, his sources are mostly texts translated by Westerners. As such, it is possible to see a transfer of Western assumptions and ideologies. The final trajectory is the study of African rhetorical practices by Africans. There are several notable names, including Blake (2009), Ige (2009, 2012), Yankah (1991, 1995, 2012), and Bokor (2014), but I will briefly review only the works of Kwesi Yankah and Michael Bokor.

Although he considers himself a linguist and not a rhetorician, Yankah has produced numerous works that are essential in shaping the understanding of African rhetoric. Two of his most famous books are The Proverb in the Context of Akan Rhetoric 
(2012) and Speaking for the Chief: Okyeame and the Politics of Akan Royal Oratory (African Systems of Thought) (1995). His work on the proverbs of the Akan people in Ghana is significant in challenging the stereotypical description about African rhetoric and the use of proverbs in traditional society in particular. He rejects the claim that African proverbs are static, quotable short sentences, and mainly used for instrumental purposes in traditional societies. He argues that when studied in their own context, one will realize that a proverb "embodies the high point of rhetoric in traditional and contemporary Africa" (p. vii). In the second edition of his book, he significantly updated the way proverbs are used in contemporary political discourse. He claims that a proverb can no longer be confined to its traditional usages in the royal courts and by elders. It has transcended that sphere to permeate contemporary speech and political platforms, hip life music, and cyberspace. The central contribution of this study to the development of African rhetoric is that his interpretation and the understanding of his rhetorical value are situated within the contextual understanding of Akan indigenous aesthetics. Unfortunately, since Yankah does not see himself as a rhetorician, his work is not entirely considered a contribution of African perspective to mainstream rhetorical discourse.

Bokor's (2014) work, on the other hand, is on the relevance of drum in rhetoric. He claims that beyond their use as cultural artifacts for entertainment, religious and social purposes, drums' "rhythms are highly developed mechanisms for creating meaning to shape both personal and group behavior in traditional African societies" (p. 166). Bokor's work provides interesting insights into the nature of rhetorical performance in the non- 
Western world where in Africa aside the function of speech, drums performs an important similar rhetorical function that human speech does in influencing human behavior. However, Bokor seems to apply theories uncritically derived from EuroAmerican experience into African contexts such that his understanding of pathos is drawn from the Aristotelian tradition.

Critical interrogation of theories derived from experiences other than Africa is helpful to refine and further develop the theories. According to Skinnell (2015) "much current historical research in rhetorical studies is underwritten by an imperative to 'broaden' the field's horizons in order to develop new perspective(s) on and for the field" (p. 112) instead of a "search for critical perspective around which the [field] developed" (p. 113). Skinnell goes further to argue that not providing avenues for contemporary historical research in rhetorical studies where the world can be seen differently is not the only issue, more to this is the idea that such avenues "do not invite the kinds of critical interrogation of the present that Berlin et al. once advocated" (p. 118). This critical examination, Skinnell asserts, was the primary goal of revisionary historians as was reflected in their first roundtable discussion on revisionary history ("Octolog", 1988). This was when Berlin stated that revisionary historians should "search for the excluded other...exploring the margins, examining the supplement - excluded and silenced - and giving it a voice" (Octolog, 1988, p.7). In this light, my dissertation is an attempt to involve such critical interrogations as I engage in analyzing political rhetoric in Nigeriaalso tending to probable silences or nuanced details due to a lack critical investigation. 


\subsection{The Problem of Methodology and the Way Forward}

Looking at the three trajectories identified above, the central problem with most of the studies is that of methodology. This raises many questions. What theories should inform our scholarship when we analyze data from Africa or other non-Western contexts? What analytic framework will best examine our practices while avoiding automatic one-way application of theories derived from Euro-American experiences? Interestingly, the problem of a methodology is a general concern within comparative rhetoric. Because of its significance, a group of rhetoric and composition scholars gathered in Lawrence, Kansas to "articulate the goals, objectives, and methodologies for comparative rhetoric and to map out an inspiring and inclusive future" (Mao et al., 2015, p.239). It is perhaps not surprising, however, that the African perspective was missing from the discussion because as pointed out earlier, we are yet to come to terms with how to investigate meaning making in African situated contexts. Of particular interest to theorizing African rhetoric is Lyon's (2015) discussion titled "Tricky Words: Rhetoric and Comparative" (emphasis original). Lyon questions the use of the term "rhetoric" and "comparative." She argues that the term rhetoric from its Western origin has an inherent "ideal of individual strategizing to move an audience towards singular truth or action, but this ideal is not shared by all cultures" (Mao et al., 2015, p. 244). She contends further that by using the term "rhetoric," one automatically invokes its Western ideologies that could affect the theorization of rhetoric from other cultures. In a similar vein, Mao (2014) enjoins us not to ask "what is rhetoric" but "what do we do in comparative rhetoric and how do we do it ... for the 'what is' question gestures towards, if not already 
predetermines, the existence of reality that is objective or free of social, cultural, and linguistic incongruities" (p. 215).

The case of Africa is a complex one because of its postcolonial context where external and internal rhetorical practices are intertwined. For example, one of the key external influences is the issue of language. Most African countries conduct their political communication through foreign languages like French and English. The continuous use of foreign language as Ngũgĩ asserts reinforces a colonial mentality and because language is an important carrier of culture, the rhetorical culture among politicians in an African context is significantly influenced by choice of language. According to Wang (2013), the postcolonial preoccupation has created a hybrid identity that for us to fully understand the different dynamics, we must situate our critique within a decolonial framework. Thus, I attempt to understand rhetorical practices in Nigeria from a decolonial perspective. The decolonial perspective is important because it takes on a global approach which sees rhetoric as an intermixture of different traditions.

\subsection{Theoretical Framework: Integrationist Approach}

This dissertation research is driven by an interdisciplinary philosophy aimed at integrationist approach borrowing from (van Leeuwen, 2005). This mode of doing discourse analysis borrows from different methods and disciplines in analyzing texts. The model is problem-oriented, as it recognizes "that no single discipline can satisfactorily address any given problem on its own. As a result disciplines are seen as interdependent, 
and research projects involve team work with specific divisions of labour and specific integrative principles" (van Leeuwen, 2005, p. 8).

In my integrationist approach, I employ tools from rhetoric (classical and comparative), linguistics (critical discourse approach), and decolonial studies. The use of both rhetorical and linguistic approaches is informed by the heterogeneous nature of political speech where it attempts both to persuade and yet to reshape its discursive practices. According to Fairclough (1997), the discursive event of political speech is to do a persuasive work, but at the same time, the speech is expected to intervene in the existing political order of society by trying to reshape it. Hence for a detailed analysis of a political speech we need a double orientation of both rhetorical analysis and critical discourse analysis and the two directions according to Fairclough (1997) should not be strictly separate because "orientation to the specificity of the discursive event includes orientation to how it reworks the social resource of the existing order of discourse; but it also includes the concerns of stylistic, pragmatic and rhetorical analysis" (p. 47). The decolonial approach is predicated on Nigeria's encounter with colonialism and neocolonialism, and how such an encounter has affected the mode of doing and seeing things. There are three reasons decolonial approach is significant in analyzing political discourse in Nigeria. First, it is a way of telling our stories from the perspective of colonized cultures. The goal is not as Royster (1996) states: "You talk, I talk. The goal is better practices so that we can exchange perspectives, negotiate meaning, and create understanding with the intent of being in a good position to cooperate, when, like now, cooperation is absolutely necessary" (p. 38). Second, a decolonial approach is a project 
of delinking. This delinking according to Powell et al. (2014), "encourages a shift to a set of knowledge-making practices that don't reinforce colonial logics, which also form the roots of systems like capitalism" (p. 11). Lastly, it seeks to reflect the global movement where the aim is to see that the global discourse is continually enriched so as to allow for a cross-cultural encounter that can embody different ways of seeing, knowing, being, and acting that probably suggest "a world in which many worlds fit" Mignolo (2011).

The rhetorical analysis is also informed by classical rhetorical tradition, specifically; I use analytical concepts, such as ethos, logos, pathos, and canons of rhetoric as means of providing discourse analysis with "tools for theorizing persuasion, authority, asymmetrical power relationship, and political activity” (Andrus 2013, p. 4976). But since this work is situated in a non-Western context, I also draw on cultural and comparative methodologies mainly from Mao (2014), Powell et al., (2014) and Yankah $(1995,2012)$. The cultural and comparative rhetoric is driven by questions that can explain and point to the local determination of rhetorical practices.

I am mindful of the tension and the fusion between the local and the global in doing research in postcolonial countries such as Nigeria. However, my analysis does not engage in bifurcation between the local and the global; what matters to me is the ways the two (the local and the global) can be used together in the exposition of hegemonic discourse. This marriage between the two can help me find answers to Chilton's (2004) classic question: "What does the use of language in contexts we call 'political' tell us about humans in general?" (p. xi). My work, therefore, aims at understanding human 
behavior as a whole through studying African political rhetoric from both classical and cultural rhetoric insofar as they can provide sufficient explanation on what it means to analyze political rhetoric in a postcolonial Africa.

A critical perspective drives the linguistic tradition. I specifically employ Chilton's (2004) cognitive and evolutionary approach to political discourse analysis as a framework for analysis. Chilton attempted to ground his theory in linguistics, from Grice's cooperative principle, Sperber and Wilson's relevance theory, and Chomsky's generative linguistics, to formulate three principles for a cognitive approach to political discourse analysis. His first principle is that language and political behavior can be thought of as based on the cognitive endowments of the human mind rather than as mere "social practices." Second, language and social behavior are closely intertwined, probably in natural mechanisms or innately developing mechanisms of the mind and probably because of evolutionary adaptation. The idea of evolution, however, must be critically interrogated because social Darwinism has been used to advance the ideologies that legitimated the Western domination of indigenous people. For example, the concept of "the survival of the fittest" was used to put the idea that indigenous populations are inherently weak and would die out at some point (Smith, 2012). Hence, according to Smith many strategies such as intermixing, and cultural assimilation was devised to prevent the extinction of indigenous people. This scientific view of social Darwinism legitimated the enlightenment project and later the colonization of indigenous 
populations. Third, human linguistic and social abilities are not a straightjacket; rather, language is linked to the human cognitive ability to engage in free critique and criticisms.

Chilton's approach is grounded in linguistics and could be a suitable model in the conception of an integrationist model of analysis. His approach centers on a crossfertilization of linguistic theories (generative, functionalist/critical, and cognitive linguistics) with rhetoric and critical theory, apart from its use in social critique in uncovering the opaque nature of language in legitimizing power inequality. The integrationist model is based on the assumption that it is possible to imagine a theoretical framework that is both broad enough to resonate across cultural, social and political landscapes and sufficiently to allow for diversity demanded by the different cultural contexts. On the end, I hope to find ways on how to do an analysis that is culturally sensitive to both local and global focus while offering an opportunity for non-Western societies to contribute their own stories in their own words and contexts.

\subsection{Methodology}

\subsubsection{Data and Method}

The data for this study comes from select campaign speeches delivered by the former President of Nigeria, Goodluck Jonathan in 2015. Two different campaign speeches are analyzed. The speeches are: his declaration-of-intent speech given on November 11, 2014 and his campaign speech in Lagos marking the commencement of formal campaign activities. The two occasions are very significant and unique in their respective contexts. For example, the declaration of intent speech was an avenue for Jonathan to discuss his 
government's achievements during the period he was in the office as the elected president, responding to the many criticisms leveled against his cabinet in areas such as electricity, unemployment, security, economy, and infrastructure. These are some of the sectors that seemed to have experienced little or no change despite the promises made in his first campaign speech. The full transcripts of the declaration-of-intent speech was retrieved from the Nigerian private television Channels $T V$ websites: http://www.channelstv.com/2014/11/11/full-text-goodluck-jonathans-declaration-speech. And the full transcript of his remarks at the kick-off of his campaign in Lagos was retrieved from an online news Sahara Reporters website:

http://saharareporters.com/2015/01/09/full-transcript-president-goodluckjonathan $\%$ E2\%80\%99s-remark-flag-pdp-2015-campaign-lagos. I have included all the above speeches in the appendices.

\subsubsection{Rationale for the Choice of Text}

There is no doubt election campaign speeches are widely considered negative, lacking in substance and full of buzzwords or what Whyte (2004) calls "hooray words." In fact, in some cases, victory does not even come to the best speaker. Nevertheless, campaign speeches bring to the fore, fundamental issues concerning politics and the art of politicking to the public domain. It provides an insight into the nature of democratic politics. But more importantly, even with their negative connotations, campaigns speeches have a significant effect on people's consciousness. My argument here is that it is not enough to understand only the strategic activities of political actors when making 
economic, political, and daily public decisions; we also need to study these players' campaign messages. I do not intend to argue that economic policies, power relationships, and a whole host of factors do not affect campaign speeches, but rather claim that all these factors become important in the electoral system principally through the role of rhetoric. Thus, analyzing campaign speeches can help us to understand political ideologies and philosophy not only regarding their propositional contents but also based on how prominence is given to a particular way of arguing. This analysis is a step towards creating a consciousness of the role of campaign speeches in political analysis.

The choice of Goodluck Jonathan's campaign speeches is predicated on three reasons: first, Jonathan is the first Nigerian president to describe his style of leadership as transformational leadership. When Jonathan was campaigning in 2010, Nigerians were hopeful that he was someone who would transform Nigeria. In his 2010 speech-of-intent speech, he clearly articulated an inspirational and intellectually stimulating vision. His personality also bolstered his credibility, as he was the first doctorate holder to get to the position of the president of the country, and someone who was considered by Nigerian media as humble in that even when his predecessor, the late former President Umar Yar'adua, was incapacitated, he did not show any sign that he wanted to take over. All these attributes made him look unique - not power hungry - and like somebody who could be trusted. The transformational leadership vision seems not to have been realized. It is interesting analyzing the nature of his rhetoric in the 2015 campaign speeches, especially how he negotiated his transformational leadership rhetoric and his seeming failure to make his vision a reality. 
Secondly, Jonathan is the first democratically elected president who is from a minority ethnic group, the Ijaw group. All four previous presidents and the current president came from the dominant ethnic groups (except for Abubakar Tafawa Balewa, Prime Minister 1960-996 who was from Gere ethnic group, a minority group in Bauchi): Yoruba (Olusegun Obasanjo 1999-2007), Hausa/Fulani Shehu Shagari 1979-1983, Umaru Yar'adua 2007-2010 and Muhammadu Buhari 2015-date), and Igbo (Nnamdi Azikiwe ceremonial president 1960-1966). Even during the military regime, there was never a head of state of Nigeria from Jonathan's Niger Delta region, even though Nigerian oil wells (and therefore its primary source of wealth) are all located in that region. This unique achievement deserves particular attention to understanding the nature of his rhetoric and whether it has some relationship with the rhetoric of the ruling class, the major ethnic groups, and the military leaders. Lastly, it is important to examine the rhetoric of an incumbent president seeking reelection in a tight race that he eventually lost, the first to lose an election as an incumbent president in the history of the country. Because of these three reasons, I think his speeches deserve a special place in the analysis of politics in Nigeria to have diverse perspectives on speech making in Nigeria.

\subsubsection{Analytical Techniques}

In this dissertation, I will use textual analysis methods to describe and interpret Jonathan's campaign message. I will be using three approaches: linguistic, rhetorical and decolonial. 
Under linguistics, I will be interested in exploring some of the propositions regarding political discourse identified by Chilton (2004, p. 201-205):

i. Political discourse operates indexically: The choice of language and features implicitly signal political distinctions. For example, choosing to speak one language rather than another language like English or Hausa. Also lexical items not only may be selected because of official criteria of decorum, but also because they effectively emphasize or de-emphasize political attitudes and opinions, garner support, manipulate public opinion, manufacture political consent, or legitimate political power, choosing forms of address (and in some languages, pronouns) that expressed distance or solidarity.

ii. Political discourse operates as interaction: For example, interruptions, overlaps, cooperation, signal boundaries and bonding, as well as rank and role. Communication functions to negotiate representations: people communicate among themselves partly to coordinate their world conceptions. For example, shared representations of what is presumed.

iii. Binary conceptualizations are frequent in political discourse: for instance, the tendency in much political discourse is towards antonymous lexical choices and other lexical choices that must lead to hearers making mental models that are binary in character. Descriptions and references to politicians, public figures, and organizations and their actions are of course a function of politically and ideologically based opinions and attitudes. Such evaluations 
are characteristically polarized: Whereas WE are democratic, THEY are not, and whereas OUR soldiers, or those who share our cause, are freedom fighters, those of the OTHERS are obviously terrorists (Chomsky 1985, 1987; van Dijk 1995).

Under rhetoric, I will be considering the occasions for speech (epideictic, forensic or deliberative); the issue at stake (stasis); and rhetorical appeals (ethos, logos, and pathos). Decolonial approach will be focusing on finding answers to these questions: How does the context of Nigerian political discourse inform some of the arguments? How have these forms of indigenous practices evolved and played out in emerging globalized contemporary discourse? In addition, how is rhetoric used to negotiate through our diverse culturally fractured states to enable some shared meaning with people in their daily existence? Exploring these questions will help me determine the function that intertextuality serves in light of the overall argument.

The whole analysis revolves around finding various ways Jonathan constructed his argument, and how the arguments fit into wider social practices in Nigeria. The analysis indicates the rhetorical choices Jonathan made to communicate his version of the truth in ways he thought were compelling, plausible and natural. It reveals how Jonathan's rhetorical choices and the frameworks of meaning in his discourse get circulated as a normalized communication practice and ways of making common sense within Nigerian context. The analysis is essential for the understanding and critique of power abuse in increasingly hybridized political discourses in Nigeria. 


\section{Chapter Four Data and Analysis}

\subsection{The Data}

My analysis focuses on two 2015 electoral campaign speeches of Goodluck Jonathan presented at two major campaign events. The first was made on Tuesday November 11, 2014 on his declaration of intent to run for the 2015 presidential elections on the platform of the Peoples' Democratic Party (PDP) at Eagle Square, Abuja. The second speech is Jonathan's Thursday, January 8, 2015 remarks at the start of the PDP 2015 campaign in Lagos. The first speech was made to gain the nomination by his party where the choice was between Jonathan and other PDP bidders and the other was after being nominated where the contest was between him and other parties' candidates. The speeches appear in full in the Appendices labeled A and B respectively. However, my analysis does not focus on summarizing individual speeches point by point, or in sequence. My critical focus is rather on the content of the speeches where I pay attention to examining how each of Jonathan's speeches works as a rhetorical tool to influence audience and the discursive means by which these rhetorical appeals are constructed, given my consideration of language as a site of social struggle.

The transcription conventions for the extracts I use in this chapter are as follows: I put Jonathan's original speech extract is in italicized font, my comments are in plain texts inserted in square brackets, and the words I emphasized are bold-faced. The extracts are numbered in ascending order for easier identification. While at the bottom of each text is the paragraph number that corresponds to correct numbering in the original speech. 


\subsection{Analysis}

\subsection{Jonathan's Campaign Speeches as Deliberative Rhetoric}

In his Rhetoric, Aristotle presents a tripartite division of rhetorical genres: forensic or judicial, deliberative or political, and epideictic or ceremonial. According to Aristotle:

Each of these [species] has its own "time"; for the deliberative speaker, the future (for whether exhorting or dissuading he advises about future events); for the speaker in court, the past (for he always prosecutes or defends concerning what has been done); in epideictic the present is the most important; for all speakers praise and blame in regard to existing qualities, but they often also make use of other things, both reminding [the audience] of the past and projecting the course of the future" [1358b].

Forensic rhetoric deals with the type of argument common in the courtroom where passing judgment relies on the issues in the past and thematically on justice and injustice. Its function is to accuse or defend. Epideictic, on the other one hand, is linked to the present. Thematically, it is a common language of funeral orations, commencement addresses, or when heroes are celebrated, or villains are condemned. Functionally, it focuses on praise and blame. Deliberative rhetoric, also called political rhetoric, focuses on future action. The aim is to establish the expediency or harmfulness of a proposed action, and functionally to exhort or dissuade [Aristotle 1358b].

Both addresses I analyze in this study were concerned with an electoral campaign and may therefore, be attributed to deliberative oratory in a sense that both focus on future actions of election. However, as observed by Wodak, de Cillia, Reisigl and 
Liebhart (2009), "none of the three genres mentioned above occurs in pure form: the diversity of topics and temporal references usually results in the simultaneous presence of elements from all three oratorical categories within one and the same speech" (p. 70). Thus, in addition, the speeches exhibited traces of judicial rhetoric, in that Jonathan sought to defend some of his actions and policies during his first term in office. This was the case, for example, with the issues of corruption and impunity, as this will be discussed in detail under the topic of apologia. In addition, the speeches contain elements of epideictic where Jonathan focuses on praising his government and blaming past governments for the problem of Boko Haram. Nonetheless, the campaign speeches I analyze are deliberative in nature as they were concerned with future-related political matters. Jonathan focuses his attention on advocating for the right course of action in the future. This course of action is a choice between Jonathan and his major opponent Muhammadu Buhari (who was subsequently elected President). Jonathan wants to persuade his audience that he is the best possible candidate for the election. His purpose was to receive backing to run again for the presidential position. He uses a deliberative argument to show the difference between what he called "the old" system that was run in Nigeria, and comparing it to the innovations of the present Nigeria under his own leadership, and his plans for the future. He projects the future as free and open while insisting that the electorate, by coming out to vote during the election, have the power of changing the course of the future for Nigeria. As he stated: 
1. You must vote for your liberation, you must vote for your development, you must vote to take Nigeria to the moon. You cannot vote to take Nigeria backward. (B 81)

The unstated alternatives alluded to here are suppression (as opposed to liberation), and retrogression (as opposed to development).

This attempt to get people to vote, especially for Jonathan, is driven by the presumed binary structure typical in politics discussed in Chilton (2004) where the arguments are structured as "either/or." As Jonathan puts it:

2. Either you vote and continue to be relevant in Nigeria's political history or you vote to be irrelevant. (B 5)

3. [He also says,] Vote for your liberation or imprisonment. (B 61)

This binary structure frames false dilemma where only two choices are provided: "old ways" and "moving forward." Jonathan's opponent is portrayed as threatening the future and representing "the old ways" with images of fear of Buhari's past military administration, while Jonathan positions himself as safeguarding the future for the next generation and touts himself as the person who is "moving" Nigeria "forward" to "progress" (the rhetoric of progress).

Although Jonathan acknowledges different problems and difficulties that his administration faced, such as what he called "uncommon challenges" and "the wave of insurgency" that swept through some parts of Nigeria, and the problem of corruption, 
which according to Jonathan, "[r]emains a big challenge in our national life," those challenges and problems with all the consequential sufferings were legitimated by a futurist (deliberative) rhetoric in which he claims to know the future with certainty and objectivity. The argument was that if Jonathan was voted into office again, he would turn around the tide of things in the country. The following excerpts indicate the way the future was depicted:

4. We have eradicated [corruption] in the agricultural sector and we will surely eradicate it in other sectors of our economy. (A 38)

5. We are equipping the armed forces and deploying special forces to engage the terrorist and end this senseless war. (A 5)

As Jonathan mentions, corruption and the wave of Boko Haram (without naming them, probably not to give them legitimacy) insurgency remained some of the lingering problems facing Nigeria in its:

6. March of progress as a united and democratic country. (A 2)

Nigerians were hoping that in the future Jonathan would waive the magic wand and solve those problems. Jonathan's deliberative rhetoric is an attempt at image restoration, which relies on promises of a better future. These promises do not necessarily stem from an objective description of the world, but rather as means of inducing cooperation from Jonathan's audience. 
Deliberative rhetoric is anchored on a future that is human-made, which requires a human agency to shape it, as opposed to "natural" future events that are outside human agency such as earthquakes and floods. In Jonathan's case, the possible human-made future is a choice between what are referred to as "going backward" and "moving forward". To vote for Jonathan's opponents means a future where the past misdeeds are going to return. As stated by Jonathan:

7. Railways were allowed to rot in neglect... (A 80)

8. Where there were long queues at our filling stations due to irregular supply of products and our people were exploited.... (A 85)

9. [Where] women and youths were denied opportunities in government and in responsible positions. (A 86)

10. [where women will] go back to the kitchen and die there. (B 66 \& 67)

To vote for Jonathan means a future where Nigeria:

11. Thirsts for progress with children across the nation, eager for knowledge and safely in schools! Where all who have taken up arms, would again embrace peace! Where our women can aspire to any heights, without hindrance! Where one day the next generation will take us to outer space. (A 98, 99, 100, \& 105)

The choice between "going backward" (doom) versus "moving forward" (confidence and optimism) is expected to lead listeners to make mental models that are binary in character. We have seen the binary tendency at work in representations of Nigeria's conditions into two: "old ways" and new ways ("moving forward"). Also, the 
choice in the verbs between "going" and "moving" could be deliberate where "going" does not specify the nature of motion but "moving" specifies "progress" or entails "positive action." The deliberative rhetoric offers Jonathan the opportunity to legitimize the present and its conflicts and sufferings in the name of a good future. However, some of the future projects could affect Jonathan's credibility. For example, the project of going to the "outer space" does not seem to be one of the pressing priorities for Nigerians hence; this might suggest that Jonathan has lost touch with the pressing problems facing Nigerian people.

\subsection{Contrastive Tenses as Linguistic Frames in Jonathan's Deliberative Rhetoric}

The linguistic concept of tense and aspect is significant in the evocation of deliberative rhetoric. The contrast between the temporal moments of past, present, and future in Jonathan's speeches represent the temporality of situations and actions in different ways. Jonathan juxtaposes the simple past tense and the present tense and aspect to describe the "old ways" and "moving forward" respectively. The following excerpt illustrates that:

12. My brothers and sisters, we cannot go back to the old ways! Our railways were allowed to rot in neglect, we have revived and are modernising them. We cannot go back to the old ways! Our road infrastructure collapsed. We are reconstructing, and expanding federal roads across the country. We cannot go back to the old ways! Our airport terminal buildings were dilapidated and our airspace [rendered] unsafe. We are fixing this. (A 80, 81, \& 82) 
Jonathan uses the simple past tense to recount the events of the past related to Buhari's military regime - what he called the "old ways" - to portray "the old ways" (military regime) as issues that are entirely of the past and, thus, not desirable in the progressive present moment hence should not be allowed to return. The past tense "were allowed to," "collapsed," and "dilapidated" in the above excerpt were used to achieve this purpose of persuading the audience to see the past as nothing but evil. He used the present perfect and present continuous to represent the events of the present: what he called "moving forward" which helps to draw a picture of an ongoing progress (his continuing tenure) that should not be interrupted. The present participles "reconstructing," "fixing," and the present tense copula "are" render the sentences as statements of a timeless principle that is not unique to any particular temporal moment, hence should not be limited to his expiring tenure but rather allowed to go on into the future. Similarly, the perfective aspect "have revived" rendered Jonathan's past projects as natural extensions of a recent, desirable past into the present and future. Jonathan also uses repetition as a powerful rhetorical device to complement the use of tense in constructing the binary frame between the past and the future. The phrase "we cannot go back to the old ways" was utilized as a repetitive rhetorical device to help the audience remember and recognize the importance of voting for Jonathan who represents the "new way."

Jonathan projects the future through deontic and epistemic lenses - projections of both what ought to be done (voting for him) and what will be at some future moment (journey to progress). The contrastive use of simple past tense verbs and present perfect 
aspect function rhetorically to indicate a break from the past, which is not a desirable moment, and the present moment that will necessarily develop into a fruitful future. Jonathan construes the "present" as he indicates with the use of temporal deixis "today" and "now" as durative, as continuing into the future unless obstructed by electing another person other than him. Example:

13. We came and cleaned up the sector and today there is no corruption in the fertilizer industry again...[W] e developed the e-wallet system and through that the farmers now get their fertilizers directly. (B 25 \&26)

14. Now our trains are moving. Egbin power sector got burnt in 2005 and remained so until now when we are fixing it. (B 43)

Through manipulating the present tense to project an image continuing into the future, Jonathan "de-futurizes" the future by rendering it as already existing in the present moment. The future is thus linguistically and discursively construed as the "here now" and a vision one possible future.

\subsection{Postcolonial Frames in Jonathan's Deliberative Rhetoric}

The futuristic rhetoric can be equated to optimistic projections of modernity during the colonial era. According to Mignolo (2011), the project of modernity interprets colonialism as the vehicle that brings modern values and institutions to the colonized world but behind the so-called progress of modernity lies a logic and history of coloniality. While recent political rhetoric in the colonized world is not a justification of 
colonial rhetoric, it found its expression in narratives of progress and expansion, which necessitated different types of movement, including "flows of knowledge, materials, commodities, practices" (Mignolo 2011, p. 9) and social and physical movements. Every rhetoric exists in the contexts of the people's overall experience or a segment thereof. In this light, Jonathan's campaign speeches reflect a tradition that evolved out of vestiges of colonial legacy. According to Addei, Osei, and Annin (2013):

For the masses in many African countries, the postcolonial era did not offer them anything too different from the colonial era itself. The only difference, however, is that their white colonial masters have simply metamorphosed into their own natives, the elite few, who have assumed control. In other words, it is a period of change of batons where white colonial masters have given way, after independence, to black masters lording it over their fellow black men. To these black masses therefore, the dream of freedom after independence is simply a mirage. (p. 164)

Apparently, postcolonial Africa has maintained some of the colonial rhetoric molded in the name of provisions of development and progress. According to Törnquist (1999), the argument often touted is that the developing countries found themselves on an inherited and undeveloped traditional level and that is due to their own backwardness, not to colonial rule. Hence, political and other forms of development in these countries required modernization of a kind similar to that which, according to these scholars, today's developed countries had undergone. These scholars also argue that the developing 
countries did not need to reinvent the wheel, but could take in most cases a shortcut by copying the advances pioneered by the developed countries. Such rhetoric of development relies heavily on a deliberative rhetoric, where the elites promise economic growth and financial prosperity with little evidence to support the actualization of those promises, while ignoring existing poverty and social inequality in the society. The following excerpts features these promises of progress and economic growth:

15. In moving forward, I see a Nigeria that thirsts for progress with children across the nation, eager for knowledge and safely in schools! (A 98)

16. I remain grateful for the trust you reposed in me to lead our Nation through uncommon challenges in our march of progress as a united and democratic country. (A 2)

17. In our journey to progress, knowledge is indispensable. You must vote for the progress of this country. (A 47)

Colonial occupation and European modernity were defined by a discourse of progress and development. Post-colonial political elites in Africa eventually inherited this discourse, most importantly, with the globalization of democracy; this discourse has become even more entrenched and perhaps defines African political discourse. This rhetoric of progress serves as the framework for African political discourse, and all other issues become subsumed within this progressive discourse. Ironically, as Mignolo (2011) asks if discussions of progress and economic growth function to "save capitalism and not to save human beings?” (p. 144). Significantly, the promises of progress and economic 
growth have remained a myth to the local people and demonstrate one of the ways the enduring legacy of colonialism still frame our experience with the world.

In sum, the sub-genres of deliberative rhetoric are "ideologically and materially consequential because of their capacity to define and delimit the future possibilities of a given present moment" (Dunmire 2011, p. 67). Through rhetorical acts, Jonathan created an expectation, which had material effects of legitimizing his political goals and interests. Edelman (1988) sees this creation of expectations "as a rhetorical act through which political actors make "rhetorical evocations of a remote time unlikely to arrive which, in turn, have material effects on the present by legitimating more immediate proposals and policies that serve the partisan's political goals and interests" (p. 18). Through binary conceptualizations of events and issues, Jonathan legitimated his political policies and actions by projecting images constructed as "moving forward" and declaring that certain good things will happen soon if he is re-elected as president. What Jonathan does with deliberative rhetoric is an attempt to place two choices before his audience: images of hopes and "progress" if Jonathan is re-elected as the president, versus images of fears and threats if his main opponent is elected as the president. Through the means of deliberative discourse, Jonathan casts his political goal with language that intend to speak in the interest of the audience, including prioritizing promises of the provision of good roads, security of lives and property, health care, good educational system and a host of others while ignoring the real impact of those projects in effectively dealing with poverty and inequality. It is possible to say that facts can be easily ignored when people are dealing 
with future probabilities as it is shown in Jonathan's deliberative rhetoric. Therefore, campaign rhetoric is largely an appeal for support, not a form that can be used to objectively measure the validity of future things because politicians are likely to deceive people by overstating what actually they can be able to do.

\subsection{Rhetorical Appeals and Electoral Campaign}

Apart from the three genres of rhetoric, there are three meta tools of persuasion available to speakers which help them make their arguments agreeable and receptive to their audience. According to Aristotle these are "in the character [ethos] of the speaker, and some in disposing the listener in some way [pathos], and some in the speech [logos] itself, by showing or seeming to show something" [1356a]. Aristotle goes ahead to elaborate more on the three rhetorical appeals and says:

that Since pisteis come about through these [three means], it is clear that to grasp an understanding of them is the function of one who can reason logically and be observant about characters and virtues and, third, about emotions (what each of the emotions is and what are its qualities and from what it comes to be and how). (1356a).

My subsequent analysis is based on this three-broad division: argument by character (ethos), argument by logic (logos), and argument by emotion (pathos). Jonathan used all the three means of persuasion together to convince the audience to vote for him. 


\subsection{Argument by Character (Ethos)}

Ethos is persuasion through character and according to Aristotle "we believe fair-minded people to a greater extent and more quickly [than we do others], on all subjects in general and completely so in cases where there is not exact knowledge but room for doubt... character is almost, so to speak, the most authoritative form of persuasion" [1356a]. According to Kennedy (2007):

Unlike Isocrates (Antidosis 278), Aristotle does not include in rhetorical ethos the authority that the speaker may possess due to position in government or society, previous actions, reputation, or anything except what is actually said in the speech. Presumably, he would regard all other factors, sometimes highly important, as inartistic. One reason for Aristotle's position may be that speakers in the law courts were often ordinary people unknown to the jury, and a relatively unknown person might speak in the Assembly as well. (p. 39)

During electoral campaigns, politicians come to people for votes, so they need to earn the people's confidence and trust. Earning confidence and trust has a lot to do with a speaker's character or authority - what is commonly referred to as ethos. Ethos is central to campaign discourse because campaign discourse centers on a speaker and how the speaker's character, virtues, and goodwill make them a worthy and credible candidate for the particular post they vie for. A candidate is expected not only to reinforce all the good things about themselves, but must also be able to delegitimize their opponents' credibility so that they make themselves look more credible and trustworthy. 
According to Martin (2014), appeals to ethos can be either explicit or implicit. An explicit appeal will involve saying why the speaker should be trusted, perhaps by listing existing accomplishments or by recounting their past experiences, family upbringing and moral values. This explicit appeal to credibility plays a large role in Jonathan's speech. Jonathan spends the bulk of his time informing the audience of what he has accomplished as a president in the past years, from building twelve new universities to the construction of roads and reviving railways, among others. He also cites his previous experience in holding important political offices. As he puts it:

18. I served in Bayelsa as deputy governor and governor for eight years; I also served as Vice President and President for another four years at the centre. (B 25)

By pointing out his experience in the political field, he projects himself as a better choice and builds his credibility with his audience.

\subsubsection{Building Ethos through Apology}

Apology was one of the ways Jonathan used to establish trust and confidence. Apologies are rhetorical acts that appear in the form of public statements showing regrets in response to transgressions. In politics, they are mostly presented in the name of collectivities (e.g., governments) or individuals for wrongful acts. While apologies are supposed to serve as statements of regret, political apologies seem to be primarily 
concerned with a rhetorical goal of establishing credibility with the voters. The following are the excerpts that include Jonathan's apology:

19. At this point, let me apologize to some Nigerian civil servants who did not receive their salaries in December early enough and I will tell you what happened. I apologize to those families that suffered because we believe that for you to fight corruption; you must take measures, establish and strengthen institutions. (B 23)

20. Let me sincerely on behalf of my party apologize to you because we are having this rally today so the whole of Lagos is at a standstill. We beg you, we have to do it and we know you love us. (B 72)

By apologizing, Jonathan seems to attempt to identify with people's sufferings and the courage and humility to stand up and admit that something terrible happened to people under his watch. However, by just invoking or mentioning the words "I apologize" Jonathan cannot be deemed to have succeeded in enacting the speech act of apology. According to Austin (1962) for speech act (performative utterance) to achieve its purpose, there are what he calls felicity conditions (necessary conditions) that must be satisfied for a successful execution of the act. Austin states that for a performative utterance to be considered successful "there must exist an accepted conventional procedure, having certain conventional effects, the procedure to include uttering certain words by certain persons in certain circumstance" (p. 12).

Lakoff (2001) outlines six underlying conditions necessary for a successful performance of an apology: first, a speaker expresses regrets; second, a speaker assumes 
responsibility for the act; third, the speaker acknowledges that the act committed is wrong; fourth, the act was bad for the addressee; fifth, the apology puts a speaker clearly one-down; and six the speaker promises that such an act will never happen again. Based on Lakoff's taxonomy, we can say that Jonathan's speech act of apology has not been completely executed because it fails on a number of the necessary conditions an apology presupposes. For example, after Jonathan's apology about not paying workers their December salary (paycheck), he goes ahead to justify why it happened, suggesting it was a corrective act to prevent corruption and therefore was done for the good of the affected people. Here is Jonathan's justification:

21. What happened in December was that IPPIS, software for processing salaries, sometimes people steal through salaries - and some federal government agencies including some ministries tried to divert funds to pay some allowances. The system is scientific, it is not a human being, and as long as money meant for salaries is about to be diverted to other things, it shuts down. Those departments of government were shut down, this is the only way that you can prevent corruption. (B 24)

By this justification, Jonathan shifts the responsibility to a non-human agent (a Computer program) that seems to mitigate Jonathan's responsibility in the act and thus helps to exonerate himself and the staff working on behalf of his government. He speaks in a tone that lacks regrets because to him the action was not entirely wrong but if properly understood was meant to "prevent corruption" and thereby depicting Jonathan as 
not guilty of the offense. Moreover, in his explanation, there is no sign that such an act would not be repeated in the future to prevent the recurrence of the act. One would expect to hear Jonathan promise the audience that such an act will not be repeated and indicate if there was any directive he issued about the act as a preventive measure to assure the affected people that there are amends to the existing system. On the contrary, there was nothing to ensure that the same process is not repeated. Also, Jonathan is expected to end up one-down after the apology. However, the justification and explanation Jonathan provides tend to put the affected people one-down. Lakoff (2001) suggests that, for presidents, it is always significant for them "not to be one-down because that constitutes a loss of power and influence" (p. 206) and most presidents would prefer to avoid any apology that would put them one-down rather than to remain on good terms with the affected people.

From the speech act theory perspective, we can conclude that Jonathan's apology is infelicitous and it thereby follows that the sincerity of his apology is doubtful and could be viewed mainly as a strategy of legitimatization for electoral value. However, Jonathan's invocation of the words "I apologize," has the potential of restoring his credibility and goodwill. It might also depict Jonathan as the president who listens and is not indifferent to public outcry when a wrongful act has been committed by his administration. Nonetheless, the explanation and justification that accompany Jonathan's apology have a rhetorical end that benefit him rather than reconcile him with the offended people because the explanation is intended to downplay the severity of the act committed. 
However, when one looks at apologies offered in everyday conversation, and those made by politicians, Jonathan's explanation is justifiable because in everyday conversation speakers get instant feedback whether their apologies are accepted or not. Apologies from high-profile politicians such as presidents barely get an immediate response to show if the apology is accepted or not, hence the need for elaborate explanation to cover all aspects of what happened and the reasons for why the offense happened. Nonetheless, the detailed description that accompanies Jonathan's apology is capable of delimiting the scale and the severity of what happened actually and likely to mislead the audience.

While it is hard to detach entirely the rhetorical end of an apology when politicians offer it, an apology gives us an insight into the complex ways politicians negotiate their positions and identities when the act is enacted in public discourse. Reflecting upon the major dilemma Jonathan faces in negotiating his positions as both the president of Nigeria and as an apologizer, we can say that apology has two implications in politics: first, it barely satisfies those who feel offended by their action even after they have apologized, and second, the apology leaves the apologizer (the politician) without "any shred of self-esteem" (Lakoff 2001, 212). This is because the act of apology by presidents brings an ambivalent power dimension where leaders might consider it dehumanizing or a loss of power to go one-down in public to apologize to their followers. However, other serious misdeeds will always make an apology the most appropriate thing to do in order to save face. As Lakoff (2001) states, an "[a]n apology is always facethreatening for the speaker; but not making a necessary apology may occasion more 
serious face loss in the long run" (p. 211). Thus, the speech act of apology offers us an opportunity not only to recognize the values of the formal aspect of official apologies but also their function in educating the community about the importance of upholding particular societal values and the rules and assumptions that bind a society together.

\subsubsection{Building Ethos through Apologia}

In traditional rhetorical theory, apologia is defined as the speech of self-defense (Aristotle 1358b). Either people make mistakes, honest ones or by their own self-interests, which put their image under intense attack and threaten their reputation. Because of the importance of image to politicians and their desire to maintain positive ethos, when their reputation is at stake, they naturally look for ways to explain, justify, rationalize, or excuse for undesirable behavior. According to Benoit (1995) "human beings possess a basic instinct to engage in recurrent patterns of communicative behavior designed to reduce, redress, or avoid damage to their reputation (or face or image) from perceived wrong-doing" (p. vii). Jonathan's ethos was particularly questioned on three important areas as he mentions during his campaign speech:

22. The first is the issue of insecurity. I am also going to address whether this administration is fighting or encouraging corruption. I am going to address the issue of weak government and unfocused government that has no plans. (B 10)

These three topics challenged Jonathan's credibility to seek reelection and demanded that he had to find all the available means to strengthen his character and elicit positive public reactions from the voters, more than even his challenger. With such situations, Jonathan 
was forced to present a speech of defense (apologia) on these three issues and this occupies the largest part of his campaign speech in Lagos.

Jonathan started his speech of self-defense by characterizing all the accusations against him as lies concocted by his opponents to take over power. Here in an excerpt from Jonathan's denial:

23. I am going to dwell on three things because those who say they want to take over power from PDP have been telling a lot of lies. They have hired people from all over the world and those of you in the social media carry all forms of lies, painting all kinds of colour and giving me all kinds of face that I cannot defend. (B 8)

Here Jonathan portrays the three issues he was being accused of: insecurity, corruption, and an unfocused government. He declared that they were false campaign statements and propaganda intended to convey a wrong impression about him and to create unfair notions about him in order to compromise his character. But another interesting thing that Jonathan subsequently did in the speech was not to deny the existence of those three issues but rather, he tries to shift the blame towards his opponents with the argument that his opponents were the ones that were directly responsible for the problems he was being accused of. For example, regarding insecurity Jonathan accused his opponents of instigating the crisis. Jonathan states:

24. They instigated crisis and now they are telling us they will fight insurgency. (B 
The next step was for Jonathan to evade the responsibility for the inability to defeat Boko Haram and combat corruption. He puts the blame on his opponents. On security Jonathan contends that:

25. They talk about insecurity. That they will fight insecurity. And you will ask are our armed forces weak? Are the Nigerians in the Armed Forces weak? If we have problems what is the cause-equipment. And somebody who wakes up and tells young people of 23 years old that he wants to fight insecurity, ask him when he was the head of government did he buy one rifle for a Nigerian soldier. These people did not buy anything for the Nigerian soldiers. They refused to equip them. No attack helicopter, nothing. Ask them what they did with the defence budget for the whole time they were in office. (B 19 \& 20)

On corruption, he has this to say:

26. If they had succeeded in fighting corruption, corruption would not have been with us here today. If they had set up structures and especially in today's modern science using ICT [Information and Communication Technology] to manage resources, we would not have been talking about corruption today. (B 24)

Jonathan goes further to argue that equipping the military and fighting corruption are processes that are not carried out overnight. On security, this was his explanation:

27. No country equips armed forces overnight. What they use is quite expensive and they are built over the years. Even if you spend 10 billion dollars today, you 
cannot equip the army, navy and air force. The capacity is built over time. They refused to build the capacity. (B $20 \& 21$ )

In addition, regarding corruption:

28. If somebody tells you that the best way to fight corruption is to arrest your uncle or father and show him on television, well, you won't stop corruption, you will even encourage corruption. I used to tell people and I will also address press conferences so that people can ask me direct questions. Armed robbery is still with us, despite the fact that we are shooting (death penalty) armed robbers. Is that stopping armed robbery? (B 27)

29. So arresting people and demonstrating on television will not fight corruption, we must set up institutions, strengthen them to prevent people from even touching the money and that is what we are working on and we are succeeding. (B 28)

In the above quotations, Jonathan is arguing that since he lacked control over the previous years' mode of not buying military equipment and building modern structures to fight corruption, he should not be held responsible for the inability of his government to defeat Boko Haram or combat corruption. Jonathan was not dismissing the existence of insecurity and corruption altogether in Nigeria, but rather his was an attempt to provide contextual information that may reduce his apparent responsibility in the issues and provide an alternative target for the audience to criticize. If Jonathan's audience accept his claim, it could then improve on his credibility and absolve him of culpability in the problems of insecurity and corruption. Jonathan's defense has two implications. First, it 
creates a sense of defining the stasis of the argument (insecurity, corruption, and unfocused government) as inevitable consequences of the past military administrations' mistakes; hence, people should not hold him accountable for them. Second, it shifts attention to his publicized ways of combating the problems and conceals many wrong policies his administration took that might have caused or contributed to the problems. The speeches of self-defense even if they are successfully executed Benoit et al, (2003) assert that they come with three potential liabilities:

There are three potential drawbacks to reliance on defenses. First, they can make the candidate appear to be on the defensive, reactive instead of proactive. Second, in order to refute an attack, the candidate must identify the accusation. This may remind or inform voters of a potential weakness. Third, a defense is more likely to occur on a topic that favors one's opponent. This means that a defense often takes a candidate "off-message," devoting precious message time to issues on which a candidate does not wish to dwell. (p. 22).

Because such of liabilities Benoit affirm that speeches of apologia is not frequently used as it comprises only small percentages of the overall campaign speeches of a politician compared to speeches of self-acclamation and speeches of attacks. However, when a candidate is attacked if not successfully defended against can provide the basis for voters to reject a candidate. Hence, the rhetorical situation usually necessitates speeches of defense. In his analysis of the rhetorical situation, Bitzer (1968) sees rhetoric as a discourse in response to a particular kind of situation. The criticism against Jonathan about insecurity, corruption, and unfocused government invites a response from him that 
Jonathan hopes it could restore his preferability. The response must fit the situation and "functions to produce action or change in the world... not by the direct application of energy to objects, but by the creation of discourse which changes reality through the mediation of thought and action" (Bitzer 1968, p. 4). Obviously, the immediate situation that called forth Jonathan's rhetorical act was driven by the negative perception of him because he was considered to be directly and indirectly responsible for the insecurity, corruption, and the unfocused government. Whether such defenses have helped restore Jonathan's credibility cannot be ascertained because in the end he lost the election.

Moreover, since Jonathan has lost the election that could also point to the fact that language alone is inadequate in the construction of social reality. Jonathan's rhetoric about the three issues of security, corruption, and unfocused government instead of concealing the facts on the ground or even revealing the actual nature of the reality on the ground raises many more questions about Jonathan's sincerity to keep to his 2010 campaign promises. Jonathan's main campaign theme during the earlier 2010 electoral campaign was on fighting corruption and providing adequate security for the lives and properties of all Nigerians, as it is indicated in the following excerpts:

30. Let all the kidnappers, criminal elements, and miscreants that give us a bad name be ready for the fight that I shall give them. Let the ordinary Nigerian be assured that President Jonathan will have zero tolerance for corruption. Let the international community hear that today I have offered myself to lead a country 
that will engage them in mutual respect and cooperation for the achievement of international peace and understanding.

However, four years have passed and corruption and insecurity have just become worse than before. For example, the Boko Haram terrorist group, which started killing innocent Nigerians in 2009, became more coordinated and deadly, claimed the lives of thousands, and displaced millions of people. Just as devastating was the kidnapping of more than two hundred Chibok schoolchildren on April 15, 2014, who, during Jonathan's administration, were still in the hands of their captors despite local and international outcry to rescue them. In addition, on the issue of kidnapping, there were many highprofile cases of kidnapping, such as the abduction of the mother of the former Minister of Dr. Ngozi Iweala in 2012 and the kidnapping of even the President's uncle in February 2014 (Chidi, 2014). Apart from these high-profile cases, many more kidnapping incidents did not get media attention (see Chidi, 2014).

In terms of corruption, Jonathan's ministers and aides were accused of corruption, but Jonathan either shielded them or gave them a clean bill and allowed them to maintain their positions (Ibekwe, 2015). For example, the former minister of aviation, Stella Uduah was accused of buying two armored BMW cars for her personal use N255 million naira without Jonathan ordering or calling for her prosecution. The largest scandal was when the then Governor of the Central Bank of Nigeria, Sanusi Lamido Sanusi, alleged that $\$ 20$ billion dollars were not remitted into the Federation account of the Nigerian National Petroleum Corporations (NNPC), an important agency under Jonathan's control. 
Instead of Jonathan investigating the veracity of the allegation, Sanusi was fired from his position. These and more were some of the corruption charges laid against Jonathan before the election.

The security and corruption challenges constitute significant discussion point during the 2015 election campaign and point to the obvious contradictions in Jonathan's rhetoric. This contradiction could have been one of the significant reasons why voters might find it very difficult to make sense of Jonathan's apologia about corruption and insecurity. But because such rhetoric of apologia creates a misleading characterization of the nature of these problems, leaving many of Jonathan's policy failures unstated, instead of language being a tool for establish Jonathan's goodwill, language becomes a means through which Jonathan's insincerity is revealed.

The rise of anti-rhetoric politicians in Europe and America championed by Beppe in Italy, Donald Trump in America, and even mavericks within the political establishment such as Ted Cruz and Boris Johnson is fueled by the apparent contradictions between the widening inequality and politician's official rhetoric. As opinion polls in the US, UK, France and elsewhere demonstrate, many voters have simply stopped believing in politicians' words (Thompson, 2016). They want people that "tell it like it is" (Thompson 2016, p. 4) - people that purport to tell the truth (However important to point out that there is a difference between anti-rhetoric and actually telling the truth.) According to Thompson the widening gap between the facts on the ground about inequality, and the 
claims and the promises made by political leaders have made voters to trust the antirhetoric politicians as well. In addition, once:

Listeners are convinced you're not trying to deceive them in the manner of regular politicians, they may switch off the critical faculties they usually apply to political speech and forgive you any amount of exaggeration, contradiction or offensiveness. And, if rivals or the establishment media then point this out, your supporters may dismiss it as spin” (p. 1)

When poverty, corruption, and impunity are high and promises made by politicians are not honored, language becomes only a tool that reveals rather than conceals the insensitiveness of politicians to people's plight.

\subsubsection{Building Ethos through the Discursive Construction of Nation and National Identity}

In this section, I analyze the various linguistic and argumentative schemes involved in the discursive construction of nation and national identity by Jonathan in his campaign speeches. As an appeal to ethos, the discursive construction of nations could serve the role of bridging the gap between the audience and Jonathan to generate a sense of identity with the audience. The sense of identity works to emphasize that the speaker has so much in common with the audience and belongs to the same community (in Jonathan's context, Nigeria). The most important of these linguistic and argumentative schemes include the use of deictic "we" and its possessive variant "our" to construct common "crises and 
threats" to the development and progress of Nigeria and the use of the three tropes of personification, synecdoche, and metonymy. Through these linguistic means, Jonathan appears to stress the inclusion of all his audience into one group of people - a group to which he too belongs.

\subsubsection{Building Ethos through the Deictic Use of "We" and its Possessive Form "Our"}

According to Chilton (2004) "in political discourse the first person plural (we, us, our) can be used to induce interpreters to conceptualise group identity, coalitions, parties, and the like, either as insiders or as outsiders" (p. 56). Jonathan's use of the first plural pronominal reference "we" and its possessive variant "our" helps him to construct his idea of nation and national identity. However, "we" has ambivalent uses in Jonathan's speeches. Sometimes "we" is used "exclusively" to refer to the Jonathan's administration as in:

31. We are equipping the armed forces and deploying special forces to engage the terrorist and end this senseless war. (A 5)

32. Infrastructure has been a major focus area of my administration and so, we pursued the power sector reform to this point of irreversible progress. (A 11) In addition, sometimes it is used "inclusively" to refer to Nigeria or Nigerian people as a whole as in: 
33. I am grateful for your support and understanding in the difficult periods we have journeyed through.... Clearly, this has cast a dark cloud on our Nation but we will surely win the war against terror. (A $3 \& 4$ )

But the distinction between inclusive and exclusive "we" in Jonathan's speeches cannot be ascertained simply on syntactical and morphological properties as clearly as the dual system it is found in some languages such as Tok Pisin, (the creole spoken in Papua New Guinea), Warlpiri (an indigenous Australian language), and Mandarin Chinese (Davis, 2015). The table below represents some of the examples Davis provides. 
Table 4-1 Clusivity in Chinese and Tok Pisin

\begin{tabular}{|l|l|l|l|l|}
\hline Languages & $\begin{array}{l}\text { Inclusive "we" } \\
\text { (we two) }\end{array}$ & $\begin{array}{l}\text { Inclusive "we" } \\
\text { (We more than } \\
\text { two) }\end{array}$ & $\begin{array}{l}\text { (exclusive we) } \\
\text { (We two) }\end{array}$ & $\begin{array}{l}\text { exclusive we } \\
\text { (We more than } \\
\text { two) }\end{array}$ \\
\hline English & we & we & we & we \\
\hline Chinese & zan-men & zan-men & wo-men & wo-men \\
\hline Tok Pisin & yumi & yumi pele & mi pela & mi pela \\
\hline
\end{tabular}

In English, as Weczorek (2013) indicates, to ascertain the function of "we" in political discourse one needs to rely more on the pragmatics, and the audience's mental frames, especially on the knowledge one shares about the participants' social and political roles, the different positions the participants occupy, and the different action they perform. Thus, Jonathan's audience can conceptualize themselves as insiders or outsiders based on the stored mental knowledge and the cultural context of the discourse. Based on this, the "we" Jonathan uses in connection with building infrastructure and the procurement of military equipment seems to be used as exclusive for Jonathan's government only because in our stored mental knowledge government is mostly responsible for infrastructure and security. The use of "we" in 28 and 29 excerpts above are ambivalent, and they can be taken to mean either inclusive (Nigeria) or exclusive (just the Nigerian government). Nonetheless, whenever "we" is used for inclusive (Jonathan and Nigeria and Nigerian people), Jonathan seems to use the "we" in connection to threats or challenges confronting national interest. The following excerpts indicate: 
34. Fellow Nigerians we stopped Ebola together. Just as we stopped Ebola, we are on our way to eradicating the Polio Virus in our country. (A 51 \& 52)

35. History has shown that the path of honour for any true leader is not to walk away from his people in moments of challenges. We must stand together in adversity and overcome all threats to our development. We must defend our future, for the sake of our children. (A 70)

36. I remain grateful for the trust you reposed in me to lead our Nation through uncommon challenges in our march of progress as a united and democratic country. (A 2)

37. Clearly, this has cast a dark cloud on our Nation but we will surely win the war against terror. A number of young men and women have been kidnapped by these criminal elements including our daughters from Chibok. (A 4)

Even though there is a "constant ambivalence and slippage between exclusive and inclusive 'we"" (Fairclough 2000, p. 2) in Jonathan's speeches, the "we" used in the above excerpts might be identified as a "national we" (see Dadugblor, 2016 studies on "national we") and appears to be of utmost importance in the discursive construction of nation and national identities and getting the audience to identify with him. Jonathan's use of the deictic "we" reflects Chilton's (2004) discussion that in any discourse, people "position" other entities in their "world" by "placing" these entities in relation to themselves as near or distant. Jonathan here places his audience as close to him in terms difficulties and challenges and presumes to speak on Nigeria's behalf, as Fairclough 
(2000): states, because of the vagueness in the uses of "we" politicians usually make use of "we" to portray themselves as always speaking for the whole nation.

Moreover, Jonathan represents crises and threats as an "adversity" that threatens Nigeria's "development," a threat that calls for solidarity for Nigerians to "stand together" and confront the challenges. Standing together, of course, is implied to mean electing him. And because he and his audience are the "we" which means Nigeria, voting for him means voting for themselves. Moreover, the use of the possessive pronoun "our" in connection with "country" and nation" serves to activate the symbolic resonance of an existence of a nation-state, Nigeria, that people could identify with as "our country" or "our nation". Thus, the deictic use of "we" and "our" serve as persuasive devices, which help, invite identification and solidarity with Nigeria both as a country and as a nation especially in terms of crises and with Jonathan. The deictic expressions also have the ability to annex people into a particular in-group verbally (Nigeria) and distance any other person that is not a Nigerian, thereby constructing an image of people unified and nearer to each other. In other words, it is an attempt to create a picture of what Anderson (2006) calls an "imagined community." We can accordingly say that the deictic forms "we" and "our" are ways that nation and national identity are discursively constructed (Wodak, et al., 2009).

The rhetorical goal could be seen as a strategy to appeal to solidarity, belonging, and bonding between Jonathan and the people, suggesting that the audience shares common characteristics and qualities with Jonathan that also points to an attempt by Jonathan for self-identification as a group member. For example, even though Jonathan 
has used the inclusive "we" as an in-group linguistic device to stand for all Nigerians during the Ebola crisis, he did not hesitate to use the exclusive "I" to claim responsibility for the effort his government made in combating the crisis as can be seen in the following excerpts:

38. Realizing the imminent threat, I declared a national emergency, pulling states, local and federal government into action as well as individual Nigerians to combat this disease. (A 51)

From the above sense, there is a clear switch in the choice of pronouns from deictic "I" that signals self (Jonathan as the leader of his government) to deictic "we" that signals self-group (Nigeria). The switch in the pronominal choice from "I" to "we" and vice versa suggests that Jonathan tends to assert his agency to claim glory for the actions his government takes to cope with Ebola crisis. However, in order to overcome the crisis, he says that people are required to make sacrifices. The excerpt below illustrates that kind of logic:

39. History has shown that the path of honour for any true leader is not to walk away from his people in moments of challenges. We must stand together in adversity and overcome all threats to our development. We must defend our future, for the sake of our children. (A 70)

The labeling of a set of events as "national crisis" is one of the ways crisis is usually politicized in political discourse because as Edelman (1978) states, the language 
use in the discussion of national crises is "selective in what it highlights and in what it masks" (p. 44). The stress on national crises diverts attention from economic and social deprivations to coping with the forms of threats confronting the nation. "In consequence, economic and social deprivations that flow from decisions classified as 'military,' 'security,' or 'rehabilitative' are more readily concealed from mass publics through metaphor" (Edelman 1978, p. 140). According to Edelman, to call a set of events a 'crisis' implies the following:

1. This event is different from the political and social issues we routinely confront, different from other crises, and it occurs rarely.

2. It came about for reasons outside the control of political and industrial leaders, who are coping with it as best they can.

3. The crisis requires sacrifices in order to surmount it.

The propositions highlighted above look reasonable enough to justify leaders' calls for sacrifices during "national crises." But the common assumptions in the propositions needs to be interrogated, especially by examining crises as socially constructed, as Vats (1973) observes “[p]olitical crises, contrary to Bitzer's analysis of Churchill, are rarely 'found,' they are usually created” (p. 159). Moreover, Edelman further states that if we examine crises carefully, most things that are considered national crises "flow from inequalities in economic and political power; that the burdens of almost all crises fall disproportionately on the poor, while the influential and the affluent often benefit from 
them; and that they are closely linked to the social problems we define as normal" (1978, p. 44). Hence, one can conclude that the recurrence of some crises in Nigeria, such as Boko Haram's attacks, might be predictable because they partly originate from routine problems that politicians refused to pay attention to problems such as poverty, sickness, chronic social problems, and inequalities. For Jonathan to minimize consistently social and economic problems, but be an alarmist about threats to national security is an attempt to make the claim that his economic and social policies are working. Nevertheless, more importantly, because crises suggest a need for unity and for common national sacrifice, it is politically useful for Jonathan to construct an idea of nation and national identity.

\subsubsection{Building Ethos through Personification}

Personification functions to change the metaphorically inanimate into animate. According to Wodak et al. (2009) "a personification is a special form of metaphor as it links two differing conceptual fields, i.e. a concept with the semantic feature [- human] with a concept [+ human]" (p. 44). Personification is one of the important means Jonathan employs to construct discursively nation and national identity. The following excerpts contain some of the examples of personifications of Nigeria he used:

40. We must never forget our common bond, one people from the womb of one Nigeria. (A 78)

41. In moving forward, I see a Nigeria that thirsts for progress with children across the nation, eager for knowledge and safely in schools! (A 78) 
42. My people, Nigeria is destined for greatness. (A 109)

Here we find a number of personifications, which are revealed by words, such as “womb," "thirsts," and “destined." By positioning these words with Nigeria, Nigeria is depicted in a humanized form. This humanization gives life and action to Nigeria and works to serve as a strategy of animation. The metaphor of womb and thirsts, for example, signify that Nigeria is not only "already-born" nation but also has the desire, especially a good desire for a drink rather than desires for mundane things. Moreover, the metaphor of "destiny" means that Nigeria is not purposeless but is destined to achieve a goal in this world. In terms of how these personified words are used to construct nation and national identity, the symbol of the womb, for instance, reflect an idea of Nigeria as a single whole, and as participants in this womb, no Nigerian is separate from one another. This oneness is emphasized through the choices of the phrases "one people" "from the womb of one Nigeria." In this sense, by personifying Nigeria Jonathan tends to force identification of the entity called Nigeria while skillfully ignoring intra-national differences based on ethnicity, religion, and class - considerations that will recall some of Nigeria's real problems. This discourse of sameness frequently occurs in Nigeria's political rhetoric. However, with the glaring inequality and class difference in Nigeria, "who is in" and "who is out" in the discursive reification of one Nigeria? The womb metaphor also signals potentials and loyalty. Like children to their mother, the ultimate loyalty in African cosmography, Nigerians are appealed to be loyal to their mother. As 
for the womb, it means Nigeria she shall give birth to progress and development if Jonathan's mandate is refreshed.

\subsubsection{Building Ethos through Metonymic Use of Personal Names} Another way nation and national identity was constructed was with names as a metonymic representation of the three major ethnic groups (Hausa, Igbo, and Yoruba) in Nigeria. According to Wodak et al., (2009) metonymy comes from the Greek for "name change" and "replaces the name of a referent by the name of an entity which is closely associated with it in either concrete or abstract terms" (p. 43). Jonathan employs metonymy as a discursive strategy primary to create an idea of sameness. Here are some of the metonymies used in Jonathan's speeches.

43. I see a Nigeria where the children of Mustapha, and Christopher, Ade and Ada, Timi and Bunmi, Nnamdi and Namadi, do not go hungry! I see a Nigeria where all, no matter their beliefs, live in peace and harmony! (A 102)

These names metonymically represent Hausa/Muslim (Mustapha, Namadi), Igbo/Christian (Ada, Nnamdi), Yoruba (Ade, Bunmi), and other ethnic groups such as Ijaw (Timi). The rhetorical merit of such metonymic use of names is an attempt to reduce the relevance of ethnic attachments as a means to success, and instead appeal to unity and equality in the distribution of goods and services. For Jonathan from an ethnic minority playing the ethnic card would not help his political agenda; he needed an ethnic coalition more than any other president did. Reducing the salience of ethnicity as coalition factor 
dominated Jonathan's first campaign speech presented in October 2010. In the speech, Jonathan emphasized his candidacy's capacity to represent a moderate or non-ethnic candidate. This excerpt from his 2010 declaration-of-intent speech summarizes that philosophy:

44. My story symbolizes my dream for Nigeria. The dream that any Nigerian child from Kaura-Namoda to Duke town; from Potiskum to Nsukka, from Isale-Eko to Gboko will be able to realize his God-given potentials, unhindered by tribe or religion and unrestricted by improvised political inhibitions.

In all subsequent speeches, Jonathan has used different strategies to deemphasize ethnicity. The metonymic use of personal names and place however, presents an essentialist view of ethnicity where there is an assumption that personal names and places is a marker of either ethnicity or religion or even both. In trying to increase his support, he inadvertently reminded Nigerians of their disparities. Though it is true to some extent, that there is a relationship between names and ethnic groups or religions in Nigeria, the reality is more nuanced and complicated than discursively constructed as fixed categories. There are different dimensions to ethnic identities that cannot be mutually integrated into just names. For instance, many individuals bear the name of Mustapha and other Arabic names yet they are neither Hausa nor Muslims. Moreover, the names of minority groups reflect more complexity or problems in the metonymic use of names to represent ethnic or religious groups. Many ethnic minorities take up names from Hausa, Igbo, and Yoruba who yet still maintain their links with their local traditions even with 
names from the dominant ethnic groups. This supports Bucholtz \& Hall's (2005) discussion on identity: that identity should be seen not as deriving from "fixed social categories" (p. 586) and suggests that when we approach identity we should approach it from a "broad and open-ended" (2005, p. 586) perspective. Hence, Jonathan's representation of ethnic identity with individual names might be misleading and shows how names is used as stereotypes.

Other problems can be associated with the metonymic representation of ethnicity in Nigeria. The problem is that Hausa, Igbo, and Yoruba cultural orientations are privileged above the others, and are considered eminently constitutive of Nigeria as a nation, hence, that cultural orientation is subsequently stressed as result of public mediation in politics. The assumption of Hausa, Igbo, and Yoruba as a representation of some Nigeria's ethnic groups is one of the ways colonial experience has been influential in the ways Nigerians come to see and understand themselves. According to Mazrui and Tidy (1983) the idea that Hausa, Igbo, and Yoruba represent Nigeria's ethnic groups follows the colonial government preference to have a clear-cut division that coincided with ethnic groups for easy administration and achieve their strategy of divide and rule. Since then, as indicated in chapter two, the depiction of Nigeria as comprising just three ethnic groups has become an incentive for political competition and group formation in national politics.

There is another way metonymy is used to construct nation and national identity. This deals with the metonymies of the type where the name of a place stands for the 
person(s) living at the place, which also in Jonathan speeches depicts ethnicity. According to Wodak et al., (2009) because of the effectiveness of metonymies of place to forge intragroup sameness, it has been used as a means for referential annexation, assimilation, and inclusion. As indicated earlier, Jonathan's 2010 campaign speech has some good examples of these:

45. My story symbolizes my dream for Nigeria. The dream that any Nigerian child from Kaura-namoda to Duke town; from Potiskum to Nsukka, from Isale-Eko to Gboko will be able to realize his God-given potentials, unhindered by tribe or religion and unrestricted by improvised political inhibitions.

Also Jonathan uses "Nigeria" to stand for its people as it is shown below:

46. Nigeria has undertaken a most transparent and corruption free bidding process, attracting global commendation. (A 11)

47. Nigeria is now exporting cement. We are moving forward! We must produce what we consume and consume what we produce. (A 56)

48. Nigeria is the first country in the world to develop an e-wallet system to reach farmers with subsidized farm inputs on their mobile phones. (A 39)

49. That blocked Nigerians from even going to Britain at a time and the relationship between Nigeria and Britain... the whole world isolated Nigeria. (A 33)

The use of "Nigeria" to stand for its people has the tendency of hiding the human agents behind various actions associated to Nigeria. This serves primarily to render the dominant 
human forces who were responsible for actions or who benefit from government's major policies anonymous. Let us take the statement that "Nigeria is now exporting cement." The company that is engaged in the exportation of cement is called Dangote Cement, and it belongs to one man Aliko Dangote. By using Nigeria as the responsible agent, Aliko Dangote remains anonymous even though he is the primary beneficiary in the exportation of cement.

The discursive construction of nation and national identity is not peculiar to Jonathan's rhetoric but a dominant feature of Nigeria's political rhetoric. Even with all the rhetoric of nation building, yet there exists no bond, which could bring all Nigerians together irrespective of the differences in ethnicity and religion, cherished by all the different groups. Many decolonial scholars would argue that the idea of a nation in postcolonial states is a false assumption of a nation that is constructed in the language of modernity. According to Mignolo (2009) the rhetoric of modernity preaches salvation and progress but the decisions about the salvation and progress are not constituted by free decisions made by free people but are based on top-down approach. Hence, the idea of a nation follows that logic of modernity where we witness a colonial creation of nations without regard to the complex nature of the people or their consent. Because of this lack of free will decisions on the status of nations, the task of nation building out of multiethnic entities is proving to be difficult. The discursive construction of nation in political discourse might be less for genuine nation-building purpose than for Jonathan and politicians generally to achieve their political goals. That is why the emphasis in Jonathan's speech is on a journey to progress or as he puts it "march of progress as a 
united and democratic country." This journey to progress emphasizes economic growth measured by statistics while ignoring the social agents.

\subsubsection{Building Ethos through Religious Discourse}

Another strategy Jonathan used in consolidating his credibility is through religious allusions. Drawing from religious discourse to persuade is seen as one of the means of persuasion in politics because religion, as Burke (1970: xi) acknowledges, "[h]as often been looked upon as a center from which all other forms of human motivation gradually diverged." Focusing on the use of religious rhetoric by presidents of the United States of America, O'Connell (2015) identifies three unique kinds of religious rhetoric most common in America. First, religious rhetoric can be merely ceremonial. The president speaks in religious terms because it suits the occasion. Examples would be funeral eulogies and holiday blessings. The second type of religious rhetoric is designed to be comforting and calming. In these scenarios, the president seeks to heal the country with a faith-based balm following events like a terrorist attack, a natural disaster or an assassination. Or the president turns to religious themes to pacify a distressed and angry country, to appeal to the country's better angels. Finally, the third type of religious rhetoric is instrumental. A president uses instrumental rhetoric when he makes a religious argument to convince interested parties to support a personal or policy objective, such as passing a piece of legislation. O'Connell did not mention the common use of God which closes speeches as "God bless America" which appears in most American presidential speeches which the occasions do not determinant its use. The final type, then, is often 
seen as a strategic choice employed as a means to achieving a political point. Jonathan has employed this instrumental use of religion to persuade his audience implicitly.

Even though the occasion was not religious, Jonathan invokes religious entities and religious discourse such as the invocation of God and religious expression such as "seeking the face God" and "in quiet reflection" chiefly as a campaign strategy. The invocation of God in a political campaign seems to reflect the nature of African society described in Yankah (1995) where there appears to be no clear dichotomy between a religious gathering and a political one. Yankah (1995) states that at all times one cannot determine when it is spiritual and when it is purely social or political function in traditional African practices. The central contradiction with the modern African states is that most consider themselves as a secular state. Thus, one would expect that the conflation between religion and politics indicated above by Yankah ought not to be so. Yet religion remains an important factor for political mobilization and a common feature of political discourse.

However, in a multi-religious society such as Nigeria, how do politicians reach wider appeals beyond their own religious background when they invoke religious discourse? It is possible for instance to say that Jonathan's religious discourse is drawn from Christian theology because he is a Christian. How then does he appeal to adherents of other religions? This is perhaps possible through the idea of religious syncretism whereby different religious system are fused or reconciled into a new system. According to Assman (1997), the religious syncretism allows for unity beyond all cultural diversities because "different divinities are not just 'translated' into each other but into a third and 
overarching one which forms something like a common background. Syncretic translation renders the common background visible. It presupposes a fundamental unity beyond all cultural diversities" (p. 34). The syncretic translation allows Jonathan to subsume three fundamentally different religions (Africanity or African traditional religion, Christianity, and Islam) into his use of God.

Because the syncretic translation brings up the consciousness of dealing with the same species in spite of all other kinds of religious alterity, it offers the political class to take the advantage of a deeply multireligious society for their political goals. While the syncretic use of religious concepts such as God might serve to unify people from different religious backgrounds, religion has been long considered in the history of Nigeria as a means of division and tension rather than unity (Tar \& Shettima, 2010). As Fanon (1961) observed five decades ago, religion instead of uniting Africans became a force for division and rivalry that has affected the growth and development of many nations in Africa. Fanon (1968) observes that after independence, as Africans tried to unify and break away from the structures of colonialism, the coming to grips of the two great revealed religions, Christianity and Islam inside a single nation, "splits up the people into different spiritual communities, all of them kept up and stiffened by colonialism and its instruments... and keeps up tribal rivalries through religion" (p. 68).

Moreover, the contemporary dimension of religion in Africa at large and Nigeria in particular, has a global outlook. While people, cultures, and political system may be sharply different, the movement of religion across people, cultures, and political systems has created a transnational space of religious identity. This identity encompasses many 
culturally diversified people referred to as "Children of God" or "believers" in Christianity or an imagination of an "umma" a global Muslim community. Thus, this affects the concept of unity based on geographical location of a nation state.

Linguistically we need to look at what religious entities, processes, and roles are presumed semantically and pragmatically in Jonathan's speech. Explicitly, "God" is invoked three times for example in his speech of intent as can be seen in the following excerpts.

50. Over the years, the Almighty God has made it possible for me to develop a bond with you. (A 3)

51. Therefore, after seeking the face of God, in quiet reflection with my family. (A 75)

52. God bless Nigeria! (A 112)

Consequently, the invocation of God and the religious concepts are used as a strategy of legitimization. For example, to continue from 45 :

53. Therefore, after seeking the face of God, in quiet reflection with my family and having listened to the call of our people nationwide to run, I, Goodluck Ebele Azikiwe Jonathan, have accepted to re-present myself, on the platform of The Peoples' Democratic Party, for re-election as the President of the Federal Republic of Nigeria, in the 2015 general elections. (A 75)

The clause "Therefore, after seeking the face of God, in quiet reflection with my family and having listened to the call of our people nationwide to run" can be seen as a legitimization process where it aims to show that decisions were made after a heeded, evaluated and thoughtful procedure by consulting a higher authority and his family 
members and people nationwide. In this sense, it can be considered "rational" to have consulted other sources, especially divine sources and have explored all the options before making a decision.

Through the above clause, one might conclude that Jonathan's legitimacy is not only that the people have approved of it, but also that God has ratified his decision. He is only obedient to the divine injunction from God - like an obedient prophet rather than a power seeker. There are several presumptions in the text to arrive at the above conclusion. The first is the claim that God exists and Jonathan has a personal relationship with Him. The second is "seeking God's face" is a recognizable form of behavior. The third is the implicit claim that it makes sense and is normal in the speech for Jonathan to tell his audience that he sought the face of God before coming to meet the audience, and fourth is a supposition that a God-sent leader is a credible one above any other consideration. If Jonathan's audience shared in these four assumptions, then by noting the invocation of God in the above clause, the audience would recognize that Jonathan was heavily dependent on a presumed figure of authority and that God's approval not only legitimizes Jonathan's candidature but also guarantees his success in the election. Moreover, the allusion to God is as well an address to the candidate's opponents to view a challenge against Jonathan as a challenge against God. The approval of God presupposes that Jonathan was anchoring his bid on divine moral authority. This means that Jonathan would not have presented himself as a candidate unless divinely selected.

This search for approval from God and family can be a strategy of legitimization to justify courses of action, acceptance and to "naturalize" religious language for political 
goals. This naturalization of religious language for political goals is one forms of ideological dominance where the dominated groups are persuaded to accept the dominant ideologies in case of religious ideology as "natural" or "common sense."

\subsubsection{Building Ethos through Call-and-Response}

In both speeches I analyze, Jonathan kicks off conversational sequence in the form of a question- answer pair, such as the questions "Which other party will give that kind of opportunity?" "Is that the kind of people you want to take over government?" "Is that not the way to stop corruption?" Nevertheless, there is a conversational sequence that repeatedly appears in the speeches in the form of question- answer pairs. The question is "Do you want to go back to the old ways?" in the declaration-of-intent presented in Abuja and "Do you want to go back to the old days?" in the flag off campaign speech presented in Lagos. The structure of the question looks similar to rhetorical questioning, but it differs in some ways. While rhetorical questioning is deployed without expecting an answer (because the answer is strongly implied), in this structure Jonathan not only asks the question but pauses for a breath and receives responses from his audience. Here, feedback is imperative; its rhetorical importance lies in the opportunity to confirm, solidify, and promote cooperative agreement. Moreover, while rhetorical questioning is typically used sparingly, in Jonathan's speech these questions appear several times. Whenever the question is asked, "Do you want to go back to the old ways?" Jonathan pauses and waited for a "no" response from his audience. 
This form of communication is considered common in an African context and is generally referred to as call and response. According to Harrison and Harrison (1993), call and response has a long and rich history prevalent in West Africa as an important component of African oral performance such as storytelling and poetry performance. The concept seems to link to the African worldview that embodies the concepts of collective activity, achieving accord, and unity. Yankah (1995), in his libation performance discussion, also alludes to the structure of call and response. According to him "performance is not necessarily a single-voiced one. Libation prayers offer a unique opportunity for words spoken by Okyeame to be affirmed by a responder.... The response in libation prayer is an intrinsic part of performance" (p. 173-174). The strategy offers Jonathan ways to include his audience as co-participants in the speech event in order to build consensus and construct a positive persona for himself.

The community was strengthened by the choice of the pronoun "we," where Jonathan, before asking a question, begins with the admonition "We cannot go back to the old ways!" as shown in the excerpts below:

54. We cannot go back to the old ways when women and youths were denied opportunities in government and in responsible positions. Do you want to go back to the old ways? (A 86 \& 87)

55. We cannot go back to the old ways where individual freedoms were trampled upon and citizens were locked up for expressing their views or criticising government. Do you want to go back to the old ways? We cannot go back to the old ways! We must continue to have free and fair elections. We cannot go back to 
the era where ballot box snatching and stuffing became the norm. Where your votes never counted. Certainly, we cannot! (A 93, 94, 95, \& 96)

The choice of the pronoun "we" above does not only serve the purpose of inclusivity but also emphasizes Jonathan's goal. The emphasis was made possible by the repetition of the whole clause throughout the speech. The call and answer also constructs a binary identity and image oriented to Jonathan's positive image an ideal leader and his opponent Buhari as "old ways." As with most campaigns, Jonathan sought to define Buhari as a person the voters did not want. However, beyond persuasion, the call and response offers Jonathan a chance to tap into a social power that discourse structure provides him. The question and answer might also strengthen the relationship between Jonathan and the audience by creating a relaxed, casual atmosphere helping to portray a familiar relationship between Jonathan and the audience. While not exclusively African in origin or use, this form of communication recalls some of the discussions about African communicative events as communal and underscores the relevance of audience as active participants in speech events (Asante, 1999).

The call and response model can mask great differences in the relation of power embedded in the discourse in three ways: the unequal encounter, the power in the order of discourse, and the power in the order of the society. The unequal encounter is demonstrated through the formalizations and the conventions of political campaign speeches. The formalization restricts the contribution of the audience to what Jonathan says. For example, this is demonstrated in the ways Jonathan put his audience on the spot to answer the question posed to them. 
Moreover, the obligation to the question was underscored in each case by a pause marked by brief silence. Whenever the question "Do you want to go back to the old ways" is asked all attention is focused on the audience to fill in the silence created by Jonathan's pause. Even though the pause is rhetorical and is in tandem with the cultural norm of call and response, there is an implicit obligation on the part of the audience to respond to Jonathan's questions, and that gives Jonathan sole right to control the discourse as an active participant and the audience as passive. Moreover, Jonathan was the person who decided on what the focus of the questions was and the nature of his audience contributions and when they can talk and not. The questions constitute a strategically ordered sequence, which leads the audience to agree with Jonathan.

From the analysis, it validates Jonathan's authority as the person that is in charge of the discourse, and validates his right to impose demands on his audience by asking them questions on the spot which could block dissident since interruptions are not allowed interruptions structurally (though it might not stop hecklers which someone could yell "yes"). Even if the audience want to have their say, at what point to interrupt appropriately becomes a problem, thus staying silent and feeling powerless is more likely. This goes a long way to show the impact of power behind discourse where the powerful have the ability to linguistically control the nature of the contribution of the non-powerful. Thus, power in discourse has to do with powerful participants controlling and constraining the contributions of non-powerful participants (Fairclough, 2015). The exercise of linguistic control over the discourse and the apparent unequal encounter during the question and answer as indicated above put the audience at risk of social 
control. However, because these communicative exchanges operate within conventions of the call and response, which is based upon "common-sense" assumptions implicit in the society's cultural and social norms, Jonathan's audience might not be consciously aware of the disadvantage of their social risk during such communicative engagements.

According to Fairclough (2015) the people in power are not the ones responsible in the initializations of such marginalization in discourse (though they may and often do benefit from it), rather the working of power is because of the orders of discourse (in Foucault's terms) and the orders of society. As these practices are reiterated and repeated, they congeal as norms. What seems to be the case often is that the ruling class utilizes the apparent normalization practices to their advantage (Fairclough, 2015). However, the discourse also has some effects on social structures. Chilton (2004) argues that the "use of language can produce the effects of authority, legitimacy, consensus, and so forth which are recognized as being intrinsic to politics" (p. 4). These effects of language contribute to social continuity and social change, which legitimize the existing social relations and differences of power. This explains what political actors do when they use language - to retain their grip on power.

The above analysis on ethos indicates that it is still an essential element of persuasion in a rapidly changing electoral campaign. Appeal to ethos constituted one of Jonathan's important campaign strategies and the most used of these appeals in his attempt to appeal to voters. However, ethos is not important only to Jonathan or relevant only in the Nigerian context to induce cooperation and create common interest; it is also an important rhetorical tool around the globe. The Quarterly Journal of Speech dedicated 
its Volume 103, 2017 to analyzing America's 2016 presidential campaign. In the editorial comment, Stuckey (2017) states that "even in the context of a new kind of historical campaign context, some important things remain the same; candidate 'character' is still an important element of the ways we understand campaigns and make political judgments" (p. 2). In fact, two other authors in the same Quarterly Journal of Speech make this poignant conclusion about the significance of ethos in an electoral campaign. They say that "American presidential campaigns and elections are mostly (if not exclusively) about candidates rather than issues. The judgments voters do make about public policy and issues are often influenced by perceptions of leadership and credibility" (Parry-Giles \& Steudeman, 2017, p. 67). The above quotation corroborates the position of Bryan Dean Wright, a former CIA officer and a member of the Democratic Party. Wright (2016) states that "as a shell-shocked campaign and party struggled for answers - coming up with a litany of excuses - they missed the obvious: successful campaigns are built on candidates first, policies second, and coalitions of voters last. We had it completely backwards" (p. 1). The quotations above underscore the valuable role in which individual candidacy serves as an important window into understanding campaign processes. The analysis also indicates that appeal to ethos is a deeply rhetorical act and points to the different ways rhetoric is fundamental to understanding politics. According to Stuckey (2017) "to understand campaigns as rhetorical is to understand the ways in which history, political context, and character interact with institutional structures to produce certain kinds of political formations" (p. 6). Apart from the rhetorical dimension of politics, the analysis also points out that rhetoric is rooted in language. Goodluck Jonathan's appeals 
to religion, nation and national identity, and the invocation of call and response are all achieved through different linguistic means.

\subsection{Political Discourse Operates Indexically}

The choice of English as a language of politics in Nigeria is something that is closely related to the establishment of ethos. According to Chilton (2004), the language one chooses as a medium of communication in politics can signal distance or solidarity, group boundaries or bonding. Jonathan's 2015 campaign speeches were both delivered in English. The choice of English as the medium of political communication in a multilingual country such as Nigeria indexes four different roles: class distinctions, hybridity, appropriation, and transnationalism. These four roles Sandhu and Higgins (2016) argue, are the common functions one can pick whenever English is being used in a postcolonial context. The concept of identity according to Zotzmann and O'Regan (2016) links the "individual with the social and thus allows us to capture the processes by which individuals affiliate with or distance themselves from particular communities, what kind of information they aim to convey about themselves and how this information in turn resonates with the ideas others hold about them" (p. 113). The language one uses is crucial in identity formation and conveys so much information about the person, especially information about the individual's place, ethnicity, social class, and geographical location. 


\subsubsection{Class Distinctions}

Drawing on Edward Said's (1978) book Orientalism Sandhu and Higgins explain how the use of English has created a class distinction - the Self and the Other. The use of English during the 2015 campaign by Jonathan reproduces Said's dichotomy between those who can speak English assumed to be educated and belong to the elite class and those who cannot. In addition, by their knowledge of English, the members of this English-speaking group have access to and can participate in the power forums of politics. Moreover, being equipped with the language of those forums enables these elites to achieve their individual and social goals. The non-English speakers on the other hand who represent half of Nigerian population are tacitly denied the rights to participate in the forum of national political discussion, and most cases are portrayed as uneducated and lower in status. That election campaigns are conducted in this way attests to a general disregard among candidates for the specific interests of this large majority.

For Chilton (2004), the existence of these groups of people speaking a language different from the official language of the state gives rise to questions about minority rights in political theory, questions such as, "do individuals have the right not to have a language imposed upon them which they do not wish to speak?" (Chilton, 2004, p.14). This question draws our attention to the legitimacy of imposing a particular language on people as the only means where they can participate in national politics. However, more importantly, the fact that such a mode of communication excludes the majority of the governed is a strong reason to question the legitimacy of the concept of the so-called participatory and inclusive democracy Jonathan copiously referred to in his speech as 
one of his achievements. The following are some of excerpts where Jonathan prided himself as the person who contributed immensely in deepening the ideals of participatory and inclusive democracy:

56. It is in furtherance of a peaceful, participatory and inclusive democracy that I signed the Freedom of Information (FOI) Bill into law, to expand the frontiers of our fundamental freedom. (A 67)

57. Democracy is a collective action, energized by individual responsibility. Your mandate at this time will inspire in me the strength to complete the good work we have started together. (A 76)

58. I do not intimidate; I expand the democratic space. I give voice to the voiceless and uphold the weak, for the nation belongs to us all. (A 108)

The choice of language in national politics according to Chilton is connected to the institution of democracy because the language may be demanded openly or tacitly, rightly or wrongly for participation in political life. By this, it means that if one cannot speak English in Nigeria one may not be able to participate in national political deliberations. Thus, the choice of a language that mostly excludes those who do not understand English creates a class dimension of the Self and the Other. But it also contradicts to some degree Jonathan's claim about deepening the ideals of Nigerian democracy. Though access to information and participation are the essence of a citizen's right in national life, without a language that provides equal opportunity for citizens to voice out their views, it becomes difficult to "give voice to the voiceless and uphold the weak" as is stated in Jonathan's speech. It has been suggested that "healthy democracies 
require creating an equal platform where people can communicate with fellow citizens and use their linguistic skills to participate actively in, for instance, associations, movements, cultural groups and political parties” (Starkey 2002, p. 9).

Jonathan also suggests that democracy was deepened by conducting:

59. transparent, free, fair, and credible elections. Elections have been conducted across the country with local and international election observers testifying to their transparency. (A 60)

Bamgbose (2011) and Obeng and Hartforth (2002) believe that the concept of participatory democracy goes beyond the ritual of voting to elect governments. It includes a citizen's right to make his or her views and needs known as well as the right to be able to influence policy as far as his or her welfare is concerned. It follows, therefore, that "as long as the language of governance is accessible only to the educated elite; a majority of the citizens will be excluded" (Bamgbose, 2011, p. 27). Thus, Jonathan's choice of English language as the sole language of his campaign contradicts his argument of furthering participatory and inclusive democracy and has become a marginalizing tool.

\subsubsection{Hybridity}

Hybridity can be considered as an inventive mixture of different cultural elements, for example, a combination of global and local practices. One of the influential descriptions of hybridity in postcolonial studies is Bhabha's (1994) notion of a third space "where local linguistic resources mix with global resources to produce new identities" (Sandhu \& Higgins, 2016, p. 182). In Jonathan's speech, there are different local expressions and 
cultural influences in his use of global Englishes. These could represent what is referred to as a "Nigerian English" which is "a legitimate national variety that has evolved, over several decades, out of Nigeria's unique experiences as a post-colonial, polyglot nation" (Kperogi 2015, p. 4). Some of these examples include the metonymic use of names I earlier stated:

60. I see a Nigeria where the children of Mustapha, and Christopher, Ade and Ada, Timi and Bunmi, Nnamdi and Namadi, do not go hungry! (A 102)

In terms of vocabulary choices, there are local features in Jonathan's speeches. For example, there are local names such as Azikiwe, local name of places, such as Yobe, Chibok, Zungeru, Azura, and names of organizations - such as Cattle Breeders Union, Miyetti Allah, and the Market Women Association.

There are other words, which assume meanings that, reflect local understanding and usage, for example, the use of what Kperogi (2015) calls "fictive kinship terminologies" such as brothers, sisters, mothers, uncles, etc. According to Kperogi "[u]nlike in the West where kinship is traced primarily through blood ties, marriage, and adoption, most African (and other non-Western) societies democratize notions of kinship to include social, cultural, ethnic, communal and even national ties” (p. 8). Below are some of the examples from Jonathan's speeches.

61. My brothers and sisters, to encourage entrepreneurship and self-reliance among our teeming graduates. (A 53) 
62. My brothers and sisters, our economy is heading in the right direction and our efforts are yielding positive results. (A 58)

63. My brothers and sisters, this is a growing attestation of our country's growing influence. (A 61)

64. Your brother, Goodluck Ebele Azikiwe Jonathan stands ready to continue in service to you. (A 79)

65. My brothers and sisters, we cannot go back to the old ways! Our railways were allowed to rot in neglect, we have revived and are modernising them. (A 80)

66. That document is to liberate you, we did not influence it, our fathers, mothers, brothers and sisters that are credible came up with it. (B 77)

The use of these family kinship terms might create a sense of community, which is one of the hallmarks of African culture. According to Asante (1999), the role of communication practice in an African context is about not only coherence and participation, but it is also about the stability of the traditional society. The African traditional cosmology of community is being reinforced in the use of "brothers and sisters" and creates a natural connection. Most African societies still consider a member of a community as a "brother," a "sister," a "mother" or "father" even if they are not biologically related. A member of a community is expected to accord all the respects to other members of the community as if they were biological fathers, mothers, sisters, or brothers. All these point to the relevance of community in Africa as a strong cultural force and its use as a political strategy for group coalitions. Jonathan's use of the family kinship terms helps sustain the idea of Nigeria as a harmonious and unified country. Jonathan's use of these kinship 
terms, however, is to define rhetorically citizens of Nigeria as a single family of brothers and sisters, a definition that advances his political ends.

The terms "brothers" and "sisters" also could also be the evocation of biblical allusion popularly among Christians. In Christianity, brothers and sisters is a name that exclusively refer to the followers of Christ. Jesus made it categorically clear in the Bible in the book of Matthew chapter 12 verse 50 which says: "For whosoever shall do the will of my Father which is in heaven, the same is my brother, and sister, and mother" KJV. Christian philosophy embodies a rite of passage in which the whole hierarchy of identities seemed to be dissolved into the family of children of God where "There is neither Jew nor Greek, there is neither bond nor free, there is neither male nor female: for ye are all one in Christ Jesus" (Galatians 3:28 King James Version). This Christian understanding presupposes liberty to slaves, equality irrespective of class or race, and brotherliness or unity of the human family. While liberty and brotherliness can be envisaged in a Nigerian context, it is hard to envisage equality for all people. The ruling class have access to power and privileges, which the non-elites do not have. For example, the presence of heavy securities operatives to protect Jonathan from the crowd during his campaign rallies is enough to show the differences in class and privileges and contradicts the idea of equality and family ties that the biblical allusion of brothers and sisters is meant to convey. 


\subsubsection{Appropriation}

Sandhu and Higgins (2016) describe appropriation as "the act of taking a cultural or linguistic legacy, such as English, and making it one's own through shaping it to fit the local circumstances and to express the local aesthetics and worldview" (p. 183). Historically, English is a colonial legacy and a cultural imposition. However, its retention after independence is assumed to serve the social function of inter-ethnic communication, as it proved difficult to come up with a single indigenous national language that could serve the purpose of English without rancor and division. There are other appropriations of English language. It is the medium of instruction, the language of the law, and language of governance. English language does not only serve official function but it is used to capture African experience through literary writings as Achebe (1993) explains:

The real question is not whether Africans could write in English but whether they ought to. Is it right that a man should abandon his mother tongue for someone else's? It looks like a dreadful betrayal and produces a guilty feeling. But for me there is no other choice. I have been given this language and I intend to use it. I hope, though, that there always will be men, like the late Chief Fagunwa, who will choose to write in their native tongue and insure that our ethnic literature will flourish side by side with the national ones. For those of us who opt for English, there is much work ahead and much excitement. (p. 434).

Although, the former colonial nations still appropriate the language of their colonizers to communicate and make sense of their world, the use of English is not neutral. According to Smith (2012) "language carries culture and the language of the 
colonizer became the means by which the 'mental universe of the colonized' was dominated (p. 37). Language is still one of the means that imperial forces still frame the indigenous experience.

In politics, the English language is not officially required as a language of the electoral campaign. However, the norm is that one is tacitly expected or sometimes openly demanded to participate fully in national politics through the medium of English, in part because of the need to project themselves to the elite and on the international stage as copiously prepared for the seriously intellectual business of leading. Beside candidates (and people already in government) themselves, their family members are traditionally subjected to rigorous analyses by the public which puts their utterances in English on the scales of good or bad grammar. For instance, the recent travails of Jonathan's wife, Patience, proves this. There is hardly a public utterance she made in English that was not subjected to audit.

Since the language of politics in Nigeria is English, it requires that the indigenous language media have to fill a gap in discourse by translating political discourse, especially political speeches, into the local languages most notably Hausa language. This means that almost $80 \%$ of Nigerians would have accessed Jonathan's speech through translations or interpretations into local languages by local newspapers, radio stations, television stations, or international media stations such as the Hausa service of the British Broadcasting Service (BBC) and the Voice of America (VOA). In such cases, the mediator is a mass media service that adapts the message from English to a native 
language. In translating the speeches, the indigenous media select from the speeches those aspects they consider newsworthy, as it is the norm in news reporting around the world. News is never a regurgitation of everything political leaders say in a speech; journalists always impose newsworthiness criteria to make determination on what is worth reporting and what should be ignored.

The excerpt below indicates the different nuances involve in the translation which might be driven by the ideological agenda of the news media.

\section{English Original:}

67. We must continue to sustain the banner of freedom and justice that we have held high in our country. I am proud to say that there are not political prisoners in Nigeria today. No Nigerian has been driven to exile and no one will be, under my watch. (A 66)

Hausa:

68. Wajibi ne mu ci gaba da hakan a kasarmu. Ina alfaharin cewa a yau a Nijeriya babu wani fursunan siyasa. Babu wani Dan Nijeriya da aka tura gudun hijira, babu, ina kuma kara jaddada cewa babu wani da za a yiwa hakan (Leadership Hausa November 14, 2014)

The back translation:

69. We must continue with this in our country. I am proud to say that there is no any political prisoner in Nigeria today. No Nigerian has been sent into exile, no one, I emphasize that no one would be treated this way. 
From the above translation, there is a situation of complete omission of the phrase "the banner of freedom and justice that we have held high in our country" from the original message. There are additions of words such as "emphasize" and "treated." However, the point here is not whether the original words are different from the translated version, but to examine the various levels of power relations involved in the conveyance of the campaign message. Apart from Jonathan's attempt to use various linguistic means to convince his audience that he was the credible candidate, the role of the translator brings another dimension of power and ideology (I need to emphasize again that this form of translation is mostly found in Hausa language).

The interesting thing about the mainstream media in Nigeria is that English language dominates the language of news. Yet, ironically, it is indigenous language media that often reach the largest audiences in broadcast space (Salawu 2016). For example, a 2010 qualitative research report on the BBC Hausa Service says that BBC Hausa has a weekly reach of 23.5 million adults, around four times the size of the audience for the English service in Nigeria. With this number, the indigenous language medium has a wider audience, in terms of expected consumers, than the English language media. For example, the following excerpts shows how the British Broadcasting Corporation (BBC) Hausa service, in reporting Jonathan's campaign in Lagos, utilizes its power to completely evade discussing some of the issues Jonathan raised in his campaign speech: 
70. Shugaba Goodluck Jonathan ya kaddamar da gangamin yakin neman a sake zabensa matsayin shugaban Nigeria a birnin Lagos. Birnin ya cika da dubban magoya bayansa, sannan aka tsaurara matakan tsaro bisa fargabar hari daga masu tada kayar baya. Tabarbarewar tsaro da gwamnati ta kasa magancewa shi ne babban kalubale da gwamnatin Jonathan ke fuskanta. Babban abokin hammayarsa shi ne Janar Muhammadu Buhari na jam'iyyar adawa ta APC wanda ke cewar zai tabbatar da tsaro da kuma yaki da cin hanci da rashawa. A ranar 14 ga watan Fabarairu ne za a gudanar da zaben shugaban kasa a Nigeria.

English Translation:

71. President Goodluck Jonathan has launched his presidential re-election campaign in the city of Lagos. The city was crowded with his supporters with tight security for fear of attack by a violent group. The insecurity situation in the country is one of the problems the Federal government is unable to solve and the biggest challenge facing Jonathan's government. His main opposition, General Muhammadu Buhari of the opposition, APC is saying that he would end insecurity and corruption. The Nigerian presidential election will hold on 14th February. (BBC Hausa November 11, 2014)

The BBC's translations, rather than focusing on Jonathan's arguments, completely diverted its attention to making commentary about the challenges the Jonathan administration was facing. 
This sense of periodic struggles between politicians and the indigenous language media creates an atmosphere of struggle that seeks to redress the balance between the politicians' control over the public. But the question still remains whether indigenous media can offer a space that resists, perhaps even transforms, dominant discourses? According to Martin (2014) 'mediated politics constitutes a deceptive 'spectacle' that obscures rather than reveals the workings of power" (p. 143) and distracts us sometimes from the issues we should be talking about. Martin refers particularly to the traditional media. He said that because traditional media are expensive to fund they sometimes have to depend upon commercial revenues. According to Martin, this has made traditional media too accepting of politicians' official statements even when they are supposed to engage critically with the news. With the rising significance of new media scholars (see Martin 2014, Salawu 2016) new media might offer sites of democratic engagement more than what is obtainable in the traditional media. The new media has provided a massive participatory access to media more than ever before but for them to become an alternative platform for the marginalized people, according to Martin (2014), they have to address their audiences as citizens and participants on the events they cover and have to fight the homogenization of the public domain that reinforced the hegemonic control of the politicians. Despite all these, media still provides a space for rigorous political debate and its role extends to more than judicial, ceremonial, and political spaces of persuasion, to supplying "vast communities with representations of themselves far beyond the constraint of local times, spaces, and political authorities" (Martin 2014, p. 146). Despite this hegemonic struggle between the indigenous media and politicians, English language will 
remain the preferred mode of communication in most formal domains such as education and politics.

\subsubsection{From Postcolonial to Global}

Discussions about globalization are incomplete when very little or no attention is given to the role of English language in globalization processes. Sandhu and Higgins (2016) suggest that the commodification of English language is one of the major consequences of globalization, without which there would be little debate about the role of English as a global language. According to Crystal (2003), English is spoken as a native and as a second language in more than seventy countries and it is learned as a foreign language in more than one hundred countries. As it stands today, English language is widely spoken and established so much that it can no longer be thought of as owned by any single nation (Crystal, 2003). It has also maintained a visible presence in most countries of the world, to the extent that English speakers feel comfortable travelling outside English-speaking areas because at most airports, hotels, parks, they are certain about meeting an Englishspeaking audience no matter how small the audience is. Thus, even though one must acknowledge that the English language is a colonial legacy in Nigeria, as a matter of historical fact, the use of the language by Jonathan shows the desire to achieve a global presence and to have a voice in world affairs. This was demonstrated in Jonathan's speeches where in several instances, he demonstrated an appeal to both Nigerians and international audiences. For example: 
72. Preliminary works have started on my administration's planned re-construction and expansion of the Murtala Muhammed International Airport Road in Lagos to a world class entry point into our country. (A 26)

73. Our partners such as the World Bank group are supporting this with US300million dollars interest free credit, while my administration will back it with over 100billion naira in bonds. (A 29)

74. Nigeria is the first country in the world to develop an e-wallet system to reach farmers with subsidized farm inputs on their mobile phones. Several African countries are now borrowing this transparent and efficient e-wallet system for their own countries. (A 39)

75. Our own Innoson Motors is producing world standard vehicles, and Nissan, Hyundai, and Kia, have set up factories in Nigeria and are employing thousands of our people. (A 55)

76. I see a Nigeria where the green passport is accorded a royal reception the world over! (A 104)

All the above extracts show that Jonathan's audience were not only Nigerians, but also geared towards other global audiences. For example, the phrases "a world class entry point into our country," "Our partners such as the World Bank group," and "I see a Nigeria where the green passport is accorded a royal reception the world over!" apparently, appeal to the global visitors in Nigeria, international partners, and admonition to other countries to accord respect to Nigerian citizens respectively. Jonathan's choice of 
English can reach audiences beyond Nigeria's space to multiple audiences at the same time. Hence, his discourse cannot be limited to "here" (Nigeria) or "there" a particular outside country, but could appeal to both locals and the transnational individuals. Thus, the choice of English language has helped in identity formation that signals a crossborder positionality rather than a national positionality.

However, Phillipson's (2003) question is relevant in the discussion about English language and globalization. Phillipson (2003) asks: Is English language for the globe, or only for globetrotters? His argument is that the English language does not serve all world citizens equally. The language still functions along the similar lines of power imbalances seen in the economic and the political world order where there is a huge polarization between the haves and the have nots. Phillipson (2003) further believes that global usage of English language represents the continuation of the world of colonial order. According to Phillipson, the neoliberal world "has required only minor modifications in the structural and ideological legitimation of English as a dominant language” (p. 24). Yet, Jonathan's use of the global English language tends to portray it as a universal language that serves Nigerian citizens equally.

While it must be acknowledged, that English language has become part of Africans' heritage and is both global and a language of wider communication, the concept of agency in language choice is important in safeguarding the minority languages. The language choice politicians make to communicate with their audience in spite of colonial legacy and global influence is significant in asserting their agency. Thus, 
besides using the English language, Jonathan's choice of language during his political campaign should be strategic and inclusive, what Crystal (2003) calls "bilingual identity." Bilingual identity is a situation where "one of the languages within a speaker is the global language, providing access to the world community and the other is a wellresourced regional language, providing access to a local community" ( $\mathrm{p} 22)$. The point here is that politicians can be protagonists of cultural assertiveness through the promotion of their local languages in ways that are innovative. This means that along preparing his speeches in English, Jonathan can have other versions translated into other languages by his campaign team. This linguistic inclusiveness and democracy would have contribute significantly to increasing the number of people who can actively participate in the local politics and democratic processes, and thus become genuine actors in democratic processes.

\subsection{Emotional Appeal (Pathos)}

Pathos refers to appeal to emotions, and the techniques usually used to arouse those emotions. Pathos seeks to persuade "through the hearers when they are led to feel emotion [pathos] by the speech; for we do not give the same judgment when grieved and rejoicing or when being friendly and hostile" (Aristotle 1356a). Emotional appeal is mostly frowned at as too sentimental and perhaps simplistic, and therefore it cannot substitute for a clear thinking and logical reasoning. However, according to Kennedy (2007) “Aristotle's inclusion of emotion as a mode of persuasion, despite his objections to the handbooks, is a recognition that among human beings judgment is not entirely a 
rational act. There are morally valid emotions in every situation, and it is part of the orator's duty to clarify these in the minds of the audience (p. 40). In Jonathan's campaign speeches, he evokes the emotion of fear through his choices of certain expressions. These terms include "arrests," "prison," "jungle society," references to human right violations and even death, so as to invite responses of fear from people and portray Buhari as an embodiment of all what those words connote. Here are some examples:

77. We cannot go back to the old ways, when women and youths were denied opportunities in government and in responsible positions. (A 86)

78. Do you want Nigeria to be a jungle society? Immediately I suspect you that you have done something wrong I just ask the police or army to arrest you and throw you into jail. Is that the country you want? They say to be strong is to jail people indiscriminately for 300 years. Is that where you want to go? (B 36)

79. They said that is the way to fight corruption. So immediately I suspect your uncle, I can just crate him and throw him into Kirikiri. (B 34)

80. Somebody wakes up and says "O, Nigerian women I am going to give you position." And you ask him when you were a Head of Government, you had a cabinet, I have the list of the cabinet members, there was no one single woman. Not even one in the cabinet. So Nigerian women, you cast your votes and go back to the kitchen and die there or you cast your votes to liberate yourself. (B 65 \& 66) 
81. We cannot go back to the old ways where individual freedoms were trampled upon and citizens were locked up for expressing their views or criticising government. (A 93)

These phrases: "go back to the kitchen and die there," "jail people indiscriminately for 300 years," "crate him and throw him into Kirikiri" carry particular emotions that can be connected to Nigeria's socio- political experience. Something critical to pathos is that it usually appeals to an already existing socio-political situation without which the "pathetic" strategy might fail to generate the kind of emotion it is expected to. According to Finlayson (2014) this already existing socio-political situation works within the "common sense and culture of those being addressed — the sorts of things that might move them to joy, anger, pity or indignation" (p. 143). What Finlayson means here is that appeal to pathos is mostly effective if our audiences share the emotion we expressed. Jonathan seems to tap into the fear that characterized the history of the military rule in Nigeria, especially the fear of human rights abuses and the use of military force against innocent civilians. So when Jonathan mentions that "We cannot go back to the old ways where individual freedoms were trampled upon and citizens were locked up for expressing their views or criticising government," he is specifically referring to Buhari's regime, leader of the 1983 military coup, which was famous for stifling criticism, when journalists were harassed and arrested, and handed jail sentences without trial. Buhari's regime was heavily criticized for various human rights violations across different sections of Nigeria. Moreover, the clause "So Nigerian women, you cast your votes and go back to the kitchen and die there or you cast your votes to liberate yourself" reveals the 
disregard for women Buhari’s regime had during his term. For example, as Jonathan mentions, "there was no one single woman. Not even one" in Buhari's cabinet. "Kirikiri" symbolizes inhuman treatment meted out to Nigerians because "Kirikiri" prison was a notorious prison in Nigeria that was infamous in the terrible treatment of prisoners, having sub-standard living conditions that caused high date rates. The image of jail and arrest was aimed at depicting Buhari as human-rights violator who did not ground his arrests on fair trial and hearing but Buhari's personal judgment. This comparism that Jonathan makes is one of the ways that hegemony is excersised through "a general conception of life, a philosophy, which offers to its adherents an intellectual "dignity" providing a principle of differentiation from the old ideologies which dominated by coercion, and an element of struggle against them" (Gramsci 1999, p. 285). In associating Buhari with the above atrocities, Jonathan is trying to frame the public's perception about Buhari in order to elicit love for himself (Jonathan) and hatred for Buhari.

Thus, Jonathan's appeal to pathos is an attempt to push the argument that allowing Buhari to win the election poses a threat to women, youth, and the entire future of Nigeria and it requires the audiences' immediate action. In order to provoke a whole array of feelings and bring the threat closer to people, Jonathan tries to relate all the terrible things he associated with Buhari happening to family members such as "your uncle," "women," and "youths" thereby identifying victims from vulnerable populations. The evocation of fear involves cognitive mappings. Jonathan's listeners would have to rely on their knowledge of Buhari’s military regime either from experience, history books, or media reports already held in their long-term memory, as well as short-term 
memory. Jonathan may be presuming that such frames are not only known but also accepted as a historical fact. That is why Chilton (2004) says that there is an overlap between the domain of feelings and factual representations and that "such propositions are not easily challenged in explicit dialogue, even when hearers might find them inconsistent with their own representations of reality or find the truth claim faulty" ( $p$. 118). But the claim that facts are necessary elements of emotional appeal might be misleading, as evidence from our contemporary politics shows otherwise which I elaborated more later in this section.

The negative representation of Buhari and the attribution of good things to Jonathan shows the overall strategies of what van Dijk (1997) calls "ideological square." The overall tone of Jonathan's campaign messages created two sides that promote love and hatred. The first side is the "us-group" which include Jonathan and the audience who are depicted in a positive light and generally associated with freedom and progress as is indicated in Jonathan's speech. According to Jonathan, he has contributed in "advanc[ing] the rise and rise of womanhood," "ensur[ing] that women were given more opportunities in government," making sure Nigerians "have the right to free speech," where Nigerian "views, no matter how freely expressed, will not send [them] to prison or into exile." He then places Buhari in the "them-group," depicted as anything but positive, and any "good things" are usually ignored or downplayed and the negative emphasized, as in "We cannot go back to the old ways where individual freedoms were trampled upon, and citizens were locked up for expressing their views or criticising government," "when women and youths were denied opportunities in government and in 
responsible positions." As Jonathan tries to define the terms and the issue in a way that stacks an argument in his favor, he attempts at predicting the causal effects of electing Buhari as Nigeria's president. For example, predicting that people will be arrested indiscriminately and put into jail for 300 hundred years' jail terms, individual freedoms will be trampled upon, citizens will be locked up for expressing their views or criticizing government, women will be pushed back to the kitchen, and youth will be denied the opportunity in government and responsible positions. In terms of speech acts, these predictions can be considered as issuing warnings about the likelihood of these themes mentioned happening to Nigerians if Nigerians failed to re-elect Jonathan. Through the invocation of these fears, Jonathan seems to be rhetorically establishing some moral authority and common moral ground over his opponent and creating an avenue that leaves a place for the audience to infer that Buhari is not moral. Hence, reelecting Jonathan becomes a moral imperative.

In postcolonial discussions, Said (1978) says that emotion is one of the distinguishing elements between the Oriental and the Occidental or between the self and the other. According to Said, the Oriental were portrayed as overtly emotional who always based their decisions on emotional stimuli. Logic and reason, on the other hand, were considered as fundamental to the Occidental and formed the core basis for their decision-making. Although colonial preoccupation relied on so-called rational argument as justifications for their civilizing mission of the native people, such as the social evolution argument, I mentioned in chapter one, one of the colonial instruments was religion, and religion's underlying strategy was the appeal to emotions. According to 
Mudimbe (1988), colonial missionary rhetoric was more of the emotional appeal of salvation and restoration - a kingdom not of this world - than an appeal to rationality. As Mudimbe states, the colonial Christian doctrine rested on "the conversion from savagery and Satan's darkness to the light of civilization and God's kingdom. The transformation is sometimes described as the introduction or restoration of health in a sick universe, the establishment of order in a world of disorder, madness, corruption, and diabolical illusions" (p. 32). Through the rhetoric of saving souls from eternal damnation and progress from poverty and backwardness, colonial forces introduce emotional arguments in the building of an empire and give the natives the reason for hating their "old" ways and reasons to love their new settlers and their ways of lives and hence, themselves. Taking into account this kind of rhetoric of saving souls, Jonathan represents Buhari as an antithesis to the mission of saving, for instance, of saving women from the "kitchen," and saving Nigerians from lack of opportunity to serve their nation. Generally, Jonathan portrays himself as the savior and the person who is leading Nigeria to the Promised Land. The constant repetition that Buhari belongs to the "old ways" (the military order) and Jonathan belong to the "new way" (democracy) is an attempt to control people's emotions.

The use of emotional argument in a political campaign is not only peculiar to Nigeria or colonial politics. The contemporary politics is widely becoming an appeal to emotions (Caplan, 2006). However, in political science, there is an attempt to maintain the traditional view that voters act or should always act rationally, what Caplan calls "the myth of rational voter" (p. xi). The idea of rational democracy in contemporary political 
analysis became entrenched since Descartes' "Cogito ergo sum” ("I think, therefore, I am") which marked a shift from theo-politics to ego-politics. Ego-politics lays emphasis on rational judgment in political decisions, but contemporary political theorists are leaning more towards the conclusion that sound economic policies are gradually being left out from political campaigns speeches and are being replaced by special interests and appealing to audience's biases (see Chilton 2004, Caplan, 2006, Redlawsk, 2006, and Martin 2014 who indicate considerable evidence in the use of emotional politics.) According to Redlawsk (2006) "since politics is concerned at its most basic level with the allocation of scarce resources, and since this means some people get things while others do not, it is not surprising that people's feelings are an important part of any political calculus" (p. 1). In fact, with the rise of populist rhetoric in Europe and the United States of America, emotional appeal is becoming an integral part of decision-making in a political campaign. Populist philosophy shares "three core features: anti-establishment, authoritarianism, and nativism" (Inglehart \& Norris, 2016, p. 6). However, the populist rhetoric is driven by xenophobic scaremongering, peddling a mélange of fear of immigrants stripping them of prosperity and job opportunities, Muslims attacking through an act terrorism, and Mexicans as bringing drugs into the United States of America. Fear here is perhaps one of the most exploited in populist rhetoric. However, the liberals too usually prey upon audience's fears, such as if you vote for this person they will endanger your environment, will change your welfare benefits, will criminalize abortion and gay rights, among others. Whether these fears are real or illusory, the goal of politicians is to use emotions of fear as a strategy of manipulation for the sole purpose of 
winning an election. Thus, when one analyzes the campaign rhetoric across the political spectrum, emotions appear not only to accompany campaign policies, but it is becoming the driving force of political campaign messages.

\subsection{Logical Appeal (Logos)}

Logos is also one of Aristotle's (2007) three means of persuasion, and it is concerned with an appeal to reason. Providing commentary in his translated version of Aristotle's Rhetoric Kennedy (2007) says that logical appeals are either: a) Non-artistic: direct evidence (facts, witnesses, documents, etc.) that the speaker uses but does not—or should not-invent; or b) Artistic: logical arguments constructed by the speaker, of two types: i. An inductive argument, called paradigm, or example, drawing a particular conclusion from one or more parallels ii. Deductive argument, called enthymeme, or rhetorical syllogism, drawing a conclusion from stated or implied premises. Aristotle considers enthymeme (which he called the "body of persuasion") as the strongest of rhetorical proofs because enthymeme unlike syllogism usually leaves out one premise of the argument missing and the audience have to make the conclusion based on "commonly accepted premises - what 'everyone' knows to be the case” (Finlayson 2014, p. 761). When a part an argument is missing, there is an assumption that not only the missing part is right, but it so obvious that is not worth mentioning and therefore difficult to challenge. In Jonathan's speech, we can see the use of both non-artistic and the enthymeme.

The first type of logos Jonathan uses is what Chilton (2004) calls epistemic. Epistemic has to do with the speaker's claim to have a better knowledge, and recognition 
of the 'real' facts. Lists, statistics, and sources mostly back up these claims. Jonathan's main arguments are that he has done much that have contributed to Nigeria's development (economic, education, roads, agriculture, and electricity), progress to nation building, and expansion of the democratic ideals. Jonathan backed all these claims by providing a rundown of various projects his administration has embarked on. Of particular interest to me is the claim about economic growth. "Economic growth" is one of the achievements Jonathan spent a lot of time defending and providing various evidence to support. Jonathan argues that economic growth was a result of the efforts his administration have made to support "inclusive growth and economic development" and that since his effort is "yielding positive results" he is going to "continue to deepen the reforms in the financial sector, in order to sustain the growth of [the] economy." The following are some of the evidence Jonathan provided to back up his argument that Nigerian economy is growing. That Nigerian economy is:

- "Economy heading in the right direction and yielding positive results."

- "the top investment destination."

- "the largest economy in Africa."

- "The 26th largest economy in the world."

- "Exporting several products, including cement."

- Growing "at the rate of 6 to 7 percent annually, one of the highest in the world."

- Having "a GDP of 80 trillion naira (510 billion dollars)" 
According to Chilton (2004) when a speaker focuses on providing statistics, sources, and lists to back up their claim, they are also making the claim that they are rational, more objective, even more, advanced in their mode of thought that their rivals. With this evidence Jonathan provides, he may be presuming that his audience will accept them as authoritative. Based on enthymeme, the logical argument Jonathan is making here with the economic growth can be represented as the following:

a. All developed countries of the world are top investment destinations, have large economies and a high GDP growth (Major premise - unstated premise)

b. Nigeria's economy is the largest in Africa, 26th in the world, etc. (Minor - stated premises).

c. Therefore, Nigeria's economy is growing (Conclusion - stated premises).

According to Aristotle, "[a]11 [speakers] base their praise on fine things that are or seem to be relevant facts. Thus, one should not speak on the basis of all opinions but of those held by a defined group" (1396a). This is why enthymeme is a powerful tool of persuasion because the conclusions belong to the cognitive domain of the audience and are not only drawn from what is necessarily valid, but also from what is true for the most part in the long-term or short-term memory of the audience. Thus, when we consider Jonathan's argument about the relation between Nigeria and all developed countries, the logical links are not explicit; however, the links depends on background assumptions and inferences related to the mental model being built up based on textual and extra-textual contexts. 
From a cognitive frame analysis, Jonathan's argument about economic growth represents different kinds of metaphors that could signal distance or solidarity, and group boundaries or bonding. The fact that the economy is "heading in the right direction," for example, is framed by a journey metaphor which can help define such an action in terms of positive movement and relates the economic growth to a mechanical process (motion), more especially a vehicle (probably train). When a train is on the right track, it will keep moving in that direction. In relation to the economic growth, just as train, an economy heading in the right direction will maintain its current course. The economic growth as a mechanical process might be a conception of growth influenced by the Western notion of neo-liberal capitalist economy. According to Whyte (2003), the metaphor of economy as a mechanical process is affected by the dominance of mechanical and industrial elements in Western culture. Western culture plays a role in Jonathan's conceptualization of economic growth. However, more importantly, Jonathan conception of economic growth is borrowed from a neo-liberal culture where the primary responsibility of a state is to focus on creating a healthy business climate for optimal capital accumulation without paying serious attention to its consequences on social well-being.

Thus, the growth in GDP making Nigerian the largest economy in Africa and 26th in the world, as well as the top investment destination, is mapped as the output and the efficiency of the machine or what Jonathan called the outcomes of "economic growth's "positive results." According to Whyte (2003), the "economic growth" as journey metaphor, shares and can influence our conceptualization of economic growth as a 
dynamic process and a non-static process. According to Martin (2014), the journey metaphor allows the issue to unfold as enthymeme where the metaphor serves "as an implied or unexplained premise or conclusion and relying on the audience to make the connection" (p. 79).

As indicated above Jonathan's evidence to support his claim that Nigeria's economy is growing includes "the largest economy in Africa" and "the 26th largest economy in the world." The fact that the economy is growing "at the rate of 6 to 7 percent annually, one of the highest in the world" with "a GDP of 80 trillion naira (510 billion dollars)" are all the empirical evidence Jonathan brings to support his argument. However, Jonathan's judgment is anchored largely on those things that reinforce monetary value most notably GDP to the exclusion of material use or waste production of cutting timber, and pollutions. In Jonathan's speech, he evaded any discussions on the existence of environmental destructions and its negative impact on human welfare. However, one cannot talk about economic growth without recognizing that economy is a whole system that interacts daily with people and their environment. Jonathan's lexical choices is a misdirection of what actually is the stasis of the argument about economic growth.

There is a need to interrogate the various presuppositions in the logic of economic growth. One of the presuppositions of economic growth is the claim that economic growth benefits everyone. However, for Nigerian populace, for example the Ogoni people, there is always a correlation between economic growth and local victims. For 
example, a primary source of revenue in Nigeria is crude oil, but the drilling of the oil has arguably caused more harm than a blessing to the local people of that area. The oil business is a system in a crisis where hundreds of spills occur every year in Nigeria, damaging the environment and destroying the livelihood of fishing and farming communities in the Delta region. The now Vice President of Nigeria, Professor Yemi Osinbajo's analysis captures the reality of the plights of the people around the oil producing States. Osinbajo observes that the source Nigeria's wealth is from the Niger Delta region and it is 70\% of National earnings and 90\%of Nigeria's foreign reserve. However, Osinbajo further notes that:

The people of historic Oloibiri and the many oil-producing communities in this state and the Delta region of Nigeria, the blessing of oil paradoxically became a curse or at best a burde. Their means of livelihood, fishing and farming has consistently been destroyed by pollution. Worse still, huge resources earned over the years have simply disappeared. The roads, schools, hospitals and social amenities that the oil wealth should have provided are either not there or are patently inadequate. The majority of people of these communities and several parts of the oil-producing states have heard of the wealth that oil has brought but have hardly benefited from it. (Punch News Online, February 10 2017) For example, the issues of oil spillage and pipelines ruptures were omitted from Jonathan's speech, even though at that time, the locals of Niger Delta were in court demanding Shell to pay them about a $\$ 83$-million-dollar settlement. The apparent 
omission of all the problems associated with economic growth might be partly a deliberate attempt to distract people from how the expansion in the number of goods and services and the capacity to produce depletes our natural resources, such as trees that are cut down for timber, and how the use of toxic chemicals and oil spills pollute rivers that the locals use as their primary source of fishing. The locals can relate more closely to the negative consequences of economic growth than the so-called positives, the latter of which are only for the few elites and business executives.

Moreover, the discourse of economic growth seems to conceal the real agents in the economic growth. Economic growth is considered as a process with responsible agencies and affected participants. The agents appear to be Jonathan's economic team and the concerned participants are Nigerians. However, such representation conceals who actually are the forces of economic growth. The primary agents in Nigeria's economic growth are actually those with economic power and wealth who can invest their wealth to doing different businesses. The responsibility of Jonathan's government is to facilitate conditions for profitable capital accumulations that are both necessary and sufficient for the creation of wealth and to some extent less attention to the well-being of the people (Harvey, 2006).

From the local perspective, growth should not just be about GDP, investments, and expansion of market, but also, it should be focused on providing immediate and practical solutions to everyday problems in local communities and satisfying local needs and aspirations so that people can be allowed to develop and use their full potential. Thus 
from the perspective of the local population, it is possible to say that the neo-liberal conceptualization of economic growth, instead of empowering the locals, have deprived them of valuable things such as land, culture, and freedom, in what Harvey (2006) calls “accumulation by dispossession." For locals, the metaphor “economic growth" might actually mean dispossession rather than the literal meaning of "growth" because the logic of the growth does not reinforce what the local people value. Jonathan's lexical choices related to economic growth does not include all possible real-world situations in the Nigerian context. Economic growth should encapsulate multiple ways of experiencing and knowing that are beyond the neo-liberal and capitalists' conceptualizations of growth and include the growth that is dictated by local conditions such as the issue of environment, land, and local means of production.

I am not claiming that knowledge produced from below can automatically provide the solution to the problems in Nigerian society. What I am claiming is that since knowledge are epistemically located in the dominant culture, it is significant to see the contribution knowledge produced from the perspective side of the periphery, and the colonial subjects can contribute to the global discourse in the understanding of economic growth. The understanding of economic growth focuses on economic and national progress on statistical figures while ignoring the social ramifications. The constant repetition of this particular discursive representation of economic can be considered as one of the efficient forms of ideological dominance where the dominated groups tend to accept the dominant ideologies as "natural" or "commonsense." 
For Socrates, it is only the reasoning process, represented in living speech or dialogue (logos), that makes us truly 'remember' what and who we are. Significantly, it is also in this part of the dialogue that Plato offers a positive statement of what constitutes a true rhetoric. The "true rhetorician, the real master of persuasion" (269c-d), Socrates argues, depends on a profound understanding of the nature of the human soul and its parts; this is acquired by the application of the art of reasoning or dialectic (271a-b). That is, the right orator needs to know how many types of soul there are and he must closely observe how each one is affected by different events, and he must watch in turn to see how his persuasiveness affects their conduct. Only then can he be said to be wise, and only then can he be said to be eloquent. Logos is a major component of deliberative rhetoric because it "involves reasoning about the future (whether in the long or short term) and thus requires the use of particular intellectual processes such as abstraction and calculation” (Martin 2014, p. 59).

\subsection{Discussion}

The observations made about Jonathan's speech in the previous sections raise significant issues about the nature of political discourse in non-Western contexts in general and Nigeria in particular. The observations are here broken down into the four elements of my integrationist methodology in the following order: decolonial (intertextuality), cultural rhetoric (a culturally saturated form of verbal communication), classical rhetoric (evasive responses and misdirection), and critical linguistics (binary conceptualizations 
and the interface between discourse, social, and cognition). Running through the four elements is the recognition that language is powerful, but it is not all-powerful.

From the decolonial perspective, Nigerian political campaign discourses can be said to be inundated with intertextual material - that is the explicit presence of other texts or voices in the discourse of any political speaker at a point in time. The concept of intertextuality is a term, according to Bakhtin (1981), all discourse by its nature bears the traces of the other people's voices, and all utterances come with the words of others. That is, the way in which speech is constructed is determined by an awareness of, and reaction to, the speech of the other. In Jonathan's speech, we can identify more than one voice so that Jonathan's own thoughts no longer completely dominated the speeches but could be seen as responses to other voices or it can be said that other voices were speaking through Jonathan's utterances (hence his were modifications of what others said). When we analyze Jonathan's speeches, it is possible to establish some connections with other ideologies or views both from within (precolonial, colonial, and postcolonial) and outside (imperial and global discourses) Nigeria. Some of the discourses and the themes in Jonathan's campaign speeches reflect what would count as development and progress discourses, which have been entrenched in the reproduction of colonial ways through neoliberal discourse and development paradigms that have remained the organizing principle of our social and political lives. The real problem is not development or progress per se but the possible paths of development and progress that we must choose from. For example, we see Jonathan acting in accordance to the neoliberal creed that 
preaches "economic growth" as the best way to ensure human "progress." The question is: why should we assume that "progress," defined as such, is necessary for human happiness and the good life? Some of these programs of economic growth and progress, for example, the Structural Adjustment Programs (SAP) I indicated in Chapter 2, have contributed to more poverty and inequality than the prosperity and the wealth they preach.

Multiple voices from global institutions and agents with divergent origins have today been intermeshed and bound, creating and furthering what we call globalization. Specifically, Western European/American orientations to things have largely now become globalized and are continually being adapted to suit various societies globally, chiefly through the capitalist's neoliberal ideals because it is cover for continental exploitation. The goal appears to make such ideals naturalized across societies, a fact that demonstrates that the cards are still stacked in favor of neo-colonial and imperialist forces and their local collaborators. As Mignolo (2005) affirms "[w] estern neo-liberalism [is] entangled in a long history of the logic of coloniality (domination, oppression, exploitation) hidden under the rhetoric of modernity (salvation, civilization, progress, development, freedom and democracy) (p. 111, italics original). In this light, Nigerian political campaign discourse is not just the reflection of local discourses but also a set of diversified and competing constructions of meaning that requires a cross-cultural and interdisciplinary approach to its study. Some of these local and global discourses are deeply rooted in the past and because these patterns reproduce themselves over time, they 
tend to organize society in a particular way and tends to persist as a "taken-for-granted" truth. Thus, political discourse in Nigeria has to, as a matter of reality, be conceived from a broader social context (both local and global) in order to better interrogate this organized patterns of the society that serve the benefit of a narrow elite at the expense of the vast mass of people. Some of these discourses that show systemic inequality or structural discrimination featured prominently in Jonathan's campaign discourse, as is presumably the case in most of the postcolonial countries in the globalized age.

From the cultural rhetoric perspective, my analysis indicates that Nigerian campaign discourse is a culturally saturated form of verbal communication. However, because of the theories we use in the analysis of campaign discourse in Nigeria which are largely Euro-America in orientation, there is the tendency to neglect the local diversities, hybridities and other dynamics within Nigerian campaign discourse. For example, these dynamics and intersections are locally relevant in the practices of language and communication in Nigeria and capable of reflecting the society's values and common traditions. For example, one of the hallmarks of African culture is the idea of communalism. Jonathan's campaign discourse offers a significant reflection of this idea of communalism through a type of communication called call-and-response and fictive kinship terms of "brothers and sisters." According to Moemeka (1998), Africans believe that community is more important than the individual is and believe in collective responsibility and cooperation. The call-and-response depicts this communalism where the audience was involved in interactive model of communication that offered them the 
opportunity to be both co-interlocutors and spectators or listeners. The fictive kinship terms such as "brothers and sisters" also show a belief in inclusivity where fellow Africans see themselves as connected to each other as one people. But in a postcolonial context there is another dimension to the use of terms such as "my brothers and sisters." The use of brothers and sisters could be a construction of the state as a family, signifying that we have same ancestral lineage. That is not necessarily the case in postcolonial Africa where people of different religious and cultural heritages have been brought together within borders drawn by heedless colonialists, the construction of the state as a family becomes a rhetorical performance. Thus, a postcolonial Africa is becoming increasingly interconnected in a paradoxical manner, such that the creation of the state, instead of consolidating our common cultural existence, encourages conflict and imbalance. This means that while language is powerful, it is not all-powerful as a rhetorical tool to get people to put aside their historical, local ethnic and religious for a greater good. Mbembé (2001) affirms this ambivalent nature of the postcolonial condition when he says that "what passes for social reality in sub-Saharan Africa is made up of a number of socially produced and objectified practices [that] are not simply matters of discourse and language" (p. 6). Sometimes it takes actions beyond language to achieve some greater good. The issue of nation building, for example, cannot be resolved with just words; it has to be backed up by actions.

Another important dimension to local understanding of political discourse is the issue of translation that is a significant factor in the understanding of political discourse in an indigenous space, but which has been too often ignored. Although English is the 
language of politics in Nigeria, it is not the language of the majority. This means that political speeches have to be translated into the various indigenous languages. As I indicated in my analysis, the business of translation, however, is not neutral. It involves controlling the quantity of the original text, reorganizing its structure, transforming the message and supplementing messages. Thus, translation has the potentiality of leaning towards the ideological position of the political group(s)/actors whom the media house/translator is more or less openly or tacitly lending its voice to. The different ideological position between the indigenous media and the elites bring up the issue of hegemonic struggle between the indigenous media and the political elites. These are some of the subtexts that are pertinent when analyzing discourses in postcolonial Africa, which attest to the value of contextualizing our analysis within the local postcolonial context. As Lyon (2015) indicates, "the examination of a text within its cultural contexts seems to be the most revealing of political insight, and the most useful to political and cultural rhetorical studies" (p. 158). There is a tendency to be global in our analysis. Consequently, we neglect local issues such as the issue of language choice in politics and the language of the majority. The cultural forms of communication I have pointed out are some of the central issues that need more attention in the contemporary political discourse analysis in Nigeria. Of course, I do not mean that there has not been analysis that attempt to reflect on diverse cultural forms of communication in Nigerian political discourse (see Adegoju \& Oyebode, 2015 and Chiluwa \& Odebunmi, 2016). Nor do I suggest that there has been no theoretical attempt to take note of non-Western forms (see Yankah 1995, 2012). But what I do want to stress here is that endeavors that bring 
decolonial and cultural rhetorical approaches to discourse analysis do not yet exist. In this dissertation, therefore, I affirm the centrality of local cultural ways of knowing and local voices in the rhetorical and linguistic analysis of Nigerian political discourse.

The classical rhetorical perspective indicates that there are evasive responses and unwillingness to address directly the problems by Jonathan. Responding evasively, according to Obeng (1997), is a face-saving strategy that attempts to "avoid candid or obvious statement and choose to communicate indirectly, especially when the topic of the discourse "communicates difficulty"' out of political interest and political necessity (p. 17). Chilton (2004) categorizes evasive responses into selective reality, which is being economical with the truth, and strategic ambiguity, where politicians employ ambiguous concepts which their meaning cannot be settled based on empirical evidence or linguistic usage and these include concepts, such as freedom, democracy, justice, and liberty in order to prevent the people from rounding them up in clear conclusions. As indicated in my analysis, Jonathan did not completely ignore the facts on the ground about insecurity, corruption, and unfocused government, but adopted the selective reality that included various kinds of omissions about corruption allegations against his government through “"blurring' or 'defocusing' unwanted referents, be they objects or actions" (Chilton 2004, p. 34). He also used verbal evasion by diverting attention from the real activities of Boko Haram to redirect attention to his opponent (Buhari) and the allegation that Buhari's past (military) administration failed to buy military equipment that could have been useful in the fight against Boko Haram. Jonathan also engaged in an outright denial that his 
government was unfocused. All these represent the way Jonathan used language to create a scenario that could favor him and make him preferable.

In Jonathan's case because of the nature of insecurity and the magnitude of corruption allegations against his government, which were very cogent grounds for the electorate to vote him out, he needed to create urgently an alternative reality, independent of what people might think or what actually existed on the ground. However, as we know from hindsight, it became impossible to make his own version of reality tenable in the people's experience. This lack of confidence is reflected in the election results where Buhari got 15.4 million votes against Jonathan's 12.8 million. But it was not only Jonathan who engaged in deploying diversionary strategies to present alternative facts. Erecting half-truths or even total fabrications is in the nature of political campaigns, according to Benoit (2007), who categorizes the various modalities to include acclaiming, attacking, and defending (Benoit, 2007). Political campaign is a comparative act by its nature, where "[e]ach candidate strives to obtain enough votes to win by persuading voters that he (or she) is preferable to other candidates," hence whenever a candidate is attacked, a timely and a good defense has the potential of restoring the disequilibrium that the attack might have caused. Since such attacks usually resurrect some undeniable facts on the ground or from the forgotten past, politicians have to defend themselves in any feasible discursive manner, and when they do that, they are aware that defending could only be done through lying or providing alternative facts. 
Heinrichs (2007), however, contends that one should not expect politicians to focus on truth in politics because, to him, political rhetoric "unlike logic, doesn't seek the truth-only the best choice" (p. 33). Should we then assume that everything politicians say is all lies if we take Heinrichs' contention to be right? Chilton's answer is no. Chilton says "[o]ne cannot lie if everyone believes all the time that all communication is mendacious" (p. 20). What Chilton apparently means is that the word lie in the sense of falsehood exists in language because the majority of what humans say is truth; hence, lie is the recognizable alternative. If everyone believes that all the time communication is all lies, then it means one cannot lie. When people interact with politicians, they still work within the mechanism that language users follow in order to understand each other. For example, using Grice's (1975) maxim of quality, when people communicate with politicians they assume that the politicians will try to make their contribution one that is true. They will not say what they believe to be false and will not say that for which they lack adequate evidence. However, the global reality of our time is ever challenging us to rethink these claims, whether of Chilton or of Grice, because the times suggest that, at least with regard to politician's so-called truths oppose every evidence we can sense at all. Violating the expectations of people relating to truthfulness when all reality and the facts on the ground are visible for all to see is what is called the defense of the indefensible. Although language has been made the machine of the business of politics, it cannot always maintain its power to amuse, enchant, invent, and comfort, when people's evident suffering and interests are in stark oppositions to the politicians' linguistic frames. The constant reality is that people will interpret campaign messages through the 
prism of their own preexisting experiences, whereupon politicians seeking to be elected manufacture means of gaining power other than through the fact based consent of the electorates. The gap between factual evidence and Jonathan's language indicates that language is powerful but is not all-powerful. It rearranges our thoughts and perceptions but there are other factors also contributing to our cognitive models.

The critical linguistics perspective reveals that binary conceptualizations are frequent in political discourse. We have seen the binary tendency at work in the constant repetition of the question "do you want to go back to the old ways?" which aimed at the binary model of distinguishing between "the old ways" (of Buhari) and "the new way" (of Jonathan). Such dichotomies were also the primary means Jonathan used to forge or claim group identity with inclusive "we." The binary classifications work within van Dijk's (1997) ideological square where the political space is classified between "us" versus "them." Those who share the same values and commitments with us are "good" versus those who do not, who are "evil." The chief weapon of dichotomization is the emotional appeal where the main division is between (our) hopes and fears (of them). When Jonathan defines Buhari as dangerous, he might gain support of all who share this view or who need a scapegoat to rationalize Jonathan's own failings. Jonathan, as the beneficiary of the existing economic and social institutions, needs to create hope and assure people that Nigerian institutions are sound, that their own success reflects his merit to be reelected, and that the failures have chiefly to be blamed on past leaders such as Buhari. People who are hurt by Jonathan's policy are being manipulated in the binary 
conceptualization of opposition; there are no third (or fourth) categories. Such thinking blinds us to innovative solutions available outside the binary system we desperately cling to.

Finally, just as the social context of discourse does, human cognition plays a significant role in its production and interpretation. It can be argued that Nigerian analysts largely recognize that political discourse cannot be understood solely on its internal discursive character; meaning also needs to be seen as a dialectical relationship between discourse and other cognitive systems. In this light, only a handful of scholars, such as Taiwo (2008) refers to the mediated role of complex neural systems in communication, which is indeed pertinent. Through the application of Chilton's (2004) cognitive perspective to the analysis of political discourse, my analysis reveals crucial moments in Jonathan's speeches where meaning depended in large part on the interface between linguistic elements and complex cognitive structures. For example, the analysis of figurative manipulations of language (e.g. metaphors of economic growth, metonymic use of personal names and places), deictic expressions (e.g. the inclusive and exclusive use of "we") as well as call and response in Jonathan's speeches, suggests "that meaning is not 'contained' in words, nor is it a thing to be discovered, or uncovered; rather meaning is constructed by human minds on the basis of language "in use and the understanding of 'background' knowledge” (Chilton 2004, p. 61). In other words, meaning is not stable, but alters within contexts, and as shaped by the tact the strategy of the language user. 
Jonathan's use of the deictic "we" varies depending on the purpose and particular rhetorical point that he tries to make in any particular speech. In analyzing this further, it is discernable that the deictic "we" suggests both the inclusive (self - Jonathan and other - audience) and exclusive (self- Jonathan and his government) at different points of the speeches. However, the meaning of "we" in Jonathan's speech is not always expressed in an explicit form, nor is it always possible to determine it purely through his syntactic choices and morphological category. What this suggests is that the different linguistic choices that politicians make, such as their wording and phrasing, do not automatically translate into a fixed message their audience receives. Such linguistic choices are much more efficient when the audience shares similar beliefs and perceptions, as well as appreciate the intended meaning. However, given that there is sometimes lack of correlation between the beliefs and opinions shared between the politicians and the audience, the politicians need to enhance their strategic use of language to align with common dominant ideologies shared with the public. As I indicated in my analysis, Jonathan's attempts to defend himself against the allegation of corruption, insecurity, and lack of focus made against his government did not correlate with what the evidence on ground showed. What Jonathan did in his speeches could be further understood in the light of Chilton's argument on the relationship between language and politics. Chilton in his discussion of the nature of language and its connection with politics identifies three principles: 
The first is that language and political behaviour can be thought of as based on the cognitive endowments of the human mind rather than as social practices. The second is that, despite this point, language and social behavior are closely intertwined, probably in innate mechanisms or innately developing mechanisms of the mind and probably as a result of evolutionary adaptations. The third principle, again despite what the last point might be taken to imply, is that human linguistic and social abilities are not a straitjacket; rather language is linked to the human cognitive ability to engage in free critique and criticism. (p. 28-9)

What Chilton's explanation avers, and as this analysis corroborates, is that rather than thinking of language largely in terms of vehicles containing information, meaning in language is rather a blending of linguistic, social, and cognitive structures to produce different types of impact. Thus, when analyzing the language of politics, our theoretical perspectives should not only investigate language as a social phenomenon but also as a mental phenomenon. Hence, on this basis, we find that meaning creation is a sociopsychological process. However, because of the cognitive dimension in politics, and its dynamicity, it is never entirely clear in advance how language use will play into the audience's background assumption about given issues at any period. But once politicians have found a style that works for them, they are likely to continue to put it to use as much as possible, as we have seen in Jonathan's 2010 and 2015 campaign speeches. A straightjacketed audience, one could say, appears to deserve a straightjacketed speech. Jonathan used religious rhetoric and the deconstruction of the relevance of ethnicity in 
politics in 2010 and they seemed to have worked in his favor. In 2015, he redeployed the same tools. This shows that in politics utterances are produced on the expectation (by the audience) that the audience shares some common ground with the speakers, while in reality it is merely the speaker tactfully managing the audience's expectations. Thus, a successful communication is the one that speakers discreetly take an imaginative leap into the minds of their hearers to feel and know what they are expecting. The understanding of these (supposedly) shared sentiments has been one of the principal ways by which politicians have discursively legitimated their interests. 


\section{Chapter Five Summary, Conclusion, and Future Research}

\subsection{Summary and Conclusion}

Mainstream critical discourse analysts often pride themselves on their interdisciplinary and/or multidisciplinary approaches to the analysis of political discourse (Chilton 2004, Fairclough, Wodak \& Meyer, 2016). They incorporate knowledge from other disciplines such as sociology (Fairclough 2015), cognitive linguistics (e.g., Chilton 2004), social cognition, (van Dijk 2005), and history (Wodak 2011), among others, into what would otherwise have been purely linguistic investigations. These interdisciplinary and multidisciplinary approaches are held up as the best methods to guarantee rigorous analysis and greatly enhance the appreciation of any given discourse. However, implicit in these approaches is a belief grounded in universal rationality, what Grosfoguel (2011) calls the "point zero" perspective. The "point zero" perspective is a "god's-eye view" that hides its local and particular perspective under an abstract universalism. Historically, in Nigeria, the "point zero" perspective has allowed the values and norms assumed in the CDS approaches to be ultimately taken to be universal with little or no thought given to their cultural origins.

As these CDS perspectives become globalized and internationally dominant (through institutions such as, Western journals, universities, research agendas, and international conferences), practitioners more and more neglect other underlying analytical frameworks and context-specific conventions of investigating communication, 
such as the moral and social paradigms that imbue in African conditions. This is not to say that Africa's moral and social concerns, (such as injustice, human rights abuse, corruption, and domination), do not figure into American and European analyses; obviously, they do. It is instead to stress that the nature and extent of these concerns differ across cultures such that in adopting the western-embedded approaches, there is the tendency to over-generalize, and consequently to neglect local historical, social, and cultural factors. For example, through the analysis of Goodluck Jonathan's campaign speeches, I have revealed how rhetoric is used to navigate Nigeria's diverse ethnic and religious backgrounds, and examined how some forms of local practices have evolved and played out in the emerging globalized contemporary discourse. These issues point to the fact that there is no detached political rhetoric. No matter how much politicians reject or neglect their society, their rhetoric is always deeply rooted within their social and cultural landscape, thus acting as a mirror for the massive cultural undertones of the society. For example, as my analysis indicated, Jonathan's campaign discourse points to the function of intertextuality in Nigerian political discourse and provides a space for, as Smith (2012) would say, "a constant reworking of our understanding of the impact of imperialism and colonialism as an important aspect of indigenous cultural politics” (p. 25).

In this dissertation, I made the case that there is the need to complement the multidisciplinary approach to political discourse analysis with critical attention to cultural pluralism. I drew attention to the often unstressed diverse forms of communicative 
practices and hegemonic struggles in Nigerian political discourse that are beyond the dominant concerns in other parts of the world, in order to help promote the dynamic interdisciplinary stance among political discourse analysts on the one hand, while bringing attention to the limits of western-embedded approaches. I am aware that in a globalized context, values and other cultural contents are flowing both ways, just as people and commodities do, and many boundaries are dissolving, which makes it difficult to extract the exclusively local or the indigenous material in Jonathan's campaign speeches. However, to say that there are local issues does not mean that such issues and traditions are exclusively Nigerian. Rather, as Atanga, Ellece, Litosseliti, and Sunderland (2007) assert, such a stipulation means that some issues may be more salient in or closely relevant to Nigerians than most outside contexts. Thus, I believe that identifying topics and characteristics that are locally prevalent in the Nigerian context is not to essentialize, nor to assert that such "traditions" and/or identities are static. Rather, it is an attempt to take a reflexive critique of the dominant theories by allowing for locally - and culturally - derived values and knowledge in order to prioritize and structure research, while at the same time not losing sight of the power relations that inform difference both internally (local) and externally (global).

It is against these cultural practices of language and communication that I propose an integrationist approach to critical discourse studies that brings together rhetorical (classical and cultural approaches), critical linguistic, and decolonial approaches to the analysis of political campaign discourse in Nigeria, ultimately going beyond West- 
centered theories and centering Africa's cultural diversity in the overall argument of my project. My dissertation brings attention to what Jonathan's campaign discourse tells us about the Nigerian society, and it points to the fact that different discourses embody different experiences and realities, in congruence with Whorf's (1956) claim that specific languages embody particular cultural worldviews. This interdisciplinary approach also brings attention to the limits of any discipline-specific focus in the analysis of political discourse.

Though this integrationist approach that gathers rhetoric, linguistics, and decolonial perspectives is long overdue, there are various factors which have militated against this theoretical and methodological fusion being satisfactorily achieved so far in critical linguistics projects in Nigeria. One is the isolation of language studies from other social sciences, and the domination of linguistics by a plethora of formalistic approaches. Another factor is that throughout Nigerian universities, there is yet no department of rhetoric or even departments that focus on teaching different rhetorical theories. The irony is that most Nigerian discourse analysts often use rhetorical terms such as appeal to character, reasoning, and emotion (see Adetunji 2006, Chiluwa 2012) without calling out their technical rhetorical names. This means that discourse and rhetoric have similar concerns but the accidental appropriation of rhetorical terms by discourse analysts does not necessarily build a bridge where an interdisciplinary approach can be usefully forged.

The cooperation between linguistics and rhetoric in the analysis of political discourse is no longer optional but should be perceived as a necessity, because it is 
difficult to imagine a Nigerian public sphere without the strategic use of rhetoric. By its nature, politics involves making choices between (in most cases) two polar approaches (represented as good and evil), and persuasion is integral to helping people make appropriate decisions. The ability to change people's minds from uncertainty to making a final determination often involves transformations through argument. In my analysis, I consider rhetoric in a contemporary Nigerian social and political life and assess its benefit as a tool of political theory. According to Martin (2014):

There are many ways to persuade, no doubt, and threatening violence is one of the most common. But human communities are unique in their use of speech in making persuasion a matter not always or exclusively of brute force, but also of mutual understanding, shared perceptions and interpretations. (p. 1)

Rhetoric offers us a key to understanding the nature of how the soft power of the pen (and words) at certain times works more effectively than the blunt power of the sword (and weapon). This phenomenon, therefore, demands that we examine the ways in which people are discursively manipulated.

My analysis draws from the classical rhetorical terms, such as apologia, stasis, enthymemes, rhetorical appeals (ethos, logos, pathos), and the three genres of rhetoric (epideictic, deliberative, and forensic). However, I do so by examining the pervasive and mediating role of rhetoric in the Nigerian political context, in order to broadly examine rhetoric not only as the art of persuasion but also as a way of understanding the different ways language functions in the establishment of social relationships and social identities 
in a non-Western context, particularly in Nigeria. Nigerian political discourse reflects varieties of influences and combinations based on Nigeria's history of colonialism, internal flows and migration within Africa as well as the ongoing globalization process. There are still some local practices that have found themselves adapted or blended into contemporary Nigerian communicative practices, such as the idea of a communal, interactive model of communication. For example, in the call-and-response model, the conceptualization of Nigeria as one family depicted through the constant use of "my brothers and sisters" by Jonathan is one clear instance of this. Thus, the instrumentalities of ethnicity and religious discourse in Jonathan's campaign speeches all point to some of the local ways communication is being used in the Nigerian political context to frame and present a unified national identity.

Another critical dimension to the local practices is the idea of the triadic communication process (speaker, mediator/translator and receiver) which is often taken for granted. Since the English language is not accessible to vast majority of the population for various reasons, most Nigerian audiences get access to Jonathan's speeches primarily through translations. The triadic communication process is in contradistinction with the model of campaign discourse found in the West where the focus is sender-receiver. The triadic model of communication is not a new thing in the African context, especially considering Yankah's (1995) discussion of the Royal spokesperson Okyeame that was common in Ghana and some Western African countries. The Royal spokesperson model of communication is similar in many respects with the 
situation in the Nigerian politics, where someone has to translate the message before it gets to the target audience. But in contrast to the role of Okyeame, who is the official spokesperson of the chief and is required to be faithful in reporting the message of the chief without parody or mockery, the role of mediators differ in this respect. The translations reveal some power dynamics and the role of the intermediaries in subverting the intention of politicians or colluding to exploit the masses. Whatever the intention, a translated campaign speech cannot be the same as the original speech presented. Interestingly, even though people gain access to Jonathan's speeches through indigenous languages, it is not possible to discount the influences of global discourses. For example, Hausa speakers might gain access to Jonathan's speeches through both local media and from the foreign radio stations such as $\mathrm{BBC}$ and VOA media outlets among others. This points to the role of globalization and media imperialism in the flow of discourses.

Whenever we advocate for the integration of rhetorical approaches to the analysis of political discourse, the main question that we need to answer is, what is it that rhetoric offers that linguistic analysis might miss? Examining political discourse through the lens of rhetoric presents us with access to the ways in which ideas are fashioned into persuasive arguments in order to win the assent of an audience. As Martin (2014) affirms, "[t]o understand human beings, then, we must not only observe their behaviour but also interpret the meanings they employ to construct a world” (p. 9). In my analysis, I have shown how Jonathan invokes the idea of nation-building, religious discourse, and the speech act of apology, among other things, in a concerted effort to rhetorically build a 
positive public perception of himself and gain high credibility in the eyes of Nigerian voters. Interestingly, language is the primary medium through which the positive image was constructed. Through the choice of different grammatical elements such as the selection of the deictic "we," the use of emotive words, tenses, and metaphors, Jonathan tries to construct a discursive image that aims at positively shaping people's thoughts about him and his government. This shows that there is an overlap between rhetorical goals and linguistic interests, as rhetoric mobilizes linguistic resources through the production of persuasive speech.

In the second level of analysis, I present a socially and linguistically oriented view of political discourse. My analysis recognizes the important position that language has always occupied in both political and social life. My dissertation centers upon the concept of ideology and especially on the allied concept of hegemony, in the sense of a mode of domination, which is based upon alliances; the incorporation of subordinate groups, and the generation of consent. I primarily draw on Chilton's (2004) cognitive and evolutionary approach to political discourse analysis in analyzing Goodluck Jonathan's 2015 campaign speeches. Chilton grounds his theory in linguistics including Grice’s cooperative principle, Sperber and Wilson's relevance theory, and Chomsky's generative linguistics as well as CDS. The advantage that Chilton's approach offers is that it is grounded in linguistics and therefore contributes to the conception of an integrationist model of analysis. His approach centers on a cross-fertilization of linguistic theories (generative and cognitive linguistics) with rhetoric and critical theory. Three propositions 
from Chilton's theory guided my analysis. First, political discourse operates indexically. We have seen how Jonathan's choice of English language as the only medium of his campaign discourse signals distance from the non-speakers of English and solidarity with elites. Jonathan's choice of the deictic "we," personifications, and metonymy were also associated with the idea of nation building and the establishment of community, in the attempt to convince the audience that they and Jonathan belong to one group. Second, there is the binary conceptualizations of political discourse. Through various repetitions of lexical choices, especially the choice of "old ways" versus "moving forward," Jonathan frequently attempts to represent issues and discussion in a dichotomous way. The binary conceptualization also helps Jonathan to form group identity represented as "us" (Jonathan and his supporters) versus "them" (Buhari). Finally, political discourse operates as interaction. For example, the enactment of call-and-response helped Jonathan facilitate interaction and participation but on the other hand, the call-and-response also signals hierarchy and power. Some of the features that signal power and hierarchy revolve around who has the power to initiate, interrupt, make demands, and otherwise control the nature of discourse.

While Chilton's approach is an important contribution to a theory of political discourse analysis, its western-embedded orientations might make us overlook important dimensions in Nigerian discourse. Some Nigerian discourse analysts, (e.g., Taiwo 2008, 2010, Ajilore, 2014, Adegoju and Oyebode, 2015 and Chiluwa and Odebunmi, 2016) who employ CDS theory to analyze Nigerian political discourse did not stress some 
important decolonial issues, probably because the focus of their analyses tended to stick closer to the immediate political context of the speeches without necessarily stressing the links with earlier forms of hegemonic discourse during colonialism and their reenactment in the neoliberal discourse. Moreover, as global flows and exchanges continue to proliferate new approaches will become more and more urgent and will open up fundamental issues of theory and method in analyzing political campaign discourse in contexts such as Nigeria.

This indicates the need for African political discourse analysts to not only incorporate rhetorical and linguistic analysis in our studies, but also into situate our analysis within decolonial methodologies because decolonial methodologies also privilege and legitimize African epistemologies. Through decolonial methodologies, we can begin to represent and portray African position from a broader perspective, taking into cognizance how our material, political and socio-economic conditions are deeply imbricated in multiple histories ranging from precolonial context to our encounter with colonialism and the new global order. The use of decolonial here refers to:

Specifically, to tell stories from the perspective of colonized cultures and communities that are working to delink from the mechanisms of colonialism. This delinking encourages a shift to a set of knowledge-making practices that don't reinforce colonial logics, which also form the roots of systems like capitalism. (Powell et al 2014, p. 7) 
Apart from delinking from specific Western languages, as indicated earlier, other colonial legacies constantly frame the African experiences. For example, some of the structures of colonialism are being reenacted through neoliberal discourse and development paradigms, championed in some cases directly by postcolonial indigenous leaders, or by international development organizations. These theories of development present a narrow path to economic and political development, which all countries must follow. Jonathan's description of the economic growth seems to be influenced by these neo-liberal economic policies. The basic argument behind economic growth is to facilitate conditions for profitable capital accumulations that are both necessary and sufficient for the creation of wealth, though too often pay less attention to the well-being of the broader people (Harvey, 2006). The neoliberal economic philosophy pays little attention to the local realities, such as pollution and the collapse of ecology, but is, rather, interested in the accumulation of wealth and expansion of markets. Understanding of growth from multiple perspectives can help us deconstruct neoliberal ideas of economic growth and provide a space where the values and the local systems of indigenous people can be projected. Economic growth should be about the people. The growth should not just be about GDP, investments, and the expansion of markets, but also, it should be focused on providing immediate and practical solutions to everyday problems in local communities and satisfying local needs and aspirations so that people can be allowed to develop and use their full potential. For our analysis to be useful, we need to heed to Smith's (2012) call that research is about people. It affects people. It can save and destroy lives. With Smith's call in mind, it can be pointed out that it has become a matter of 
urgency for political discourse analysts "to develop frameworks - reliant on growth and sustainability, instead of negation and destruction" (Powell 2014, p. 10).

My dissertation, therefore, takes an emancipatory political stance with the belief that Nigerian political discourse has been constituted heretofore by colonial and imperial legacies. It sheds lights on and works towards analyzing and uncovering the opaque nature of how Nigerian elites use these global discourses to legitimize their power and perpetuate inequality.

\subsection{Future Research}

The primary task of my research was to demonstrate the richness of conceptualizing political discourse analysis within its immediate and larger context and the effectiveness of an interdisciplinary approach — which I called an integrationist approach - in unmasking the different forms of hegemonic struggle in discourse. My analysis reveals that hegemonic discourse in a Nigerian context is neither autonomous, nor flowing from a single dominant power, but constituted by multiple, heterogeneous, and complex processes that connect the local and the global. The findings from my dissertation present the merits of combining decolonial epistemologies with the analysis of politics; from the perspectives of linguistics and rhetoric, particularly, the potential of such approaches to open up ways of knowing that we otherwise would have taken for granted or completely marginalized based on our positionality as academics. The awareness of the diversity of cultural ways of knowing and theorizing will also encourage us to learn not only from 
dominant Western systems of knowledge, but more widely and more inclusively, from culturally different, historically marginalized ways of thinking and knowing.

However, having explored what Jonathan attempted, both linguistically and rhetorically, I have opened up a new field of questions beyond the scope of this dissertation: a topic that demands its own extensive critical analysis: the exploration of the countervailing forces of the larger political context that worked against Jonathan's best efforts. Linked to this new area is the question of the potentialities of discourses of resistance, arising from the growing spread of social media, affording new challenges and transforming the apparatus and structures of hegemonic power. Although Jonathan and Buhari both recognized the significance of social media during the election, events in the world have conspired to make this a more complex question (e.g., the Arab Spring and other populist movements) representing resistances "from below." Unfortunately, the authorities often reassert themselves, maybe with slightly different leaders at the helm of affairs. Moreover, Buhari's victory might be because of the support of other powerful forces including religious and ethnic factors. These complex issues exploring Jonathan's defeat and the role of discourses of resistance should drive future research in finding out how far discourses of resistance from below are capable of challenging the organized system that historically works for the benefit of the elite in Nigeria.

Thus, an institution that creates incentives for true bottom-up, thorough-going incentives for economic progress, a system that truly redistributes income and power, has yet to become available in Nigeria. The fact that Jonathan has lost the election does not 
mean that new discourses about economic and social institutions will automatically emerge. The parameters of economic growth such as investments and GDP, upon which Jonathan based his 2015 campaign, have not changed. The new Nigerian government has yet to alter the system of "creative destruction" where it stands in opposition to inclusive economic and political institutions. As Acemoglu and Robinson (2012) rightly observe, "Once society gets organized in a particular way, this tends to persist" (p. 44). For some elites (e.g., Jonathan) to lose their hold on political power does not in any way alter the organized system of global capitalist rationality that has dominated Nigerian political and economic discourses. This global capitalist rationality has rather become what Foucault would call "the regime of truth," an organized network of social codes that bring the construction and interpretation of development and progress for example, into conformity with the requirements of a hegemonic system.

Nonetheless, Jonathan's defeat in the 2015 elections suggests that the power of social media may be used as a medium of resistance where alternate perceptions and opinions can be molded. Ordinary Nigerian voters might have perhaps found flaws in Jonathan's rhetoric, as his language failed to close the widening gap between what he told the electorates and what the reality on the ground was. But whether his loss was as a result of the discourses of resistance put up through social media is not yet clear, what can be speculated now is that Jonathan's rhetorical inconsistency could be one of the reasons why Muhammadu Buhari was supported more widely by ordinary Nigerians. Thus, an analysis of discourses of resistance could provide possible implications and 
consequences of alternative discourses from those who have not traditionally held power. Such a study can probably begin to refocus the direction of CDS practitioners away from the tendency to portray discourse from a linear perspective, where powerful agents use discourse for their own ends, towards the margins where the masses coalesce and organize to resist hegemonic discourses. The refocus in direction is viable if the discourses of resistance are found to be capable of reconstructing new discourses that can detach "truth," in Foucauldian terms, from the forms of hegemony (cultural, social, and economic), within which it operates. The contention here is that state-centric power struggles, including revolutions, do not always lead to a change in the social order. Hence, there is a need to examine the forms of ideology that are usually reflected in the discourses of resistance in social media, in order to explore more fully the powers that ordinary people may yield against the elite system in place. 


\section{References}

Abdullahi-Idiagbon, M. S. (2010). Language use in selected Nigerian presidential election campaign speeches: A critical discourse analysis perspective. Journal of the Nigeria English Studies Association (JNESA), 13(2), 30-44.

Abrahamsen, R. (2000). Disciplining democracy: Development discourse and good governance in Africa. New York: Zed Books.

Abrahamsen, R. (2012, Dec.). Pluralism forum - Global Centre for Pluralism. [Video File] Retrieved from https://www.youtube.com/watch?v=RCYSZFeyWxU.

Acemoglu, D., \& Robinson, J. (2012). Why nations fail: The origins of power, prosperity, and poverty. New York: Crown Business.

Achebe, C. (1983). The trouble with Nigeria. Oxford: Heinemann.

Achebe, C. (1993 [1975]). The African writer and the English language. Morning yet on creation day: Essays. London: Heinemann Educational.

Achebe, C. (2012). There was a country: A memoir. New York: Penguin.

Addei, C., Osei, C., \& Annin, F. (2013). Ngũgĩ and Postcolonial Africa: History, Politics and Morality in Petals of Blood and Matigari. International Journal of Scientific \& Technology Research, 2(9), 164-171.

Adebanwi, W., \& Obadare, E. (2010). Introducing Nigeria at fifty: The nation in narration. Journal of Contemporary African Studies, 28(4), 379-405.

Adegoju, A., \& Oyebode, O. (2015). Humour as discursive practice in Nigeria's 2015 presidential election online campaign discourse. Discourse Studies, 17(6), 643662.

Ademilokun, M., \& Taiwo, R. (2013). Discursive strategies in newspaper campaign advertisements for Nigeria's 2011 elections. Discourse \& Communication, 7(4), 435-455.

Adetunji, A. (2006). Inclusion and exclusion in political discourse: Deixis in Olusegun Obasanjo's speeches. Journal of Language and Linguistics, 5(2), 177-191.

Aduradola, R. R., \& Ojukwu, C. C. (2013). Language of political campaigns and politics in Nigeria. Canadian Social Science, 9(3), 104-116. 
Ahluwalia, P. (2001). Politics and post-colonial theory: African inflections. London: Routledge.

Ahmed, Y. (2012). A critical discourse analysis of negation in selected Nigeria and United States of America Presidential speeches. A thesis submitted to the postgraduate school, Ahmadu Bello University, Zaria in partial fulfilment of the requirements for the degree of Master of Arts (English).

Ajilore, O. O. (2015). Acclaims attacks and defenses in Nigerian gubernatorial debate. Discourse \& Communication, 9(1), 3-18.

Akindele, R. A. (1999). Donors and lenders. In O. Oyediran \& A. A. B. Agbaje (Eds.). Nigeria: Politics of Transition and Governance 1986-1996 (pp. 280-294). Dakar: CODESRIA.

Anderson, B. (2006). Imagined communities: Reflections on the origin and spread of nationalism. London: Verso Books.

Andrus, J. (2013). Rhetorical discourse analysis. In C.A. Chapelle (Ed). The Encyclopedia of Applied Linguistics (pp. 4975-498). Oxford, UK: WileyBlackwell.

Annan, K. (2002, October 1). Globalization's glass house must remain open. [Video File] Retrieved from https://www.youtube.com/watch?v=ixRPUPu2NWE.

Aristophanes. (1994) The Clouds. In four plays by Aristophanes. Arrowsmith, W. (Ed.) New York: Meridian.

Aristotle. (2007). On rhetoric: A theory of civic discourse.(Kennedy, G.A, Trans) New York: Oxford UP.

Asante, M. K. (1999). An Afrocentric communication theory. In J. L. Lucaites, C.M. Condit, \& S. Caudill, S. (Eds.). Contemporary Rhetorical Theory: A Reader (pp. 552-562). New York: The Guilford Press.

Asen, R. (2010). Reflections on the role of rhetoric in public policy. Rhetoric \& Public Affairs, 13(1), 121-143.

Assman, J. (1997) Translating Gods: Religion as a factor of cultural (Un) translatability. S. Budick (Ed.). The translatability of cultures: figurations of the space between (pp. 25-36). Stanford, Calif: Stanford University Press. 
Atanga, L. L., Ellece, S. E., Litosseliti, L., \& Sunderland, J. (Eds.). (2013). Gender and languagein Sub-Saharan Africa: Tradition, struggle and change. Amsterdam: John Benjamins Publishing.

Austin, J. L. (1962). How to do things with words. Oxford: Oxford University Press.

Bakhtin, M. (1981). The dialogic imagination: Four Essays. (Emerson, C. \& Holquist, M, Trans.). Austin: University of Texas Press.

Bamgbose, A. (2011). African languages today: The challenge of and prospects for empowerment under globalization. In E. Bokamba et al., (Eds.). Selected proceedings of the $40^{\text {th }}$ annual conference on African Linguistics (1-14). Somerville, MA: Cascadilla

Benoit, W. L. (1995). Accounts, excuses, and apologies: A theory of image restoration strategies. Albany, NY: SUNY Press.

Benoit, W. (2003). Campaign 2000: A functional analysis of presidential campaign discourse. Lanham, MD: Rowman \& Littlefield.

Benoit, W. (2007). Communication in political campaigns. New York: Peter Lang.

Bergvall, V. L., \& Remlinger, K. A. (1996). Reproduction, resistance and gender in educational discourse: The role of critical discourse analysis. Discourse \& Society, 7(4), 453-479.

Betts, A. (2016, July). Why Brexit happened - And what to do next. [Video File]. Retrieved from https://www.ted.com/talks.alexander_betts_why_happenned_and what to do next.

Bhabha, H. (1994). The location of culture. London: Routledge.

Bhambra, G. K. (2014). Postcolonial and decolonial dialogues. Postcolonial Studies, 17(2), 115-121.

Bitzer, L. F. (1968). The rhetorical situation. Philosophy \& Rhetoric (1)3, 1-14.

Blake, C. (2009). The African origins of rhetoric. New York: Routledge.

Blakeley, G., \& Bryson, V. (Eds.) (2002). Contemporary political concepts. London: Pluto. 
Blommaert, J. (2005). Discourse: A critical introduction. London: Cambridge University Press.

Bokor, M. J. (2014). When the drum speaks: The rhetoric of motion, emotion, and action in African societies. Rhetorica: A Journal of the History of Rhetoric, 32(2), 165-194.

Booth, W. C. (2004). The rhetoric of rhetoric: The quest for effective communication. Oxford: Blackwell Publishing.

Bourdieu, P. (1991). Language and symbolic power. Cambridge, Mass: Harvard University Press.

Brysk, A. (Ed.). (2002). Globalization and human rights. Berkeley, Calif: University of California Press.

Bucholtz, M., \& Hall, K. (2005). Identity and interaction: A sociocultural linguistic approach. Discourse Studies, 7(4-5), 585-614.

Burke, K. (1969). A rhetoric of motives. Berkeley, Calif: University of California Press.

Burke, K. (1970). The rhetoric of religion: Studies in logology. Berkeley, Calif: University of California Press.

Burke, R. J. (1982). Politics as rhetoric. Ethics, 93(1), 45-55.

Campbell, K.E. (2006). Rhetoric from the ruins of African antiquity. Rhetorica: $A$ Journal of the History of Rhetoric, 24 (3), 255-274.

Caplan, B. (2006). The myth of the rational voter: Why democracies choose bad policies. New Jersey: Princeton University Press.

Chabal, P. (2009). Africa: The politics of suffering and smiling. London: Zed Books.

Chen, X. (1995). Occidentalism: a theory of counter-discourse in post-Mao China. New York: Rowman \& Littlefield.

Chidi, N. J. (2014). Kidnapping in Nigeria: An emerging social crime and the implications for the labour market. International Journal of Humanities and Social Science 4(1), 133-145.

Chilton, P. (2004). Analysing political discourse. London: Routledge. 
Chilton, P. (2007). Challenges in the study of language and politics, challenges for JLP. Journal of Language and Politics, 6(3), 297-301.

Chilton, P., \& Schäffner, C. (Eds.). (2002). Politics as text and talk: Analytic approaches to political discourse (Vol. 4). Amsterdam: John Benjamins Publishing.

Chiluwa, I. and Ifukor, P. (2015). War against our children: Stance and evaluation in \#BringBackOurGirls campaign discourse on twitter and Facebook. Discourse and Society, 26(3), 1-30.

Chiluwa, I., \& Odebunmi, A. (2016). On terrorist attacks in Nigeria: Stance and engagement in conversations on Nairaland. Communication and the Public, 1(1), 91-109.

Chiluwa, I., (2012). Social media networks and the discourse of resistance: A sociolinguistic CDA of Biafra online discourses. Discourse and Society, 23(3), $217-244$.

Chomsky, N. (1957). Syntactic structures. Berlin: Walter de Gruyter.

Cicero. (2001) De Oratore. (James, M. \& Jakob,W, Trans.). Oxford: Oxford UP.

Connolly, W. E. (1993). The terms of political discourse. New Jersey: Princeton University Press.

Crystal, D. (2003). English as a global language. Cambridge: Cambridge University Press.

Dadugblor, S. K. (2016). Clusivity in presidential discourse: A rhetorical discourse analysis of State-of-the-Nation addresses in Ghana and the United States. Open Access Master's Thesis, Michigan Technological University.

Dallmayr, F. R. (1984). Language and politics: Why does language matter to political philosophy. Indiana: University of Notre Dame Press.

Dallmayr, F. R. (1996). Beyond orientalism: Essays on cross-cultural encounter. New York: SUNY Press.

Davis, G. (December 10, 2015). Why English has a 'we' problem: When we say 'we', who do 'we' mean? The Guardian. Retrieved from https://www.theguardian.com/commentisfree/2015/dec/11/why-english-has-awe-problem-when-we-say-we-who-do-we-mean. 
Dunmire, P. L. (2011). Projecting the future through political discourse: The case of the bush doctrine (Vol. 41). Amsterdam: John Benjamins Publishing.

Dunmire, P. L. (2012). Political discourse analysis: Exploring the language of politics and the politics of language. Language and Linguistics Compass, 6(11), 735751.

Edelman, M. (1977). Political language: Words that succeed and policies that fail. New York: Academic Press.

Edelman, M. (1985). Political language and political reality. PS: Political Science \& Politics, 18(01), 10-19..

Edelman, M.J. (1988). Constructing the political spectacle. Illinois: University of Illinois Press.

Ethnologue (2017). Nigerian Languages. Retrieved from https://www.ethnologue.com/country/ng/languages

Fairclough, I. \& Fairclough, N (2012). Political discourse analysis: A method for advanced students. New York: Routledge.

Fairclough, N. (1997). Rhetoric and critical discourse analysis: A reply to Titus Ensink and Christoph Sauer. In Schäffner, C. (Ed.). Analysing political speeches (pp. 86-89). Pennsylvania: Multilingual Matters.

Fairclough, N. (2000). New Labour, new language? London: Routledge.

Fairclough, N. (2015) Language and power. London: Longman.

Falk, R. A. (1999). Predatory globalization: A critique. Cambridge: Polity.

Fanon, F. (1961). The wretched of the earth. (Farrington, C, Trans.). New York: Grove.

Finlayson, A. (2007). From beliefs to arguments: Interpretive methodology and rhetorical political analysis. The British Journal of Politics and International Relations, 9(4), 545-563.

Finlayson, A. (2012). Rhetoric and the political theory of ideologies. Political Studies Review, 60(4), 751-767.

Finlayson, A. (2014). Proving, pleasing and persuading: Rhetoric in contemporary British politics. Political Quarterly, 85(4), 428-436. 
Finnegan, R. (2012). Oral literature in Africa. Cambridge: Open Book Publishers.

Fischer, F. (2003). Reframing public policy: Discursive politics and deliberative practices. Oxford: Oxford University Press.

Foucault, M., Burchell, G., Gordon, C., \& Miller, P. (1991). The Foucault effect: Studies in governmentality. Illinois: University of Chicago Press.

Fowler, R., Hodge, R., Kress, G., \& Trew, T. (1979). Language and control. London: Routledge \& K. Paul.

Friedman, S.S. (2011). Why not compare? PMLA 126 (3), 753-762.

Fuchs, C. (2014). Social media: A critical introduction. Los Angeles, Calif: Sage.

Gallie, W. B. (1956). Essentially contested concepts. In Proceedings of the Aristotelian Society 56, 67-198.

Gastil, J. (1992). Undemocratic discourse: A review of theory and research on political discourse. Discourse \& Society, 3(4), 469-500.

Gee, J. P. (2014). An introduction to discourse analysis: Theory and method. New York: Routledge.

Goffman, E. (1971). Relation in public. Middlesex: Penguin Books Limited.

Gounden, V. (2010). Reflections on identity conflicts and nation building in contemporary South Africa. Peace Prints: South Asian Journal of Peacebuilding. 3(2).

Gramsci, A. (1999). Selection from the prison notebooks. (Q. Hoare \& G.N. Smith, eds., \& Trans.). London: Lawrence \& Wishart.

Grice, H. P. (1975). Logic and conversation. In M. Ezcurdia \& R. J. Stainton (Eds.). The Semantics-Pragmatics Boundary in Philosophy (pp. 47-58). Calgary, Canada: Broadview Press.

Grosfoguel, R. (2011). Decolonizing post-colonial studies and paradigms of political economy: Transmodernity, decolonial thinking, and global coloniality. Transmodernity: Journal of Peripheral Cultural Production of the LusoHispanic World, 1(1), 1-38. 
Güven, F. (2015). Decolonizing democracy: Intersections of philosophy and postcolonial theory. New York: Lexington Books.

Hansen, E. (1974). Frantz Fanon: Portrait of a revolutionary intellectual. Transition. 46, 25-36.

Harrison, R. D., \& Harrison, L. K. (1993). The call from the mountaintop: Call-response and the oratory of Martin Luther King. In C. Calloway-Thomas \& J. L. Lucaites (Eds.). Jr. Martin Luther King, Jr. and the sermonic power of public discourse. (162-178). Alabama: Alabama UP.

Harvey, D. (2006). Spaces of global capitalism. New York: Verso.

Hay, C. (2013). Political discourse analysis: The dangers of methodological absolutism. Political Studies Review, 11(3), 321-327.

Heinrichs, J. (2007). Thank you for arguing: What Aristotle Eminem and Homer Simpson can teach us about the art of persuasion. New York: Three Rivers Press.

Herman, E. S., \& Chomsky, N. (2002). Manufacturing consent: The political economy of the mass media. New York: Random House.

Heywood, A. (2004). Political theory: An introduction. New York: Palgrave Macmillan.

Heywood, A. (2012). Political ideologies: An introduction. New York: Palgrave Macmillan.

Hodge, R. I. V., \& Kress, G. R. (1980). Language as ideology. New York: Routledge.

Horkheimer, M., \& Adorno, T. W. (2002). Dialectic of Enlightenment. California: Stanford University Press.

Hum, S. and Lyon, A. (2009). Recent advances in comparative rhetoric. In A.A. Lunsford, K.H. Wilson, \& R.A. Eberly (Eds.) The Sage Handbook of Rhetorical Studies (pp. 153-165). Los Angeles, Calif: Sage.

Ige, S. (2009). African rhetoric: Possible directions. African Journal of Rhetoric: Moments of Engagement: Power, Rhetoric and Protests, 1, 15-27.

Ige, S. (2012). African presidential rhetoric: Theorising transformational political speechmaking. African Journal of Rhetoric: Rhetoric, Political Agency and Africa, 4, 21-47. 
Inglehart, R. and Norris, P, Trump (2016). Brexit, and the rise of populism: Economic have-nots and cultural backlash. HKS Working Paper No. RWP16-026. Retrieved from: https://ssrn.com/abstract=2818659.

Jonathan, G. (2014). Address by His Excellency, President Goodluck Ebele Jonathan, and GCFR. On the occasion of his declaration of intent to run for the 2015 presidential elections under the platform of the People's Democratic Party (PDP). Eagle Square, Abuja. Retrieved from http://www.channelstv.com/2014/11/11/full-text-goodluck-jonathansdeclaration-speech.

Jonathan, G. (2015). Full Transcript of President Goodluck Jonathan's remarks at the flag-off of the PDP 2015 campaign in Lagos. On Thursday, January 8. Retrieved from http://saharareporters.com/2015/01/09/full-transcript-president-goodluckjonathan $\%$ E2\%80\%99s-remark-flag-pdp-2015-campaign-lagos.

Joslyn, R. (1986). Keeping politics in the study of political discourse. In H.W. Simons \& A.A. Aghazarian (Eds). Form, genre, and the study of political discourse (pp. 287-303) Columbia, SC: University of South Carolina Press.

Kamalu I. and Agangan R. (2011). A critical discourse analysis of Goodluck Jonathan's declaration of interest in the PDP presidential primaries. Language, Discourse \& Society, 1(1), 32-53.

Kennedy, G.A. (1998). Comparative Rhetoric: An historical and cross-cultural introduction. New York: Oxford University Press.

KhosraviNik, M. (2015). Discourse, identity and legitimacy: Self and other in representations of Iran's nuclear programme. Amsterdam: John Benjamins.

Kuhn, T. (1996). The Structure of scientific revolutions. Chicago, IL: Chicago University Press.

Kohn, M., \& McBride, K. (2011). Political theories of decolonization: Postcolonialism and the problem of foundations. Oxford: Oxford University Press.

Kperogi, F. A. (2015). Glocal English: The changing face and forms of Nigerian English in a global world (Vol. 96). New York: Peter Lang.

Kperogi, F. A. (2015). Marxist Theory of the Media or Theory of the Media by Marxists? Reconciling Adorno with Other Marxist Media Theorists. Journal of Communications Media Studies, 7, 61-78. 
Kperogi, F.A. (2015, October 11)10 Mind-blowing Facts about English that May Shock You By. [Web log Comment] Retrieved from http://www.farooqkperogi.com/2015/10/10-mind-blowing-facts-aboutenglish.html.

Kuhn, T. (1996). The Structure of scientific revolutions. Chicago, IL: Chicago University Press.

Lakoff, R. T. (2001). Nine ways of looking at apologies: The necessity for interdisciplinary theory and method in discourse analysis. In D. Tannen, H.E. Hamilton, \& D. Schiffrin (Eds.). The handbook of discourse analysis (pp. 201217). Malden, MA: Blackwell.

Lemke, T. (2002). Foucault, governmentality, and critique. Rethinking Marxism, 14(3), 49-64.

Lumumba-Kasongo, T. (2007). Africa's third-term syndrome: A trend toward authoritarianism or a unique form of democracy?. Georgetown Journal of International Affairs, 8,125-133.

Lyon, A. (2015). Rhetoric and comparison: Two tricky words. Rhetoric Review 34.3, 241-44.

Maggio, J. (2007). Can the subaltern be heard? Political theory, translation, representation, and Gayatri Chakravorty Spivak. Alternatives: Global, Local, Political, 32(4), 419-443.

Maisel, L. S., \& West, D. M. (2004). Running on Empty? Political Discourse in Congressional Elections. Maryland: Rowman \& Littlefield.

Mao, L. (2014). Thinking beyond Aristotle: The turn to how in comparative rhetoric. PMLA, 129(3), 448-455.

Mao, L., Wang, B., Lyon, A., Jarratt, S. C., Swearingen, C. J., Romano, S., \& Lu, X. (2015). Manifesting a future for comparative rhetoric. Rhetoric Review, 34(3), 239-274.

Martin, J. (2014). Politics and rhetoric: A critical introduction. London: Routledge.

Mazrui, A. A. (2005). The re-invention of Africa: Edward Said, VY Mudimbe, and beyond. Research in African Literatures, 36(3), 68-82. 
Mazrui, A. A., \& Tidy, M. (1984). Nationalism and new states in Africa: From about 1935 to the present. Nairobi: Heinemann.

Mbembé, J. A. (2001). On the postcolony. Berkeley, Calif: University of California Press.

Mbembé, J. A., \& Nuttall, S. (2004). Writing the world from an African metropolis. Public culture, 16(3), 347-372.

Mignolo, W. (1995). The darker side of the Renaissance: Literacy, territoriality, and colonization. Michigan: University of Michigan Press.

Mignolo, W. (2011). The darker side of western modernity: Global futures decolonial options. North Carolina: Duke University Press.

Mignolo, W. (2005). Prophets facing sidewise: The geopolitics of knowledge and the colonial difference. Social Epistemology, 19(1), 111-127.

Mignolo, W. (2009). Epistemic disobedience, independent thought and decolonial freedom. Theory, Culture \& Society, 26(7-8), 159-181.

Moemeka, A. A. (1998). Communalism as a fundamental dimension of culture. Journal of Communication, 48(4), 118-141.

Moghadam, V. M. (2009). Globalization and social movements: Islamism, feminism, and the global justice movement. Maryland: Rowman \& Littlefield.

Mouffe, C. (1979). Hegemony and ideology in Gramsci. (D. Derome, Trans.) In Mouffe, C. (Ed.), Gramsci \& Marxist theory (pp. 268-204). London: Routledge.

Moyo, D. (2009). Dead aid: Why aid is not working and how there is a better way for Africa. Vancouver: Douglas \& MacIntyre.

Mudimbe, V. Y. (1988). The invention of Africa: Prognosis, philosophy and the order of knowledge. Indiana University Press.

Mukavetz, A. M. R. (2014). Towards a cultural rhetorics methodology: Making research matter with multi-generational women from the Little Traverse Bay Band. Rhetoric, Professional Communication, and Globalization, 5(1), 108125.

The National Conference (2014). Final draft of conference report. Retrieved from http://www.premiumtimesng.com/national-conference/download-nigeria-2014national-conference-report-ngconfab-2/ June 22, 2016. 
Ngũgĩ, W. (1993). Moving the center: The struggle for cultural freedoms. Nairobi: East African Educational Publishers.

Ngũgĩ, W. (1994). Decolonising the mind: The politics of language in African literature. Nairobi East African Publishers.

Norval, A. J., \& Stavrakakis, Y. (2000). Discourse theory and political analysis: Identities, hegemonies and social change. Manchester: Manchester University Press.

O'Shaughnessy, N. (2014). The rhetoric of rhetoric: Political rhetoric as function and dysfunction. Atkins, J. Finlayson, A, Martin, J. and Turnbull, N. (Eds.). Rhetoric in British politics and society (pp.17-29). New York: PalgraveMacmillan.

Obeng, S. G. (1997). Language and politics: Indirectness in political discourse. Discourse \& Society, 8(1), 49-83.

Obeng, S. G., \& Hartford, B. (2002). Political independence with linguistic servitude: The politics about languages in the developing world. New York: Nova Publishers.

Obi, C.I. (2010). Forward in. Tar, U. A. and Shettima, A. G. Endangered democracy: The struggle over secularism and its implications for politics and democracy in Nigeria. Discussion paper 49, Nordiska Afrikainstitutet, Uppsala.

O'Connell, D. (2015). God wills it: Presidents and the political use of religion. New Jersey: Transaction Publishers.

Octalog. (1988). The politics of historiography. Rhetoric Review 7(1), 5-49.

Okafor, V. O. (2006). A Roadmap for understanding African politics: Leadership and political integration in Nigeria. New York: Routledge.

Okediran, W. (2013). Rhetoric, dirty hand politics and public ethics: The Nigerian experience practitioners' notes. African Journal of Rhetoric: Rhetoric and political leadership. 5, 139-161.

Okpewho, I. (1979). The epic in Africa: Toward a poetics of the oral performance. New York: Columbia University Press. 
Orwell, G. (1946). Politics and the English language. London: Penguin.

Orwell, G. (1949). Nineteen eighty-four. London: Secker \& Warburg.

Osinbajo, Y. (2017, February 10). Oil has become curse, burden for Niger Delta. Punch. Retrieved from http://punchng.com/oil-become-curse-burden-niger-deltaosinbajo/.

Osundare, N. (2016, August 1). Unitary governance structure constraining Nigeria. The Guardian. Retrieved from http:/guardian.ng/news/unitary-governancestructure-constraining-nigeria/.

Pamir, P. (1997). Nationalism, ethnicity and democracy: Contemporary manifestations. The International Journal of Peace Studies, 2(2), 1-12.

Parry-Giles, T. \& Steudeman, M. J. (2017) Crafting character, moving history: John McCain's political identity in the 2008 presidential campaign, Quarterly Journal of Speech, 103(2), 66-89.

Phillipson, R. (2003). English for the Globe, or only for Globe-Trotters? The World of the EU. In C. Mair (Ed.). The politics of English as a world language: New horizons in postcolonial cultural studies (pp. 19-29). New York: Rodopi.

Powell, M., Levy, D., Riley-Mukavetz, A., Brooks-Gillies, M., Novotny, M., \& FischFerguson, J. (2014). Our story begins here: Constellating cultural rhetorics. Enculturation: A Journal of Rhetoric, Writing, and Culture. 1, 1-25

Quijano, A. (2000). Coloniality of power and Eurocentrism in Latin America. International Sociology, 15(2), 215-232.

Quintilian (2001) Institutio Oratoria. (D. A. Russell, Trans.). Cambridge, MA:Havard University Press.

Radhakrishnan, R. (2009). Why compare? New Literary History, 40 (3), 453-471.

Redlawsk, D. (Ed.). (2006). Feeling politics: Emotion in political information processing. New York: Springer.

Rodney, W. (1972). How Europe Underdeveloped Africa. London: Bogle-L'Ouverture Publications.

Royster, J. J. (1996). When the first voice you hear is not your own. College Composition and Communication, 47(1), 29-40. 
Said, E. W. (1978) Orientalism. New York: Vintage.

Salawu, A. (2016). Indigenous language media and democracy in Africa. Salawu, A. and Chibita, M. Indigenous Language Media, Language Politics and Democracy in Africa. New York: Palgrave Macmillan.

Saldin, R. P. (2011). William McKinley and the rhetorical presidency. Presidential Studies Quarterly, 41(1), 119-134.

Sandhu, P., \& Higgins, C. (2016). Identity in post-colonial contexts. In S. Preece. (Ed.). The Routledge handbook of language and identity (pp. 179-194). London: Routledge.

Schäffner, C. (2010). Political communication: Mediated by translation. In U. Okulska \& P. Cap (Eds.). Perspectives in Politics and Discourse (pp. 255-278). Amsterdam: John Benjamins Publishing.

Schäffner, Christina (Ed.) (1997). Analysing political speeches. Current issues in language and society. Amsterdam: Multilingual Matters.

Schegloff, E. A. (1997). Whose text? Whose context? Discourse \& Society, 8(2), 165187.

Searle, J. R. (1969). Speech acts: An essay in the philosophy of language (Vol. 626). Cambridge: Cambridge University Press.

Shome, R. (2011). Internationalizing critical race communication studies transnationality, space, and affect. In T. K. Nakayama \& R. T. Halualani (Eds.). The handbook of critical intercultural communication (pp. 149-170). Oxford: WileyBlackwell.

Shome, R. (2012). Mapping the limits of multiculturalism in the context of globalization. International Journal of Communication. 6 (22), 144-165.

Shome, R. (2016). Gender, nation, and colonialism: Twenty-First century connections. Cultural Studies $\leftrightarrow$ Critical Methodologies, 1(4), 347-350.

Skinnell, R. (2015). Who cares if rhetoricians landed on the moon? Or, a plea for reviving the politics of historiography. Rhetoric Review, 34(2), 111-128.

Smith, A. L. (1971). Markings of an African concept of rhetoric. Communication Quarterly, 19(2), 13-18. 
Smith, L. (2012). Decolonising methodologies. Research and indigenous peoples. London: Zed Books Ltd.

Smith, M. (Ed.). (2006). Beyond the 'African tragedy': Discourses on development and the global economy. Alberta: Ashgate Publishing.

Spivak, G. C. (1988). Can the subaltern speak? In C. Nelson \& L. Grossberg (Eds.). Marxism and the Interpretation of Culture (pp. 66-111). New York: Macmillan Education.

Spivak, G. C. (1990). Post-structuralism, marginality, postcoloniality and value. In P. Collier \& H. Geyer-Ryan (Eds.). Literary Theory Today (pp. 225-238). Cambridge: Polity Press.

Spivak, G. C. (1999). A critique of postcolonial reason. Cambridge, Mass.: Harvard University Press.

Starkey, H. (2002). Democratic citizenship, language diversity and human rights. Strasbourg, France: Language Policy Division Monographs of the Council of Europe.

Stuckey, M. E. (2017) The changing face of presidential campaigns: Editor's introduction, Quarterly Journal of Speech, 103:1-2, 1-6.

Stuckey, M. E., \& Antczak, F. J. (1995). The battle of issues and images: Establishing interpretive dominance. Communication Quarterly, 42(2), 120-132.

Taiwo R. (2008). Legitimization and coercion in political discourse: A case study of Olusegun Obasanjo address to the PDP elders and stakeholders forum. Issues in Political Discourse Analysis, 2(2), 79-91.

Taiwo, R. (2010). Conceptual metaphors in Nigerian political discourse. A Journal of the Faculty of Arts, Delta State University 3(1), 170-185.

Tar, U. A. (2009). The politics of neoliberal democracy in Africa: State and civil society in Nigeria. London: Tauris Academic Studies.

Tar, U. A. and Shettima, A. G, (2010). Endangered democracy: The struggle over secularism and its implications for politics and democracy in Nigeria. Discussion paper 49, Nordiska Afrikainstitutet, Uppsala. 
Thompson, M (2016, August 27). From Trump to Brexit rhetoric: How today's politicians have got away with words. The Guardian. Retrieved from https:/www.theguardian.com/books/2016/aug/27/from-trump-to-brexit-rhetorichow-todays-politicians-have-got-away-with-words.

Törnquist, O. (1999). Politics and development: A critical introduction. London: Sage.

Trent, J. S., \& Friedenberg, R. V. (2011). Political campaign communication: Principles and practices. New York: Rowman \& Littlefield.

Tulis, J. (1987) The rhetorical presidency. New Jersey: Princeton University Press.

Turnbull, N. (2015). A thick theory of rhetoric as the negotiation of political distance. A paper presented to the Political Studies Association 65th Annual Conference, Sheffield, England.

Van Dijk, T. A. (1993). Principles of critical discourse analysis. Discourse \& Society, 4(2), 249-283.

Van Dijk, T. A. (1997). What is political discourse analysis? Belgian Journal of Linguistics, 11(1), 11-52.

Van Dijk, T.A. (2005). Politics, ideology, and discourse. R. Wodak (Ed.). Encyclopedia of Language and Linguistics. Vol. 2. Politics and Language (pp. 728-74). Amsterdam: Elsevier Ltd.

Van Leeuwen, T. (2005). Three models of interdisciplinarity. R. Wodak \& P. Chilton, (Eds.). A new agenda in (Critical) discourse analysis: Theory, methodology and interdisciplinarity (3-18). Amsterdam: John Benjamins.

Vatz, R. E. (1973). The myth of the rhetorical situation. Philosophy \& rhetoric, 6(3) 154161.

Venkatasawmy, R. (2015). Ethnic conflict in Africa: A short critical discussion. Transcience 6(2).

Villadsen, L. S. (2014). More than a nice ritual. Van Belle, H., Rutten, K., Gillaerts, P., Van De Mieroop, D., \& Van Gorp, B. (Eds.). Let's talk politics: New essays on deliberative rhetoric (pp. 27-43). Philadelphia: John Benjamins Publishing Company. 
Wang, B. (2013). Comparative rhetoric, postcolonial studies, and transnational feminisms: A geopolitical approach. Rhetoric Society Quarterly, 43(3), 226242.

Weiss, G., \& Wodak, R. (Eds.). (2003). Critical discourse analysis: Theory and interdisciplinarity. New York: Palgrave Macmillan.

Whorf, B. L. (1973) Language, Thought and Reality. Selected Writings of Benjamin Lee Whorf. J. B. Carroll (Ed.). Cambridge, Mass.: MIT Press.

Whyte, J. (2004). Crimes against logic: Exposing the bogus arguments of politicians, priests, journalists, and other serial offenders. New York: McGraw Hill.

Wieczorek, A. E. (2013). Clusivity: A new approach to association and dissociation in political discourse. Newcastle: Cambridge Scholars Publishing.

Wilson, J. (2001). Political Discourse. In D. Schiffrin, D. Tannen, \& H. E. Hamilton (Eds.). The Handbook of Discourse Analysis (pp. 398-415). New York: Routledge.

Windt, T. O. (1986). Presidential rhetoric: Definition of a field of study. Presidential Studies Quarterly, 16(1), 102-116.

Wodak, R. (2012). Politics as usual: Investigating political discourse in action. In J.P. Gee \& M. Handford (Eds.). The Routledge Handbook of Discourse Analysis (pp. 525-540). New York: Routledge.

Wodak, R., \& Meyer, M. (2016). Methods of critical discourse studies (Eds.). London: Sage.

Wodak, R., de Cillia, R.,Reisigl, M., and Liebhart, K. (2009). The discursive construction of national identity. (A. Hirsch, R. Mitten, \& J.W. Unger, Trans.). Edinburgh: Edinburgh University Press.

Wright, B. D. (2016, December 08). I'm a Democrat but Clinton staffer Jennifer Palmieri's twisted logic is exactly why we lost. Fox news. Retrieved: http://www.foxnews.com/opinion/2016/12/08/im-democrat-but-clinton-stafferjennifer-palmieris-twisted-logic-is-exactly-why-lost.html.

Yankah, K. (1991). Oratory in Akan society. Discourse \& Society, 2(1), 47-64.

Yankah, K. (1995). Speaking for the chief: Okyeame and the politics of Akan royal oratory. Indiana: Indiana University Press. 
Yankah, K. (1999). African folk and the challenges of a global lore, 1998 American Folklore Society Plenary Address. Journal of American Folklore, 112 (444), 140-157.

Yankah, K. (2012). The proverb in the context of Akan rhetoric. New York: Diasporic Africa Press.

Zotzmann, K., \& O’Regan, J. P. (2016). Critical discourse analysis and identity. In S. Preece (Ed.), The Routledge handbook of language and identity (pp. 113-127). New York: Routledge. 


\section{Appendix A}

Address by His Excellency, President Goodluck Ebele Jonathan, GCFR

On the Occasion of His Declaration of Intent to Run for the 2015 Presidential Elections

under the Platform of the Peoples Democratic Party (PDP) Eagle Square, Abuja

Tuesday 11 th November, 2014

1. Dear Compatriots: Four years ago, precisely September 18, 2010; I stood in this Eagle Square, to offer myself for election as the President of our beloved country on the platform of our great party; the Peoples Democratic Party (PDP).

2. Seven months after that declaration, you elected me to lead this country with overwhelming support from all parts of our Nation. I remain grateful for the trust you reposed in me to lead our Nation through uncommon challenges in our march of progress as a united and democratic country.

3. Over the years, the Almighty God has made it possible for me to develop a bond with you and I am grateful for your support and understanding in the difficult periods we have journeyed through.

4. Distinguished ladies and gentlemen, our stewardship has not been without challenges. We have had to deal with the wave of insurgency that has swept through some parts of our dear country. Only yesterday, Government Science Secondary School in Yobe State was bombed by insurgents, killing our promising young children who were seeking education to build the country and support their parents. Many Nigerians have lost their lives and property to these mindless killings. Let me crave the indulgence of all present here to stand up to observe a minutes silence in honour of these young lads who lost their lives. Clearly, this has cast a dark cloud on our Nation but we will surely win the war against terror. A number of young men and women have been kidnapped by these criminal elements including our daughters from Chibok. We will free our daughters and defeat terrorism.

5. We are equipping the armed forces and deploying special forces to engage the terrorist and end this senseless war. We must protect our country. We must save our people. I will do everything humanly possible to end this criminal violence in our Nation.

6. To ensure the long term stability and development of the affected areas, government has launched three programmes: The Presidential Initiative for the North East, the Victim Support Fund and the Safe School Initiative. The Presidential Initiative for the Northeast is focused on improving infrastructure and economic growth in the region. The Safe School Initiative is centred on creating a safe environment to encourage our children in the communities to acquire education. The Victim Support Fund, a partnership with the Private Sector, has raised about 60 billion Naira, which will help to empower and rehabilitate victims of terror. I promise the victims of these dastardly 
acts that we will continue to stand with you.

7. I am grateful to all Nigerians for standing with me.

8. Let me also thank the leaders and elders of our great party, the Peoples Democratic Party, for the opportunity you have given to me to serve our country, Nigeria.

9. I am overwhelmed by the trust, confidence and support of the various organs of our party, the Board of Trustees, the National Caucus, the National Executive Committee, the National Working Committee, the PDP Governors Forum, members of the PDP Caucuses of the National Assembly, and others.

10. This day affords me the opportunity to continue the conversation of development we started together.

11. Infrastructure has been a major focus area of my administration and so, we pursued the power sector reform to this point of irreversible progress. Nigeria has undertaken a most transparent and corruption free bidding process, attracting global commendation. The on-going 450MW Azura Power Plant in Edo State is a testimony to the success of this transformation.

12. We have also resumed development of our Hydro-Power potential, with the construction of the 700MW Zungeru Hydro-Power Plant, while construction work on the 3,050MW Mambilla Hydro-Power Plant is about to take off.

13. Our power generation and distribution companies have now been privatized. We are firmly on the road to guaranteed regular power supply in the months ahead. This our bold move, is paying off!

14. We are committed to environmental protection and conservation and reducing vulnerability to climate change. In this regard, we have embarked on a number of projects across the country. Of particular note is the African Great Green Wall Programme, where we have released about 16 billion naira for implementation. The project will create a green belt across 11 states from Kebbi to Borno.

15. In the past three and half years, the water sector has witnessed unprecedented improvement. Access to potable water is now $67 \%$, up from $58 \%$ in 2010 , while sanitation coverage is $41 \%$, from $32 \%$ within the same period. 
16. Major developments in water include the completion of 37 Dams and rehabilitation of 10, with several others on-going construction. The flagship Kashimbila Multipurpose Dam which is being built to contain flood from Lake Nyos, is now at $90 \%$ completion. We have also completed about 5,000 rural and semi urban water schemes.

17. We are reforming the National Urban Water supply programmes in 12 states, with 385 formal and informal irrigation projects, covering a total land area of 118000 ha, cultivated mostly by small holder farmers. This has yielded over 3 million metric tons of assorted grains and vegetables, with a market value of about 45 billion naira.

18. Before the advent of this administration, the Railway system was practically dead. Today, we have revived the rail sector. The narrow gauge line from Lagos to Kano has been rehabilitated with improved coaches providing regular services. The rehabilitation of the Port Harcourt-Maiduguri rail line is progressing with the Port Harcourt-Gombe segment as well as the branch line from Kafanchan to Kaduna expected to be completed and fully operational by December 2014.

19. Already, work on the Abuja-Kaduna standard gauge rail line, is progressing. The tracks of the rail line will be completed by December this year 2014. Upon completion of the project in the first quarter of 2015, it will be possible for Nigerians to live in Kaduna and work in Abuja. The Itape-Ajaokuta-Wari standard gauge line has attained an advanced stage, with the track completely laid. We hope to commence full operation before the end of 2015.

20. Other segments of the new standard gauge speed train network are planned with contract already awarded for the Lagos -Ibadan Segment. There will be more of such modern and faster rail connections in the coming years. Already, discussions are now at advanced stage, for the Coastal rail line that will traverse through 10 states, from Lagos through the South-South and South-East, all the way to Calabar.

21. My administration has successfully completed the dredging of the lower River Niger from Baro in Niger State to Warri in in Delta State. The cheering news is that over 6.7 million passengers and over 1.6 million tonnes of cargo have been moved through this channel in less than three years.

22. I am happy to also report that our ports now operate 24 hour service, which has led to the reduction of clearing time and improved efficiency.

23. When I assumed office in 2010 , out of the $35,000 \mathrm{~km}$ of federal roads nationwide, only 
about $5,000 \mathrm{~km}$ were motorable. Today, that number has increased to about $25,000 \mathrm{~km}$. We expect to complete the remaining $10,000 \mathrm{~km}$ in three years while initiating new ones.

24. I made a commitment to build two new major bridges across the River Niger and River Benue. Today, the new bridge over the River Benue, connecting Loko in Nassarawa State to Oweto in Benue State has reached an advance stage of completion, while work has commenced on the Second Niger Bridge.

25. Beyond these, my administration has concluded plans to re-commence the construction of Bodo- Bonny Road with three major bridges on the alignment that will link the Island of Bonny with Rivers mainland.

26. Preliminary works have started on my administration's planned re-construction and expansion of the Murtala Muhammed International Airport Road in Lagos to a world class entry point into our country. Only a few months ago, work started on the dualization of Kano-Katsina Road. While many Nigerians are celebrating the marked improvements on our roads, I want to assure that it will get even better as we move forward.

27. In the pursuit of an integrated transportation system, we embarked on the construction of five new Airport Terminal Buildings and Air-field facilities. We are also re-constructing existing ones. The re- construction upon completion, will lead to improved passenger processing, increased cargo handling capacity and enhanced Airfield facilities that meet international standard and improves safety. These efforts have been met with global acknowledgement including the attainment and retention of the FAA Category One status.

28. In housing, we signed the National Housing Policy to kick-start the framework for providing more affordable homes for our people. We have also expanded the National Housing Fund to accommodate more Nigerians. We have started a revolution in the housing sector with the start of the Nigerian Mortgage and Refinanced Company

(NMRC) a new initiative of my administration, that will enable more citizens in the lower income bracket to become first time home owners.

29. Our partners such as the World Bank group are supporting this with US300million dollars interest free credit, while my administration will back it with over 100billion naira in bonds. We are already processing 66,000 mortgage applications for our young people. We have amended the PENCOM Act to enable the pension funds invest in housing sector bonds. This will create a boom in the housing sector. 
30. In the Federal Capital Territory, we are rapidly building a befitting National Capital by expanding and providing new infrastructure, developing ten new districts and Satellite Towns to cater for the ever increasing population. In no distant future, you will be able to arrive at the Nnamdi Azikiwe International Airport and proceed to the city using the Abuja Light Rail. In addition to providing durable health, educational and transportation services, we are also collaborating with Organized Labour to build functional, affordable and social housing in Abuja.

31. Other critical capital developments that are being packaged by this Administration include the development of the Ultra-Modern World Trade Centre, the Abuja Town Centre, the Jabi Lake Comprehensive Centre, the Centenary City and the Land Swap Districts. This private sector driven infrastructural development will positively change the skyline of the city and provide the required office and residential accommodation, shopping and recreation as well as tourism and entertainment facilities of the FCT.

32. In our determination to encourage much greater participation of Nigerians in the oil and gas industry, one of the first actions I took, was the enactment of the Nigerian Oil and Gas Industry Content Development Act. As a result of this law, indigenous Nigerian participation levels, in upstream and downstream activities of the oil and gas industry have increased by over $45 \%$, thereby increasing employment opportunities for our youth.

33. We have also succeeded in eliminating the long queues that previously characterised our filling stations, through regular and sustained product supply.

34. Gas infrastructure to ensure adequate Gas to Power and Gas to Industry, is being aggressively put in place. Over $450 \mathrm{~km}$ of gas pipelines have been installed over the last 3years. Another 2,000km is planned over the next 4years. Critical petrochemical and fertilizer facilities have commenced including the gas industrial park in Delta State, for which I am scheduled to perform the ground-breaking this Friday. This will create millions of jobs and make Nigeria a regional hub.

35. In addition, as a result of government favourable policies the private sector is investing over 12 billion dollars in the petrochemical sector, over the next 4years. This will surely create millions of jobs for our people.

36. In terms of gas supply, we have grown from less than 500 million cubic feet per day, 4years ago, to about 1.5 billion cubic feet per day currently. Our goal is to attain 4 
billion cubic feet per day, over the next 4years.

37. We have changed the face of agriculture. We moved agriculture away from a development Programme to agriculture as a business. My vision is to create wealth for our people through agriculture.

38. We have focused on encouraging the private sector to boost investments in the agricultural sector. As a result, the number of seed companies rose from five to eighty in the past three years. Private sector investment in the agricultural sector expanded by $\$$ US 5.6 billion across the Agricultural value chain.

39. We ended decades of corruption in the fertilizer and seed sectors. We developed a transparent and efficient system of reaching farmers directly with subsidized farm inputs. Before our reforms, fertilizer procurement and distribution took from the needy and gave to the greedy. We restored dignity back to farmers. Today, 14 million farmers, of which 2 million are women, access fertilizers with their mobile phones, through an e-wallet system. Nigeria is the first country in the world to develop an e-wallet system to reach farmers with subsidized farm inputs on their mobile phones. Several African countries are now borrowing this transparent and efficient e-wallet system for their own countries.

40. Our national food production expanded by an additional 21 million metric tons between 2011 and 2014, a record, exceeding our set target of 20 million metric tons set for 2015. The Dangote Group, has committed to invest \$US 1 billion in commercial rice production and processing. With all these developments, we are expected to be an exporter of rice in the next five years. This will be a new dawn!

41. The benefits are showing on our food imports. Our food import bill has declined from 1.1 trillion Naira in 2009 to 684 billion Naira by December 2013, even with our increasing population, a reduction of $40 \%$.

42. Nigeria met its Millennium Development Goal One on reducing hunger and extreme poverty, two years ahead of 2015 target set by the United Nations, and was given an award by the Food and Agriculture Organization of the United Nations.

43. To sustain this trend, we are encouraging young graduates through the Nagropreneurs Programme to go into commercial Agriculture. We are also encouraging our students in Post Primary Schools to embrace commercial Agriculture through the National School Agriculture Programme. 
44. My dear people, corruption remains a big challenge in our national life. It corrodes our efforts at development and at motivating competence in critical sectors of our national growth. We have eradicated it in the agricultural sector and we will surely eradicate it in other sectors of our economy.

45. Going forward, my focus is to continue to reinforce institutions, systems, and processes to tackle corruption, and also to bring to justice those that perpetrate corruption. Through the Integrated Payroll and Personnel Information System (IPPIS), we have weeded out 56,000 ghost workers from the Federal Civil Service, saving 162 billion naira.

46. I have directed ICPC to bring the perpetrators of this criminal act to book. Let this be very clear, public officers must live by example, fully accounting for the national trust and resources in their care.

47. In our journey to progress, knowledge is indispensable. Knowledge is power! This is why my administration established 14 new Universities out of which 12 are conventional and two are specialized Police and Maritime Universities. Under my watch, every state in Nigeria, now has a Federal University.

48. In addition, over 500billion naira have been spent, through the Tertiary Education Trust Fund (TETFund) and the special NEEDS assessment fund on various projects to increase access and improve the quality of infrastructure at the tertiary level of our education system.

49. To provide equal access and opportunities in education and ensure that no Nigerian child is left behind, we have established and equipped 150 Almajiri Schools across the Northern states and the Out- of-School-Children Programme including Specialized Boys and Girls Schools across the country.

50. Fellow Nigerians, our country was faced with a major National security, humanitarian, and economic threat in the form of the Ebola Virus Disease, which arrived in the country on July 20, 2014, by way of a foreign national, Mr Patrick Sawyer.

51. Realizing the imminent threat, I declared a national emergency, pulling states, local and federal government into action as well as individual Nigerians to combat this disease. Without the quick action of patriotic Nigerians in the First Consultant Hospital, as well as the co-operation of Lagos and Rivers State, where the disease 
occurred, working with the Federal Ministry of Health and the co-operation of all Nigerians we could not have succeeded in overcoming this deadly disease. Fellow Nigerians we stopped Ebola together.

52. Just as we stopped Ebola, we are on our way to eradicating the Polio Virus in our country. We have reduced the incident of new Polio Virus from 300 in 2010, to 6 today.

53. My brothers and sisters, to encourage entrepreneurship and self-reliance among our teeming graduates, we have developed creative opportunities for enterprise for our young people.

54. Programmes such as YouWIN, the Graduate Internship Scheme, the Nagropreneurs Initiative, the 220 Billion Naira Micro, Small and Medium Enterprises Development Fund and the 3 Billion Naira Grant to Nollywood are empowering our graduates, the creative industry and other young people to start up their own businesses and employ others.

55. We have supported the growth of industry through policy and action. We launched The National industrial Revolution Plan (NIRP), and the National Enterprise Development Programme as key drivers to bring about our desires in the industrial sectors and to diversify our economy. Our new National Automobile Policy is transforming Nigeria into a vibrant hub for the automobile industry. Our own Innoson Motors is producing world standard vehicles, and Nissan, Hyundai, and Kia, have set up factories in Nigeria and are employing thousands of our people.

56. Our support for cement production is unprecedented. We have increased our installed capacity from 16.5 million metric tons per annum in 2011 to 39.5 million metric tons per annum in 2014. Nigeria is now exporting cement. We are moving forward! We must produce what we consume and consume what we produce.

57. Our efforts to create an enabling environment for job creation in different sectors of the economy including the MSME sector, agriculture, housing and manufacturing have yielded results. Between the third quarter of 2012, when we started tracking jobs created and the end of 2013, 1.9 million jobs were created. To deepen our success in this area, I have created a Presidential Jobs Creation Board headed by the Vice President with the mandate to create at least two million jobs a year.

58. My brothers and sisters, our economy is heading in the right direction and our efforts 
are yielding positive results. Our economy continues to grow at the rate of 6 to 7 percent annually, one of the highest in the world. Our country is now the top investment destination and the largest economy in Africa, with a GDP of 80trillion naira (510billion dollars) as well as the 26th largest economy in the world.

59. As part of its efforts to support inclusive growth and economic development in Nigeria through the CBN, my administration has created and disbursed the sum of 200billion naira via the Commercial Agric and Credit scheme, 300billion naira Power and Aviation fund, 220billion naira Micro, Small and Medium Enterprise Fund, as well as 300 billion naira rail sector refinancing facilities at single digit interest rate. We will continue to deepen the reforms in the financial sector, in order to sustain the growth of our economy and uplift our people from poverty to prosperity.

60. Dear Compatriots, I promised as President, that we would sanitize and restore integrity in our electoral process, by ensuring that our votes are not only counted, but truly count. We have gone to great length to ensure transparent, free, fair, and credible elections. Elections have been conducted across the country with local and international election observers testifying to their transparency.

61. On the international scene, we have advanced our regional, continental and global objectives. We have strengthened our relationships with our neighbours and in many instances supported them to protect their democracy, security and stability. We are serving for a second time within a period of 4 years at the United Nations Security Council. This is unprecedented in our Nation's history. My brothers and sister, this is a growing attestation of our country's growing influence.

62. In the first quarter of this year, our country celebrated its centenary. To prepare the nation for the challenges of the next one hundred years, I convened a National Conference where recommendations and resolutions were reached towards a more perfect union. We shall implement the report.

63. Four years ago, I made a commitment to advance the rise and rise of womanhood. Today, I am glad that we have made remarkable progress in this regard, trusting in the potential of our women and reaping from their dedication and ingenuity. I believe that any nation that ignores womanhood cannot achieve its full potential. It is in this regard that I ensured that women were given more opportunities in government, and I have not been disappointed.

64. Specifically, I doubled the percentage of women in the cabinet and gave them more challenging assignments. 
65. The Nigerian Defence Academy (NDA), is now admitting female cadets as regular combatants and it is now possible for a woman to rise through the ranks to the peak in military service, and become a full general.

66. We must continue to sustain the banner of freedom and justice that we have held high in our country. I am proud to say that there are no political prisoners in Nigeria today. No Nigerian has been driven to exile and no one will be, under my watch.

67. It is in furtherance of a peaceful, participatory and inclusive democracy that I signed the Freedom of Information (FOI) Bill into law, to expand the frontiers of our fundamental freedom.

68. Let me re-affirm that under a Jonathan Presidency, your views, no matter how freely expressed, will not send you to prison or into exile.

69. I am convinced that I have kept my pact with Nigerians, and it is now time to look to the future. With your tremendous support, we have collectively done so much in the last three and half years, but to take our country to the next level, there is still more to be done.

70. History has shown that the path of honour for any true leader is not to walk away from his people in moments of challenges. We must stand together in adversity and overcome all threats to our development. We must defend our future, for the sake of our children.

71. So many things have inspired me in the journey to this moment. I want to appreciate ordinary Nigerians, especially young people, for the solidarity shown to me by contributing their meagre resources to enable me arrive at this point.

72. I appreciate the kind gesture of the Cattle Breeders Union, Miyetti Allah, and the Market Women Association, who encouraged me by coming together to contribute to the purchase of my Nomination form.

73. In the same vein, I am touched by the National Association of Widows who also encouraged me with their widow's mite.

74. This labour of love, from ordinary Nigerians, has increased my appreciation of your 
solidarity, my trust in our joint destiny, and all we have achieved together these past three and half years.

75. Therefore, after seeking the face of God, in quiet reflection with my family and having listened to the call of our people nationwide to run, I, Goodluck Ebele Azikiwe Jonathan, have accepted to re-present myself, on the platform of The Peoples' Democratic Party, for re-election as the President of the Federal Republic of Nigeria, in the 2015 general elections.

76. Democracy is a collective action, energized by individual responsibility. Your mandate at this time will inspire in me the strength to complete the good work we have started together.

77. My dear people of Nigeria, we must complete the task of ensuring that we lift the poor out of the depth of want, and place their feet firmly on the ladder of prosperity.

78. In this election season, I appeal to all of you, not to harm, maim or kill; and not to incite violence of any kind. We must never forget our common bond, one people from the womb of one Nigeria. Again I say: My ambition to serve you is not worth the blood of any Nigerian. I remain committed to this principle of non-violence.

79. If you believe that we must build a country that works for all, where the strong lift up the weak, and not trample upon them, where the vote of every citizen determines who governs or represents you, where the democratic space is open to all citizens to fulfil their aspirations, irrespective of the circumstance of birth, your brother, Goodluck Ebele Azikiwe Jonathan stands ready to continue in service to you.

80. My brothers and sisters, we cannot go back to the old ways! Our railways were allowed to rot in neglect, we have revived and are modernising them.

81. We cannot go back to the old ways! Our road infrastructure collapsed. We are reconstructing, and expanding federal roads across the country.

82. We cannot go back to the old ways! Our airport terminal buildings were dilapidated and our airspace unsafe. We are fixing this.

83. We cannot go back to the old ways! Our agricultural practices did not benefit our farmers and our people. Fertilizer distribution was a major source of fraud and we 
were importing food more than our budget can carry. Now we are on our way to selfsufficiency in food production.

84. Do you want to go back to the old ways?

85. We cannot go back to the old ways, where there were long queues at our filling stations due to irregular supply of products and our people were exploited.

86. We cannot go back to the old ways, when women and youths were denied opportunities in government and in responsible positions.

87. Do you want to go back to the old ways?

88. We cannot go back to the old ways! We had skewed distribution of tertiary institutions. Whereas some states had more than one degree awarding institution, some had none. We have now made sure all states have at least one Federal University.

89. We cannot go back to the old ways! Our economy is now the largest in Africa. Once, we were virtually importing everything, now we are exporting several products, including cement.

90. We cannot go back to the old ways! In 2009, average life expectancy was 47 years, by the end of 2013, it was 52 years. Some of our hospitals now perform open heart surgeries, kidney transplants and other challenging operations as we reposition our health service to end decades of medical tourism that drains our scarce resources.

91. We cannot go back to the old ways! Together, in unity, we overcame Ebola, and in the process demonstrated the strength of the Nigerian spirit. And together, united, we must maintain our vigilance.

92. Do you want to go back to the old ways?

93. We cannot go back to the old ways where individual freedoms were trampled upon and citizens were locked up for expressing their views or criticising government.

94. Do you want to go back to the old ways? 
95. We cannot go back to the old ways! We must continue to have free and fair elections. We cannot go back to the era where ballot box snatching and stuffing became the norm. Where your votes never counted.

96. Certainly, we cannot!

97. We have to move forward! Only forward!!, my dear people, Forward!!!

98. In moving forward, I see a Nigeria that thirsts for progress with children across the nation, eager for knowledge and safely in schools!

99. I see a Nigeria where all who have taken up arms, would again embrace peace!

100. I see a Nigeria where our women can aspire to any heights, without hindrance!

101. I see a Nigeria where the flames in the Eagles will rekindle, and the Falcons soaring higher in victory

102. I see a Nigeria where the children of Mustapha, and Christopher, Ade and Ada, Timi and Bunmi, Nnamdi and Namadi, do not go hungry!

103. I see a Nigeria where all, no matter their beliefs, live in peace and harmony!

104. I see a Nigeria where the green passport is accorded a royal reception the world over!

105. I see a Nigeria where one day the next generation will take us to outer space.

106. Distinguished ladies and gentlemen, leadership is about staying focused to achieve goals despite challenges. I have been faced with many challenges since coming to office as President. With your support and encouragement, we have stayed the course.

107. We are succeeding, against all odds. For the young Nigerian child, who grew up in the rural area, just like me, we are expanding opportunities and giving them hope. For the market woman, we are expanding opportunities. For our young entrepreneurs, we are expanding opportunities. For the right of our people to vote and for their voices to be heard, we are expanding opportunities. For Nigerians to have the right to free speech, we are expanding opportunities. For the job seekers, against all odds, we are 
expanding opportunities.

108. While serving our people, I will always ensure the rule of law. I do not intimidate, I expand the democratic space. I give voice to the voiceless and uphold the weak, for the nation belongs to us all. Fellow Nigerians, as we build our democracy, leaders must show temperance at all times. That is a virtue, one which I treasure, and will always uphold.

109. My people, Nigeria is destined for greatness. Today, here at Eagle Square, I say to Nigeria, that working together in love, in strength and in faith, we will build a nation of one people, united in purpose and in action.

110. Fellow Nigerians, it is forward ever! We must put our hopes to work! Together, we will realize our collective destiny.

111. Thank you!!

112. God bless Nigeria!! 


\section{Appendix B}

\section{FULL TRANSCRIPT OF PRESIDENT GOODLUCK JONATHAN'S \\ REMARKS AT THE FLAG-OFF OF THE PDP 2015 CAMPAIGN IN LAGOS \\ ON THURSDAY, JANUARY 8, 2015}

1. Your Excellency, the chairman of our great party, Alhaji Adamu Muazu, senior members of our party here on this great occasion, we have spent so much time here so I will not bore you with protocols.

2. Today, I am going to address only a segment of the Nigerian population. I am going to address the people who are voting for the first time, those of you who will attain 18 years this year.

3. That means I am addressing the young people. I donot want to address old people like me, because we are spent already and I will crave your indulgence Nigerian youths, those of you who are here, and those of you watching us at home, listen to what I am saying.

4. I am going to address political gatherings in 37 cities and I am going to dwell on three key things. I am focusing on the young people.

5. Whatever I say, when you go back, call your aunts or call your uncles, your father or your mother, or your cousin, that is at least 60 years old and confirm and ask them what you heard that the Presidential candidate of PDP mentioned in any of the rallies because 2015 elections is about the young people: either you vote and continue to be relevant in Nigeria's political history or you vote for you to be irrelevant.

6. And I will repeat it, those of you who are voting for the first time, your decision to vote could mean you vote for a Nigerian youth to be important, to be relevant in this country or be a Nigerian person to be treated as a nonsense person and I believe all of you want to be relevant.

7. Of course you have seen...we have just introduced our governorship candidates and you see how many of them that is of your age bracket. Which other party will give 
that kind of opportunity?

8. I am going to dwell on three things because those who say they want to take over power from PDP have been telling a lot of lies. They have hired people from all over the world and those of you in the social media carry all forms of lies, painting all kinds of colour and giving me all kinds of face that I cannot defend.

9. If you listen to us in the 37 places we will address these issues, you will now know where to cast your votes. I will address you in all the places on three issues.

10. The first is the issue of insecurity. I am also going to address whether this administration is fighting or encouraging corruption. I am going to address the issue of weak government and unfocused government that has no plans. Yours is to listen and compare with everything that has been done before in this country and take a decision.

11. I will not keep you here for too long because we still have the opportunity... I am going to raise just very few issues today and tomorrow I will continue in Enugu and then on and on and on.

12. First let me tell you about the voter's card. First when we came in here we saw some placards, some of you complaining that we are yet to get a permanent voters card. Only yesterday, I directed that every Nigerian (of voting age) must vote. INEC must make sure and government will not allow a situation where some (eligible) Nigerians will not vote; we will not allow it. All Nigerians must vote and I mean it.

13. I told you that I am addressing those of you who are voting for the first time. Those of you in the age bracket of 20 to 24, if you go back, ask your uncles, before 2011 no Nigerian complained that he had no voters card. People voted themselves into office. We came and said every Nigeria vote must count and since then, the voter's card has become relevant.

14. This is the party that is giving political strength to all Nigerians. Already you have been told from intelligence reports that some people are already cloning cards so that your voter's card will no longer be relevant. Is that the kind of people you want to take over government? 
15. They want to take us to the old days when nobody sawvoter's cards but results were announced. They want to take us to the old days when ballot papers would be in South Africa and results would be announced. Are you going back to the old days?

16. Nigeria must move forward, Nigeria is for the youths. Nigeria is not for old people like us. The young generation must redefine this country. We must take this country to where we want it to be. Nobody can push us backwards. The past is past. They have led us backward and backward.

17. In fact when we were young, we were told that at Independence, Nigeria, Brazil, Malaysia, Indonesia and even India were all at the same level. That was what we were told when I was in the secondary school and the university. Now all those countries have left us behind and now some people want to take us backward. Do you want to go backwards? Nigerian youths do you want to go backwards?

18. Young Nigerians were doing things fantastically well, they were acting films and these very people were snubbing them, they were playing music and these very people were abusing them. But we are encouraging them and the world has accepted them. Do you want to move forward? .... Do you want to go backward?

19. I told you I was going to address things and I will be very brief. They talk about insecurity. That they will fight insecurity. And you will ask are our armed forces weak? Are the Nigerians in the Armed Forces weak? If we have problems what is the cause - equipment. And somebody who wakes up and tells young people of 23 years old that he wants to fight insecurity, ask him when he was the head of government did he buy one rifle for a Nigerian soldier.

20. These people did not buy anything for the Nigerian soldiers. They refused to equip them. No attack helicopter, nothing. Ask them what they did with the defence budget for the whole time they were in office. No country equips armed forces overnight. What they use is quite expensive and they are built over the years. Even if you spend 10 billion dollars today, you cannot equip the army, navy and air force.

21. The capacity is built overtime. They refused to build the capacity. They instigated crisis and now they are telling us they will fight insurgency. Ask them and they will answer. I will elaborate more as we progress to other places.

22. The next is that they say government is corrupt; or we are not fighting corruption. 
Only yesterday, I addressed the anti-corruption agencies. I said look people are deceiving young Nigerians. You must tell Nigerians what you are doing. We have arrested more people within this period. Gotten more convictions within this period but everyday they tell us lies.

23. At this point, let me apologize to some Nigerian civil servants who did not receive their salaries in December early enough and I will tell you what happened. I apologize to those families that suffered because we believe that for you to fight corruption; you must take measures, establish and strengthen institutions. You just don't wake up, enter the street, arrest one person and lock up and show on television and say that you are fighting corruption.

24. If they had succeeded in fighting corruption, corruption would not have been with us here today. If they had set up structures and especially in today's modern science using ICT to manage resources, we would not have been talking about corruption today. What happened in December was that IPPIS, software for processing salaries, - sometimes people steal through salaries- and some federal government agencies including some ministries tried to divert funds to pay some allowances. The system is scientific, it is not a human being, and as long as money meant for salaries is about to be diverted to other things, it shuts down. Those departments of government were shut down, this is the only way that you can prevent corruption.

25. I served in Bayelsa as deputy governor and governor for eight years; I also served as Vice President and President for another four years at the centre, for all this period, the fertilizer area is where states and federal governments spend billions of naira but less than 10 per cent of fertilizers go to the farmers. The rest is stolen and sent out of the country. Even the 10 per cent sometimes is adulterated. We came and cleaned up the sector and today there is no corruption in the fertilizer industry again.

26. What did we do? We assembled some young Nigerians that are IT gurus and we developed the e- wallet system and through that the farmers now get their fertilizers directly and nobody is cheating the government again. Is that not the way to stop corruption?

27. If somebody tells you that the best way to fight corruption is to arrest your uncle or father and show him on television, well, you won't stop corruption, you will even encourage corruption. I used to tell people and I will also address press conferences so that people can ask me direct questions. Armed robbery is still with us, despite 
the fact that we are shooting (death penalty) armed robbers. Is that stopping armed robbery?

28. So arresting people and demonstrating on television will not fight corruption, we must set up institutions, strengthen them to prevent people from even touching the money and that is what we are working on and we are succeeding.

29. Some people say they are finding corruption... some of you know, I am not addressing people of 20 years and below but people from 30 years and so on... Nigerians go to fuel stations and sleep overnight to buy fuel or tip those who sell fuel to buy fuel. They hoard fuel and they benefit from the hoarding. Who are those who benefitted from hoarding fuel? Since we came on board, have you suffered? Do you need to bribe someone before you get fuel?

30. When the crisis of insecurity came up, we had nothing. So to get things very quickly, we used some vendors to make procurement. But now what we are doing is government to government. Now any new procurement we are doing whether for the air force, navy or army it's government to government, so there is nothing like corruption anymore. Even if we have some issues, maybe... is that not the way to fight corruption?

31. You must prevent people from touching money, you don't give them the opportunity or test them with money and this is what government is doing and we are succeeding in a number of areas in our procurement processes. The relevant agencies will address Nigerians for you to appreciate what we are doing.

32. They say the government is weak, they say we are un-focused; we have no plan.

33. They say we are weak because there were some people who took our fathers, our mothers and our uncles while they were abroad put them in a crate and flew them to Nigeria but they were intercepted by superior powers. That blocked Nigerians from even going to Britain at a time and the relationship between Nigeria and Britain... the whole world isolated Nigeria.

34. They said that is the way to fight corruption. So immediately I suspect your uncle, I can just crate him and throw him into Kirikiri. Is that the way to stop corruption?

35. If somebody tells you that he will not follow due process... I came in with 
Yar'Adua and he advocated due process and I stand by due process. Any country that does not abide by the rule of law is a jungle.

36. Do you want Nigeria to be a jungle society? Immediately I suspect you that you have done something wrong I just ask the police or army to arrest you and throw you into jail. Is that the country you want?

37. They say to be strong is to jail people indiscriminately for 300 years. Is that where you want to go?

38. A country is like an industry. It must be managed properly by people who have brain and great ideas upstairs.

39. Let me just give you some highlights: they say we are not focused; we are not planning. But our economy has become the biggest in Africa; it was not the biggest in Africa before. Without planning, can your economy become the biggest in Africa?

40. They say we are not planning, we are not focused but we have cleaned up the corruption in fertilizer distribution in the country. The farm inputs are getting to the farmers and our import bills, the money we use in buying things from outside is coming down. Can you get that without planning?

41. You are no longer queuing up and leaving your cars in fuel stations. Can you do that without planning?

42. I believe that some few years back some young people have not seen trains except when you travel abroad and you have never boarded a train. Now our trains are moving. Can you do that without planning?

43. In the power sector, we are in Lagos; Egbin power sector got burnt in 2005 and remained so until now when we are fixing it. We have been able to finish the privatization of the power sector. This is an interface period but you already know that the generation capacity is almost double. Can you do that without planning?

44. This government feels that Nigerians are very dynamic people, very creative, very industrious, very talented in music, arts and business. Many of them do not have money and you know we are almost 200 million in Nigeria and we cannot reach everybody the same day. We came up with the concept of YOUWIN to give grants 
not loans to young Nigerians that have ideas. If you interview them, some of them are already manufacturing and in the next four to five years, we will be exporting things from this country. And they say we have noplans for the youths? They should come and tell us what plans they have for the youths.

45. I believe that young Nigerians, not people who are spent and finished. not people of my age, we are gone... that is why I said I am addressing people from the ages 18 23 those who are voting for the first time, we believe that you people will take us to the moon. My generation has failed we couldn't take Nigeria to the moon. Look at what India is doing. Look at what countries we were at par with at independence are doing and I said for us to get to the moon, that's a special area; you need to expose your best brains.

46. I came up with a special scholarship that you must first of all make a First Class in the university. We have scholarship for everybody but you must first of all make First Class from your university and then we test the best brains and send them to the best 25 universities in the world. Can someone who has no plans for the future of this country do that?

47. Can somebody who does not think about the Nigerian youth do that? Do you want to go back to those days when they had no plans for us?

48. When I came on board as President, I noticed that though in the country and on paper, there is this programme or policy of government that every state must get a Federal government owned university. Out of the 36 states we have, 12 had no federal universities and people were deceiving Nigerians that they were doing something.

49. I said we must establish these 12 universities in the remaining 12 states, start as small universities and grow and we have done that successfully and they are growing gradually.

50. We did not stop there. We looked at the school drop-outs in some parts of the country and they were quite high. We came up with the Almajiri educational programme and we thank the Governors from many of the states where we have those set of students. We have programmes for Almajiri students and we have the programme for out-of-school children. Can somebody who has no plan for the country think about that kind of programme?

51. You will ask some of those people who are deceiving you now and who hired some people from outside the country to go on social media and tell all kinds of lies, that when they were in power did they build any nursery school for anybody? Ask them, 
ask them, I say go and ask them.

52. If they did not build nursery schools for anybody, what did they use our money for? They built prisons or universities for you?

53. I will build universities for you, I will build secondary schools for you, I will build primary schools for you.

54. They say we have no plans for this country but we established the Sovereign Wealth Fund (SWF) - out of the money that comes into this country we reserve a little so you just don't squander it.

55. This is a government that introduced for the first time what we call the SWF and I want to thank the Governors from the states who keyed into the SWF idea. In addition to the SWF, you know that there are some stolen monies, which from time to time government gets back. They have been getting these monies back but we do not know how they are spending it.

56. The ones that have come in within this period, we have not even started spending it but first of all we agree on how to spend it. Because we have security challenges and this money is primarily for security and they used security channels to take it, 50 per cent of it will be used for security, 25 per cent of it for development and 25 per cent of it will be used for future generations. This is the decision we have taken even before we start spending the money. Can somebody who has no plan for the future of the country do that thing? They should come and tell you what they used our monies for.

57. We believe that so many young Nigerians, some young workers find it very difficult to own a house of their own. We introduced the Mortgage Refinancing Company. It is just coming up, estates are being built and we are working with the Labour unions. As we pursue that programme in the next five years, most Nigerian workers either working in private sector or in government can own houses.

58. They have no plans for you; they are coming to tell you false stories. We have said you do not need to have so much money to own a house. Do you want to go back to the old days?

59. We have plans for employment generation. We know one of the greatest challenges for most governments including Nigeria is to get jobs for our youths but we are not sleeping. So far we have been able to create a number of jobs... I have set up two 
bodies headed by the Vice President made up of people in government and the private sector. We call them Presidential Job Creation Board and Micro, Small and Medium Scale Enterprises Council, working very hard to ensure that every year two million jobs are created. Can somebody who has no plans do that?

60. Of course we have been told that I have other opportunities. I have many other things to say but people are getting tired ...... we'd have the opportunity to talk and talk and talk.

61. Some groups of people have said that you have to vote for your liberation or imprisonment. Some groups of people came, and I read it in the papers, when they see people in government maybe governors, ministers, commissioners and so on ... they will say we will draw a line, we are not probing the past because they want to deceive them to get their support.

62. So they will draw a line and start fighting corruption after they cross the bridge. Only two days ago, somebody stood in Port Harcourt and said he was going to catch people in the streets and throw them into Kirikiri.

63. The same mouth says something from the right, and from the left, making contradicting statements. Can you trust those people? Are they not deceiving you?

64. They want power by all means and all what they want to use power for is to lock up and imprison their enemies. I have no enemy to fight. My interest is your interest. My interest is the Nigerian interest and for the future generations and young Nigerians to develop. Not to fight enemies. We must stop corruption. I will not stop corruption by catching people, putting them in trailers and dumping them off to be killed. You can't stop corruption that way. Someone wakes up and he feels he can jail all his enemies and he thinks that is how to fight corruption? I think we have advanced beyond that point.

65. Somebody wakes up and says "O, Nigerian women I am going to give you position.' And you ask him when you were a Head of Government, you had a cabinet, I have the list of the cabinet members, there was no one single woman. Not even one in the cabinet.

66. So Nigerian women, you cast your votes and go back to the kitchen and die there or you cast your votes to liberate yourself.

67. The Nigerian women must decide where to cast their votes: you vote and go back to 
the kitchen and die in the kitchen or you cast your votes to liberate yourself. We are ready to liberate all Nigerian women.

68. Let me say one more thing and conclude. I read a headline in one paper yesterday: MEND DUMPS JONATHAN... did you read it?

69. I am from the Niger Delta. The leader of MEND is one Okah. He is in South African prison. Why is he there? South Africa is not Nigeria where people will say Oh, President (Jonathan) manipulated it.

70. Okah is in the prison because $1^{\text {st }}$ October 2010 when we were to celebrate our independence, our golden year of independence, Okah was procured by some Nigerians to assassinate me. Okah bombed Abuja, but the attempt was to assassinate me and South Africa intelligence system caught him in the plan to assassinate me. He is now in jail in South Africa and they say MEND dumps Jonathan.

71. Okah that wanted to assassinate Jonathan, will he support Jonathan? I am told that Okah is supporting some people... I am told that Okah who is in a South African prison for killing Nigerians is endorsing some people. Is that the country you want to live in? Count me out.

72. Let me conclude by thanking all Nigerians, especially Lagosians. Let me sincerely on behalf of my party apologise to you because we are having this rally today so the whole of Lagos is at a standstill. We beg you, we have to do it and we know you love us, will support us and we promise to make sure that... this is the very first government that has supported the industrial sector very well. Ask your brothers and sisters in the private sector, if they are sincere they will say that we have come up with policies that have encouraged commerce and industry.

73. Government alone cannot employ people. The private sector must grow to create jobs for the people. Bear with us because the PDP government will continue to encourage the private sector to create jobs for Nigerians.

74. Finally, let me tell all of you especially those of you, who want to go to the National Assembly that we just had a national conference. The document from that conference, because of the controversy we have in the present National Assembly, you know how chaotic the present Assembly is, we know that if you bring that document to the Assembly they will dump it. 
75. So we want to present it to the next Assembly. So those people you are sending, if you mean well for this country, you must vote people who can go to the National Assembly, discuss and adopt that document that our leaders have agreed so that this country can move forward.

76. I stand today in the city of Lagos, in the south west on behalf of the leader of our party, Alhaji Muazu, the Vice President and all the leaders and promise that if you vote the PDP en masse to the National Assembly and to the Presidency, we will adopt that document so that this country will move forward.

77. That document is to liberate you, we did not influence it, our fathers, mothers, brothers and sisters that are credible came up with it.

78. Ask them, we did not influence it. I did not ask them to dot any 'I' or cross any 'T' because I have no personal interest. My interest is the Nigerian interest.

79. It is either we vote to be prisoners as we were- and I will tell you maybe some of you do not know, in 1983, I don't know for the young people, some of you who are writing all sort of things on the social media. In 1983/84, what they called discipline as a post graduate student instead of reading my book, the whole night I queued up to buy two tins of milk. And they say that is discipline.

80. So we should make you queue up the whole night as students to buy two tins of milk? Is that the discipline you want?

81. You must vote for your liberation, you must vote for your development, you must vote to take Nigeria to the moon. You cannot vote to take Nigeria backward.

82. Leave us who are half dead to bury our dead.You must vote for the progress of this country, you must vote for the Nigerian youth, you must vote for the Nigerian women. PDP!... POWER!

83. Thank you all. 